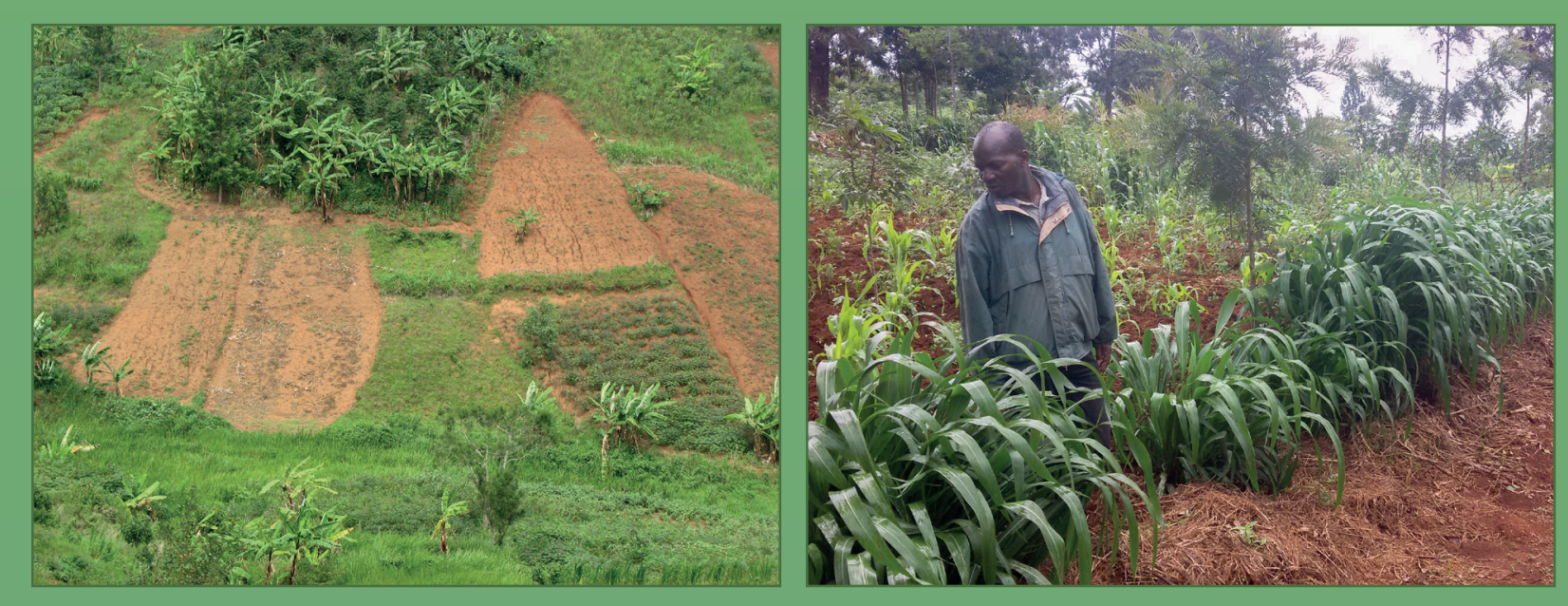

COPING WITH RISK AND CLIMATE CHANGE IN FARMING: EXPLORING AN INDEX-BASED CROP INSURANCE IN BURUNDI

\title{
Marcien Ndagijimana
}

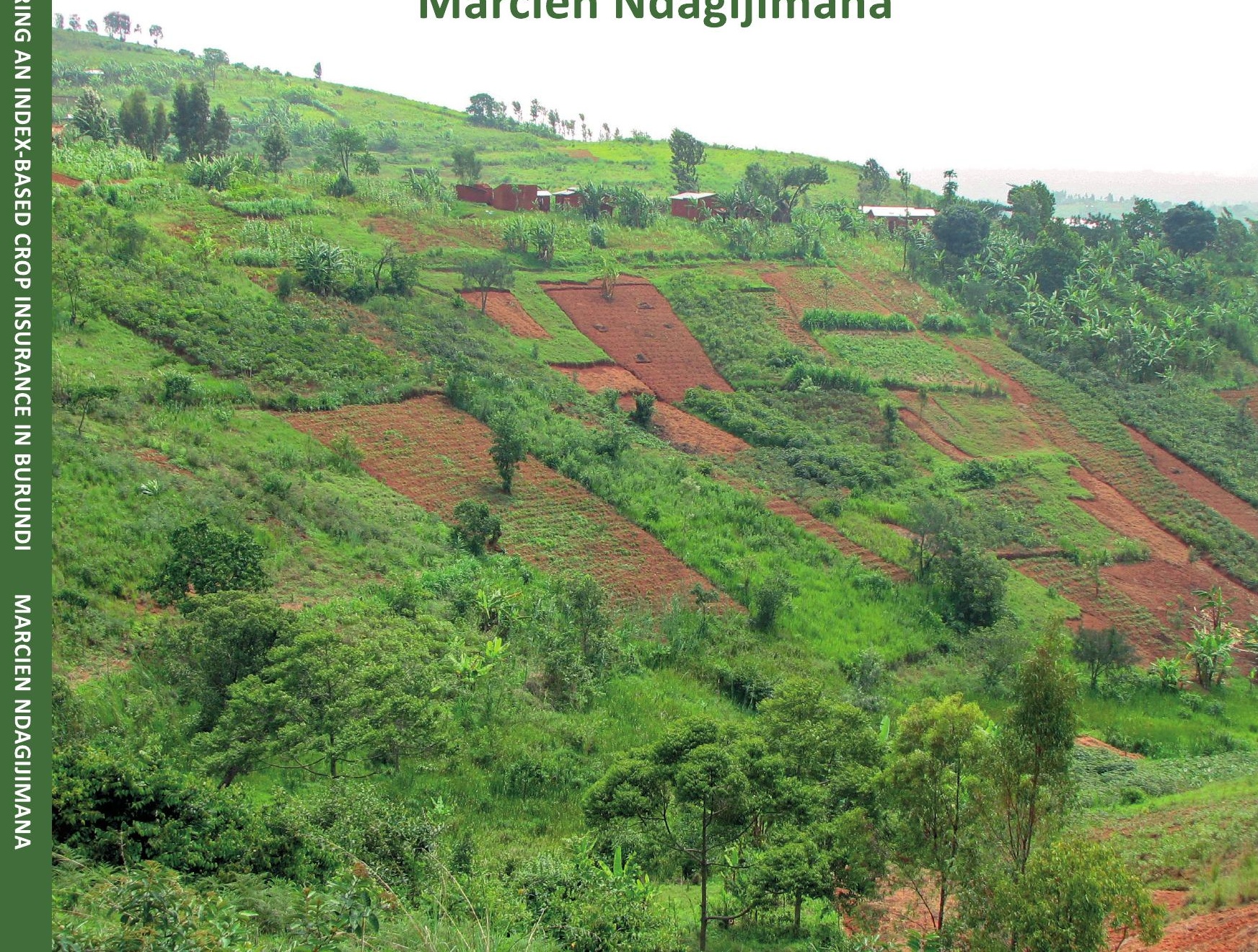




\section{Propositions}

1. Saving for upcoming premium payments by Village Savings and Loan Associations increases the adoption of index-based crop insurance. (this thesis)

2. Providing farmers access to credit markets is an essential element in stimulating investments in sustainable land management. (this thesis)

3. Availability of food is more important for early childhood nutrition than the quality of food.

4. Nutrient rich water attracts more vectors that spread disease than just warm and poor quality water.

5. Social inequalities are the pathways to endless poverty.

6. Unemployment of educated people costs more than education itself.

Propositions belonging to the thesis, entitled:

Coping with Risk and Climate change in Farming: Exploring an Index-based Crop Insurance in Burundi

Marcien Ndagijimana

Wageningen, 1 February 2021 
Coping with Risk and Climate change in Farming: Exploring an Index-based Crop Insurance in Burundi 


\section{Coping with Risk and Climate change in Farming:}

Exploring an Index-based Crop Insurance in Burundi

\section{Marcien Ndagijimana}

\section{Thesis committee}

\section{Promotors}

Prof. Dr C.J. Ritsema

Professor of Soil Physics and Land Management

Wageningen University \& Research

\section{Co-promotors}

\section{Dr C.A. Kessler}

Assistant Professor, Soil Physics and Land Management

Wageningen University \& Research

\section{Dr M.A.P.M. van Asseldonk}

Senior scientist, Wageningen Economic Research

Wageningen University \& Research

\section{Other members}

Prof. Dr M.P.M. Meuwissen, Wageningen University \& Research

Dr G. Sterk, Utrecht University

Dr J.W. Nibbering, Ambassade des Pays Bas au Burundi, Bujumbura, Burund

Dr T. Lans, Managing Researcher, CINOP-ECBO, 's-Hertogenbosch

Thesis

submitted in fulfilment of the requirements for the degree of doctor

$$
\text { at Wageningen University }
$$

by the authority of the Rector Magnificus

$$
\text { Prof. Dr A.P.J. Mol }
$$

$$
\text { in the presence of the }
$$

Thesis Committee appointed by the Academic Board

to be defended in public

on Monday 1 February 2021

at 1:30 p.m. in the Aula. 


\section{Table of contents}

Chapter 1

General introduction

Chapter 2

Understanding farmers' investments in sustainable land management

in Burundi: a case-study in the provinces of Gitega and Muyinga

Chapter 3

Analysing risk experience, risk perception and coping strategies in

Burundian agriculture

Chapter 4

Effect of village savings and loan associations on adoption of index-based

crop insurance under limited liabilities

Chapter 4

Analysing the links between index-based crop insurance adoption and agricultural investments in Burundi

\section{Chapter 6}

Synthesis

Literature cited

English summary

Acknowledgements

About the author

Certificate of the Netherlands Research School for the Socio-economic

and Natural Sciences of the Environment

Funding statement

Marcien Ndagijimana

Coping with Risk and Climate change in Farming: Exploring an Index-based Crop Insurance

in Burundi, 134 pages.

PhD thesis, Wageningen University, Wageningen, the Netherlands (2021)

With references, with summary in English

ISBN: 978-94-6395-591-1

DOI: https://doi.org/10.18174/533040 
Dedicated to my late father, Balthazar Barankitse 


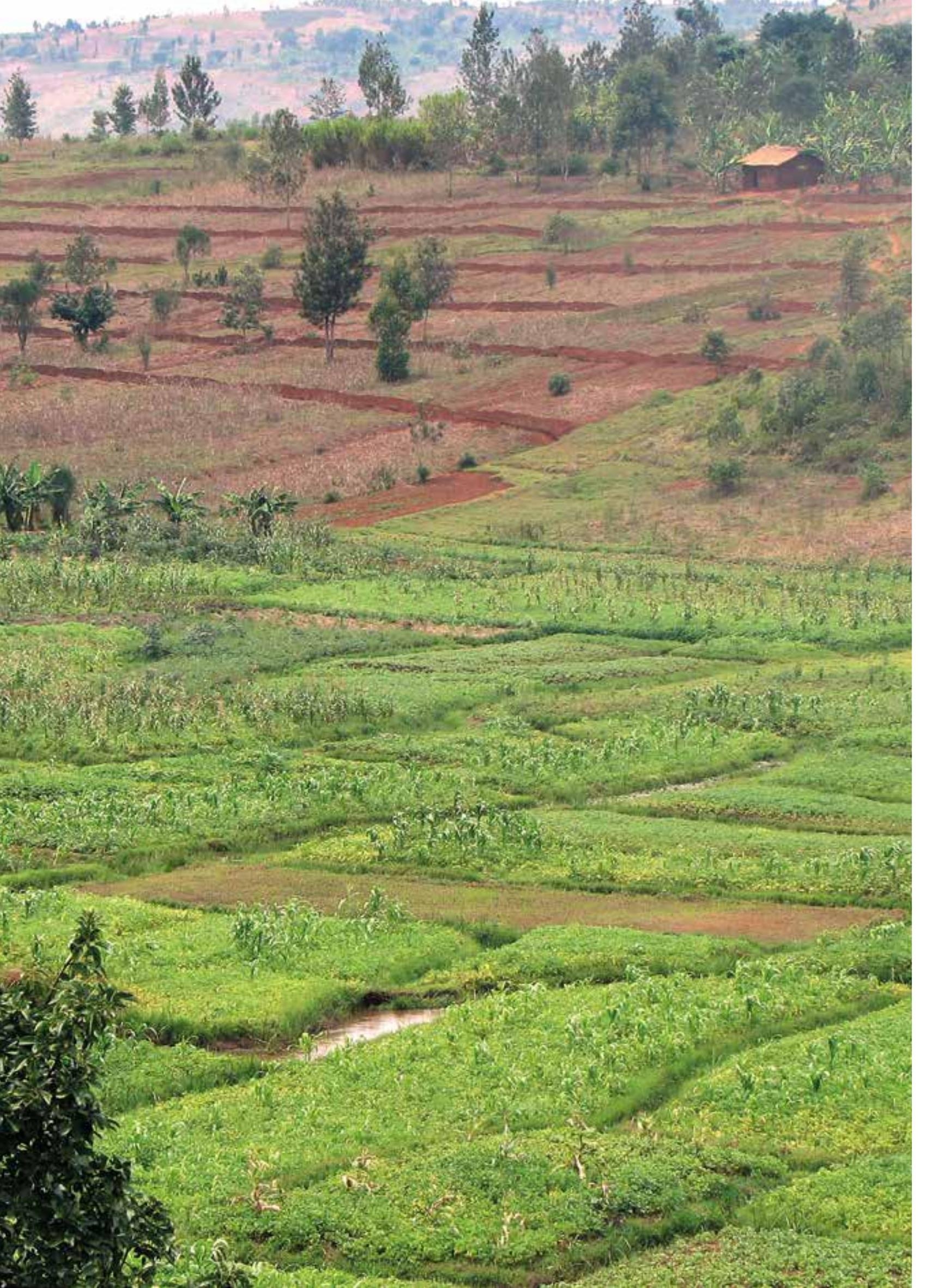

\section{Chapter 1}

General introduction 


\subsection{Land degradation and land management investments in Burundi}

Inappropriate agricultural practices especially on sloping lands often lead to soil erosion, which is one of the key processes of land degradation (Wairiu, 2017), and an expanding universal problem that influences many areas of human prosperity (Ullah et al., 2019). In addition, climate change is a factor that enhances land degradation particularly in Africa, because most of its arable lands are poorly protected against more intensive rainfall events, leading to enhanced soil erosion. Recent research revealed that the main barriers to mitigate and adapt to the effects caused by climate change in Africa are lack of access to technology, information, credit and incentives (Cholo, 2018). For tackling land degradation, limited resources and low knowledge levels amongst the population are furthermore serious obstacles to the implementation of sustainable land management practices (Wairiu, 2017) Sustainable Land Management (SLM) is defined as a knowledge-based procedure that helps integrate land, water, biodiversity and environmental management to meet rising food and fiber demands, while sustaining ecosystem services and livelihoods (Faham et al., 2008). What keeps agriculture in developing countries in a subsistence state, being unsustainable and not resilient, is that farmers apply only few of the needed SLM practices to actually tackle land degradation effectively (Cholo, 2018).

The same is true in Burundi, where despite the importance of the agricultural sector for economic development of the country, investments in agriculture and SLM are low (Niragira, 2016). This results in poor agricultural production rates and unsustainable land use, as such contributing to rural poverty. In highly populated rural areas of the country, land has become particularly scarce and increasingly fragmented, highly degraded, overexploited and less fertile due to the low organic and inorganic fertilizer availability and use (Niragira, 2016) In these regions, practices of land protection and soil fertility restoration implemented in the past, have had limited effects and were unsustainable due to interventions that often used direct incentives (e.g. cash for work) and top-down approaches. Moreover, effective implementation of land management practices requires financial and other resources, which are often not available because access to financial services by the rural population is limited. The current initiatives in Burundi for the decentralization of microfinance and the expansion of village savings and loans associations (VSLAs) are promising, but high interest rates are still a barrier for smallholder farmers. Hence, improving credit access in rural areas of Burundi is a critical issue. 


\subsection{Crop risk experience and coping strategies in Burundi}

Sub-Saharan Africa has been portrayed as the most vulnerable region to the impacts of global climate change because of its reliance on agriculture and being highly sensitive to weather and climate variability such as temperature and precipitation (Kotir, 2011). Agriculture is particularly exposed to risks, and many of those risks are due to climate hazards. The severity level of the risks confronting farmers vary by farming system, agro-climatic region, local policy and institutional settings. However, particularly to small-scale farmers in the developing world, agricultural risks impose a high burden (Hazell et al., 2010). For instance, Paridaens et al. (2012) show that water deficit and erosion due to heavy rain affect respectively 22 and $14 \%$ of agricultural fields in Burundi. This is very much related to climate variability, and will become worse according to the 2000-2050 climate change simulations. These indicate for Burundi an overall average increase in rainfall from 3 to $10 \%$, with a decrease of $4 \%$ for May (end of the rainy season) and $15 \%$ in October (beginning of the rainy season) (Paridaens $e$ al., 2012). Farmers are therefore perceived as risky borrowers, which reduces their possibility to access credit, and raises interest charges for farmers, with the net effect that farmers are being trapped in a vicious circle of low-productivity and poverty (Hazell et al., 2010).

Due to lack of collateral and the aforementioned high risks associated to farming, farmers in Burundi usually sell part of their assets (cattle, land, etc.) to finance agricultural investments. Comprehending farmers' perceptions of risks and their responses are important in understanding farmers' risk behavior (Flaten et al. 2005). A comprehensive risk analysis of a business such as farming entails a thorough explanation of the importance of risk and how to deal with it (Wauters, et al. 2014). Measures to adapt to climate change and the capacity of households to cope with it vary from region to region. Some households take preventive measures before the event appears (ex-ante measures), but most of them resort to adaptation measures once the shocks have occurred (ex-post measures).

For many African farmers these coping strategies are informal and rely on family and community structures, including gift exchanges, sharing food, migration, remittances, child labour, informal cash or in-kind loans, or sending children to live with relatives (Heltberg \& Siegel, 2008). In general, households do not follow a single coping strategy during those hard times, but use different strategies to maximize their chance of survival (Shuaibu $e$ al., 2014). In Burundi, it has been noticed that when farmers face input price fluctuations, drought or flooding, households resort to selling assets, depleting savings, and adjusting their consumption, including reducing the number of meals per day (Mupfasoni et al. 2013).

However, all these strategies are short-term, while coping with agricultural risks requires long-term mechanisms such as building irrigation infrastructure, investing in agricultural value chain development and accessing credits to finance agricultural inputs to overcome risks. Although many suppliers of inputs and fertilizers could offer credits to farmers, they are often still hesitant due to the covariate risk associated with agriculture (Hazell_et al., 2010; Levin \& Reinhard, 2007). A crop insurance could mitigate such risks and enable farmers to cope with weather risks.

\subsection{Piloting an index-based crop insurance}

Crop and livestock insurances have a long history in Western Europe. For instance, a crophail insurance was offered in Germany in the late 1700s (Mahul \& Stutley, 2010) and, by the late $19^{\text {th }}$ century, in many other European countries and the United States (Smith \& Glauber, 2012). Insurances against deficit rainfall and other adverse climatic events have raised significant interest with three main objectives, namely (i) to protect the population against adverse climatic events, so as to decrease poverty and foster economic development, (ii) prepare for disasters and provide funding for immediate mitigation, as an alternative to emergency aid, and (iii) provide a mechanism to adapt to and cope with climate change (Rosema_et al., 2014).

In Burundi, like in other countries across the world, there is a lack of specific information and empirical evidence about the effects of crop insurances, and furthermore, the rura area is very disconnected to potential insurance companies which are therefore not interested. Facing these challenges, in 2017, a pilot project was implemented in two provinces of Burundi (Gitega and Muyinga) to test an index-based crop insurance (IBI). The insurance program started with village savings and loan associations (VSLAs) selected on specific criteria in villages involved in the PAPAB project ${ }^{1}$ ('Projet d'appui à la productivité agricole au Burundi in French). In these villages the project was already working with the PIP approach as its core intervention strategy: the integrated farm planning approach (Plan Integré du Paysan in French). This approach was developed and validated in Burundi, and is an intervention approach which focuses on the household and the farm as a "farming system", where integration of practices and a diversity of crops and activities are crucial to make the household more resilient. Hence, the pilot project to test the IBI started in villages and VSLAs where most farmers had already been trained in integrated farm management, including soil fertility and better crop management practices. To date, three years after the start of the IBI pilot with 257 farmers, $45 \%$ of them continue to pay risk premiums for the $\mathrm{IBI}$, despite the fact that project support to the IBI has already ended.

PAPAB was financed by the Embassy of the Kingdom of the Netherlands in Burundi, with main partners being the International Fertilizer Development Center (IFDC) and Wageningen University and Research (WUR). 


\subsection{Problem statement}

and degradation as well as climate change affect about one-third of the global terrestrial are and is having negative impacts on the incomes and food security of agricultural populations (Mirzabaev, 2016). Particularly recurrent phenomena of drought, excessive rainfall and floods cause enormous production losses in sub-Saharan Africa. In Burundi, the main concern in the agricultural sector is how to motivate farmers to conserve and restore the (once fertile) gricultural soils, to which it is essential to put in place an affordable and sustainable mechanism to deal with risks associated to farming. This requires long-term (national, rural development) strategies with a vision towards sustainable agriculture, and part of such a strategy could be a crop insurance. With the pilot project of IBI in Burundi was introduced in 2017, there was the opportunity to investigate how such an insurance might foster more resilient agriculture and the adoption of SLM practices. Moreover, the limited liability associated with this IBI, as well as the low level of farmers' knowledge on the functioning of such a complex insurance, requires research on adoption of an insurance by farmers and factors hindering its scaling-up, as input to further developing and exploring an IBI as a potential opportunity for agricultura development programs. Furthermore, there is no information and data on the role of VSLAs and how these could support the adoption of an insurance, which is yet another opportunity that merits to be investigated in more detail and in a practical case.

\subsection{Objectives of the study and research questions}

This study aims to shed light on factors influencing SLM investments and to what extent an $\mathrm{BI}$ helps farmers to overcome risks associated to farming, as such enabling them to increase agricultural investments. To reach this objective, four main research questions related to Burundian agriculture were formulated:

- RQ1: What are the factors influencing sustainable land management investments by smallholder farmers in Burundi?

- RQ2: To what extent do farmer household coping strategies in Burundi respond effectively to the severity of crop risks being experienced at the farm level?

- RQ3: What is the effect of village savings and loan associations on the adoption of index-based crop insurance under limited liabilities in rural Burundi?

- RQ4: What are the links between IBI adoption and agricultural investments by smallholder farmers in Burundi?

\subsection{Methodology}

1.6.1 Description of the study area

This research was conducted in four different communes of Burundi: Bukirasazi, Makebuko, Giteranyi and Butihinda. Bukirasazi and Makebuko are located in Gitega province while Giteranyi and Butihinda are located in Muyinga province. Gitega is located in the Central part of the country whereas Muyinga is located in the North-East close to Rwanda and Tanzania (Figure 1.1). Both provinces are located relatively far away from each other and have different socio-economic characteristics and physical conditions (population density, rainfall, soil, temperature, etc. - see Table 1.1). These two provinces were selected because the project "Fanning the Spark"2 carried out activities in both of them from 2014 to 2017 aiming to support farmers to enhance food security at village level based on agriculture risk adaptation and investments in crop production. The main economic activity in both provinces is agriculture and farmers grow crops in three seasons, namely season A (agatasi) which extends over the period of October up to January, season B (urushana) from February to May and season C (ici) from June to September.

Table 1.1 Main characteristics of Gitega and Muyinga provinces

\begin{tabular}{lll}
\hline Characteristics & Gitega & Muyinga \\
\hline Location & Central & North and Eastern \\
\hline Temperature $\left({ }^{\circ} \mathrm{C}\right)$ & $21-31$ & $17-27$ \\
\hline Rainfall (mm per year) & 1,180 & 1,146 \\
\hline Number of days of rain (per year) & 176 & 156 \\
\hline Rainiest month & December & April \\
\hline Number of wet days of the rainiest month & 24 & 21 \\
\hline Least rain month & July & June \\
\hline Number of dry days of the least rain month & 1 & 2 \\
\hline Soil type & acid & ferrisol-clay \\
\hline Elevation (above sea level) $(\mathrm{m})$ & 1,672 & 1,484 \\
\hline Population density (inhabitant $\left./ \mathrm{km}^{2}\right)$ & 349 & 322 \\
\hline
\end{tabular}

Source: Adapted by author from data available on www.weatherbase.com

2 Fanning the Spark, locally known as SCAD project, was financed by RVONL and Achmea Foundation, with main partners being Achmea, Wageningen University and Research (WUR) and HealthNet-TPO. 


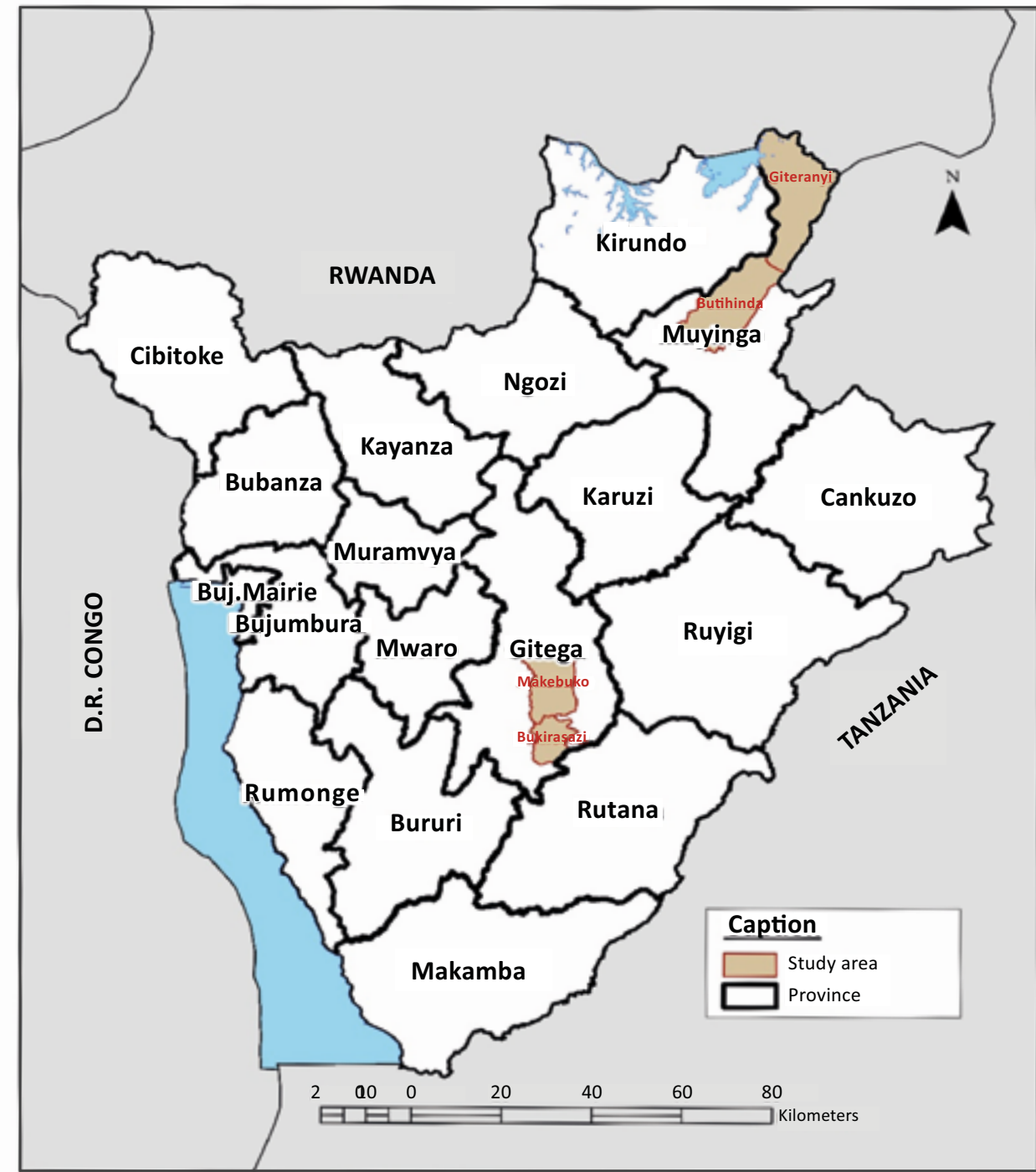

Figure 1.1. Map of Burundi indicating the location of the study area

\subsubsection{Sampling and data collection}

A two-stage procedure was employed in the selection of households for analysing research questions 1 and 2 . First, 40 farmers from each of the four communes were randomly selected from lists of households involved in the project. Next, primary data were collected in 2016 from these 160 households using an agro-socioeconomic survey. At farm level, detailed information about household characteristics, land degradation, crop risk experience and perception, coping strategies and cost associated to land management investments were collected using a structured questionnaire.

Next, for analysing research questions 3 and 4 , data about the functioning of VSLAs and the determinants of IBI adoption was collected in 2019 in the communes of Bukirasazi and Makebuko only, hence in Gitega province. The random sampling consisted of 120 farmers selected in VSLAs which adopted the crop insurance, and 40 farmers from VSLAs which had never adopted the crop insurance. Detailed information on the relationship between IB adoption and agricultural investments (i.e. use of fertilizers, crop diversification, crop and land management) was collected at this stage.

\subsubsection{Method of data analysis}

Various descriptive statistics and econometric models were applied for the data analysis Firstly, a multinomial logistic regression model was used to determine the factors influencing SLM investments (RQ1), and the determinants of IBI adoption (RQ3). Next, path analysis modelling was used to establish the relationship between risk experience and risk perception (RQ2). Then, mean comparison was used to analyse the relationship between variables related to VSLAs and crop insurance adoption for the IBI adopters, non-adopters, and dropouts (RQ3). Finally, the links between the IBI adoption and agricultural investments were analysed using the multivariate regression and the difference-in-difference models (RQ4).

\subsection{Thesis outline}

The above research questions are addressed in four chapters from Chapter 2 to 5 . Chapter 2 gives an overview of land degradation in the study areas and the practices used to address soil erosion. It analyses the factors influencing SLM investments (RQ1). Chapter 3 analyses the main crop risks experienced and perceived by farmers in the study areas and analyses the used coping strategies (RQ2). Chapter 4 and 5 focus on the IBI adoption, with Chapte 4 analysing the extent to which the VSLAs influence the adoption of the IBI under limited liabilities (RQ3), and Chapter 5 analysing the links between IBI adoption and agricultural investments (RQ4). Finally, chapter 6 , the synthesis presents the main findings, discusses them and concludes with some policy recommendations as well as future research opportunities in this field. 
Understanding farmers' decision-making to tackle land degradation by means of sustainable land management (SLM) practices is essential for policy makers. The main objective of this study was to identify factors that influence farmers' investments in SLM. A survey was conducted in two provinces of Burundi (Gitega and Muyinga) among 160 households. Methods for data analysis comprised descriptive statistics and multinomial logistic regression. It was derived that both provinces experience severe land degradation, with soil erosion experienced by $88 \%$ of the farmers and soil fertility depletion by $92 \%$. Furthermore, findings show that occurrence of soil erosion on the farm ( $p=0.025)$, access to credit $(p=0.022)$, education level $(p=0.040)$, engagement of the household head in farming $(p<0.001)$ and age of the household head $(p=0.050)$ are significantly and positively associated with higher investments in SLM. Moreover, the findings reveal that the yearly costs per farmer associated to the SLM practices' implementation ranged from US\$10.08 for soil and water conservation practices up to US\$36.24 for organic fertilizers. Therefore, in order to foster SLM, we recommend policy makers in Burundi to improve access to credit markets in rural areas and enhance efforts to strengthen smallholders' skills; bringing as such more integrated and effective solutions to cope with land degradation problems.

\section{Published as:}

Ndagijimana M, Kessler A, Asseldonk M v. (2018). Understanding farmers' investments in sustainable land management in Burundi: A case-study in the provinces of Gitega and Muyinga. Land Degrad Dev. 2018;1-9. https://doi.org/10.1002/ldr.3231

\subsection{Introduction}

Burundian agriculture still mainly relies on subsistence farming, but plays a major role in economic development of the country. The share of the population living from agriculture is $90 \%$, of which $51 \%$ are women. The agricultural sector contributes to export earnings by over $95 \%$ (Bahizi, 2011). Agriculture in Burundi is characterized by low food production due to the shortage of arable land, minimal use of improved seeds, a financial market with very limited access for farmers, the depletion of soil fertility by erosion, and sub-optima fertilizer use. Moreover, the population density ( 300 inhabitant $/ \mathrm{km}^{2}$ ) and the annual growth of Burundi's population (2.6\%) combined with land degradation have led to a decline in average land holdings from one hectare in 1973 to 0.50 hectare per household in 2009 Therefore farmers tend to continuously cultivate the same plot of land over years, causing land degradation (Baumont-Keita et al., 2011).

Next to the intensive use of the land, high intensity rainfall and erodible soils contribute to high erosion rates. Excessive rainfall in Burundi leading to soil erosion is among the main shocks that affect agricultural fields (Paridaens et al., 2012). The amount of lost soil by erosion per year is estimated around 4 tons ha- ${ }^{-1}$ in the Eastern part of the country, 18 tons ha ${ }^{-1}$ in Central and Western Burundi, and more than 100 tons $\mathrm{ha}^{-1}$ in the Highlands (MINAGRIE, 2012). Coping with land degradation in general, and soil erosion and soil fertility depletion in particular, is therefore the main challenge in Burundi; hence the call for sustainable land management (SLM) practices (Paridaens et al., 2012).

The SLM approach emphasizes finding economically viable, socially acceptable and ecologically sound solutions at a local level, with land management practices to prevent land degradation (Heyi Damena \& Mberengwa, 2012). At farm level, SLM interventions consist of soil and water conservation, soil fertility practices and technologies which are adopted either singly or in combination (Tanui et al., 2013)

Studies about Burundi that focus on the interrelationship between perception of land degradation and SLM uptake are unknown to the authors. Studies from other countries in the region show that the perception of land degradation does not automatically lead to the required investments in SLM. For instance, in the Central Rift Valley of Ethiopia the perception of land degradation does not significantly motivate farmers to invest in water erosion and soil fertility control measures (Adimassu et al., 2013). Furthermore, research in the Highlands of Ethiopia indicate that slope, soil fertility status, land fragmentation and tenure arrangements influence farmers' investments in sustainable land management practices (Teshome et al., 2014). However, a factor can influence SLM investments in one specific area but might not do so in another one, for different reasons as aforementioned. The main motivation for farmers 
to adopt SLM practices are the potential production increase, profit increase, improvement of well-being and livelihood, and reduced workload (Giger et al., 2015). In the past, the Burundian government and international donors have initiated numerous programs to stimulate SLM practices, such as trenches on the contour-lines and tree planting: these programs were undertaken through incentives such as cash for work or food for work, with the outcomes of these projects unfortunately being below expectations partly due to the incentives used. When farmers are extrinsically motivated, the motivation ceases when the incentives are discontinued (Bizoza, 2014). The objective of this study is therefore to assess motivation personal, as well as economic and financial factors that influence farmers' investments in land management, and evaluate the cost associated to their implementation.

\subsection{Methodology}

\subsubsection{Description of the study area}

This research was conducted in four different communes (2collines/commune): Bukirasazi, Makebuko, Giteranyi and Butihinda. Bukirasazi and Makebuko are located in Gitega province while Giteranyi and Butihinda are located in Muyinga province. Gitega is located in the Central part of the country whereas Muyinga is located in the North-East close to Rwanda and Tanzania (Figure 1.1). They are situated relatively far away from another and have different socio-economic characteristics and physical conditions (population density, rainfall, soil, temperature, etc.) (Table 1.1).

In the two provinces, farmers grow crops in three seasons namely season A (agatasi) which extends over the period of October up to January, season B (urushana) from February to May and season C (ici) from June to September. Farmers in both provinces grow almost the same food crops, such as maize (Zea mays), sorghum (Sorghum bicolor), potatoes (Solanum tuberosum), sweet potatoes (Ipomoea batatas), beans (Phaseolus vurgalis), cassava (Manihot esculenta), cabbage (Brassica oleracea), taro (Colocasia esculenta), rice (Oriza sativa L.), and banana (Musa acuminata) (Niragira et al., 2015).

\subsubsection{Land degradation in study area}

Land degradation in both provinces is mainly caused by continuous cultivation of the same plots and climatic hazards, given that in these areas the common activity is agriculture often on steep slopes. In this study, farmers' perception of land degradation was elicited for two main indicators, namely soil erosion and soil fertility depletion. These two indicators are elicited as binary variables, being considered 1 if a farmer experiences soil erosion or soil fertility depletion on the farm and being 0 if otherwise. A case of land degradation on badly managed farmland in the study area is depicted in Figure 2.1.

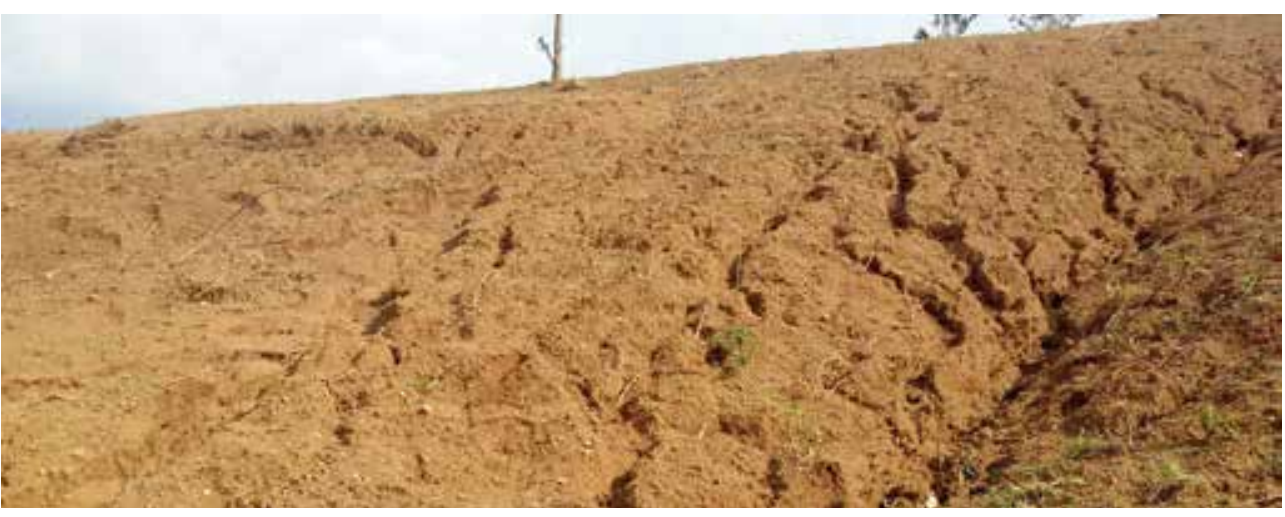

Figure 2.1 Land degradation in the study area in the form of rills

\subsubsection{Sampling and data collection in the study area}

Household surveys were conducted by an experienced team of enumerators laureates from Burundi University. The questionnaire was administered in the local language, Kirundi. Within each of the eight collines, the enumerators randomly selected 20 households, with a total number of 160 households interviewed. Moreover, eight focus group discussions were organized as a mixed method for interpreting information given by interviewed individual farmers. The sampling was determined by using a list of farmers belonging to the different Village Savings and Loans Associations (VSLAs). Selecting the VSLA as entry point for this study was twofold. Firstly, VSLAs are alternative financial structures to micro-finances institutions or mainstream banks for which accessibility by small farmers is limited. Secondly, the study was conducted in the SCAD (Solidarité Communautaire pour l'Auto-dévéloppement in french) project area where these structures were the foundation of the project. Farmers trained by SCAD (called the first generation) as well as farmers trained by this first generation (called the second generation) were included in the sample. Farmers' trainings were based on an integrated development approach known as PIP (Plan Intégré du Paysan in french). The approach entailed farm planning activities focusing on family competences and their vision (Kessler et al., 2016). The trainings received during the PIP-approach (on building a vision, SWC, integrated soil fertility management, etc.), helped these farmers to develop an integrated farm plan. Data were collected in 2016 and the questionnaire was divided into three parts, namely general information concerning the household, farmers' perception 
on land degradation, and the investments in land management practices introduced at the farm level including the associated costs of their implementation.

\subsubsection{Farmers' investments in land management practices}

Farmers' investments in SWC practices and fertilizer use (organic and chemical) were determined by asking farmers if they applied one or more of these practices (yes=1 or no $=0$ ). Next, the costs of these investments were calculated. For soil and water conservation practices (contour-lines, diversion ditches) this was done by multiplying the cost of a manday by the total number of days spent on implementation of a certain practice. For organic fertilizers, farmers estimated the quantity by using the local unit known as igiseke (basket) which contains $20 \mathrm{~kg}$. The cost used for organic fertilizer (crop residues, mulch, compost, and manure) was calculated based on the price of $1 \mathrm{~kg}$, which was estimated to be 20 Burundian Francs (BIF). For chemical fertilizers (limestone, KCl, DAP, urea), the calculation was straightforward since the price per unit is fixed by the sellers and quantity known by farmers. Some example of investments used in the study areas for soil erosion and soi fertility control are depicted in Figure 2.2

\subsubsection{Empirical framework and data analysis}

Before taking any action to invest in SLM, a farmer has to be both motivated to undertake action and be able (have the means) to invest. The motivation can be categorized as either extrinsic motivation (outside of the person) or intrinsic motivation (internal to the person) (Chaminda, 2010). This study focuses on intrinsic motivation as it is associated with longterm change which complies with the investments in SLM practices (McMurran, 2002) In this study, intrinsic motivation was captured by four factors, namely (having official) land registration (LandR), experiencing soil erosion (on own farm) (Eros), engagement (of the household head) in farming (Eng), and soil fertility depletion (on the farm) (Fert) (Teshome et al., 2016). In Burundi, unregistered land is still considered as state property and discouraging the users from introducing SLM investments. This study therefore analyzes if farmers with registered land invest more in SLM than those with unregistered ones (LandR). Furthermore, it was hypothesized that farmers who are aware of problems of soil erosion and soil fertility depletion on their farm invest more in SLM (Eros \& Fert). Also time spent by the household head in farming (Eng) was hypothesized to contribute to SLM investments, as it is an indication of the dedication of a farmer to agriculture and to keep his land productive.

Concerning the ability to invest, the ability to pay (ATP) was determined, which is the cost associated to this investment, and an essential condition regardless the type of investment.

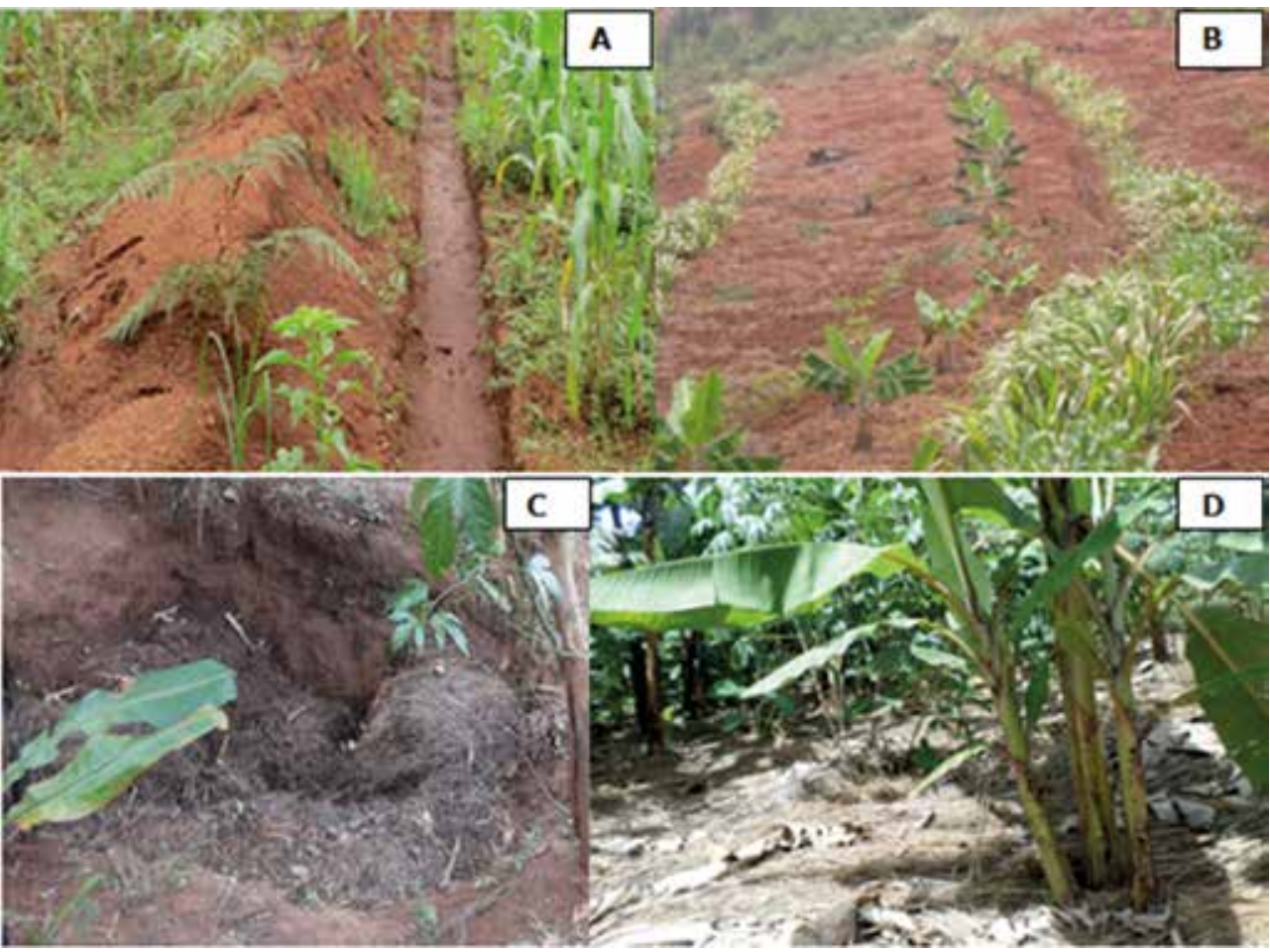

Figure 2.2 Examples of land management practices used in the study area: A\&B) Anti-erosion contour-lines without/with grasses; C) Composting; D) Mulch in a cassava and banana plantation.

In this study, farmer's ability to invest was expressed by household income stemming from farm and non-farm activities (Inc) and access to financial services like credit (Cred).

Next to these two factors (motivation and ability to invest), other personal variables potentially influencing investments in SLM were used in this study, namely the sex of the household head (Sex), education level (Educ), and the age of the household head (Age). The purpose to consider the sex of the household head as potential factor within SLM investments is to test the potential difference between women and men and guide policy makers in taking into account the gender aspect in their development programs. The education is an entrance point of knowledge acquisition and as a result potentially influences SML practices. Furthermore, the factor "age" was tested to see if old farmers invest more than the young ones given that they are considered more experienced with problems associated to farming.

Multinomial logistic regression was used to test whether farmer's motivation, ability, and personal variables influence investments in sustainable land management. Hence, 
the model consisted of three categories of investments as dependent variables, namely investments in Soil and water conservation practices (S), investment in Chemical fertilizers (C), and investment in Organic fertilizer (0); as well as the mentioned independent variables related to farmers' motivation, ability to invest, and other personal variables.

The logistic distribution function for the probability of adoption of a certain land management practice (Gujarati, 2005; Hosmer \& Lemeshew, 2000) can be specified as:

$P_{i}=\frac{1}{1+e^{-Z i}}$,

function of $n$ explanatory variables $\left(X_{\mathrm{i}}\right)$, and is expressed as:

$Z_{i}=\beta_{0}+\beta_{1} X_{1}+\beta_{2} X_{2}+----\beta_{n} X_{n}+\varepsilon_{i}$, where $\beta_{0}$ is the intercept and $\beta_{\mathrm{i}}$ are the slope parameters, and $\varepsilon_{\mathrm{i}}$ is the term's error.

The slope parameters quantify how the investment in a certain land management practice changes ceteris paribus, when the independent variables change by a unit. The odds to be used is defined as the ratio of the probability that a farmer applies or adopts the practice $P_{\mathrm{i}}$ to the probability that he or she will not apply/adopt the practice 1- $P_{\mathrm{i}}$ (Heyi Damena \& Mberengwa, 2012).

$Z(S C O)_{i}=\beta_{0}+\beta_{1}$ LandR $+\beta_{2}$ Fert $+\beta_{3}$ Eros $+\beta_{4}$ Eng $+\beta_{5}$ Inc $+\beta_{6}$ Cred $+\beta_{7}$ Educ $+\beta_{8}$ Sex + $\beta_{9}$ Age $+\varepsilon_{i}$

In the case of the binary regression the econometrics formula is as follows:

Where $S C O_{i}$ is the binary choice by the farmer to apply all practices $S C O(i=1)$ or nothing at all $(\mathrm{i}=0)$.

However, this binary choice was not used in this study, because a farmer could apply also one or two out of the three decision variables. For instance applying $S(\mathrm{i}=1)$ and not $C(\mathrm{i}=0)$ or $O(\mathrm{i}=0)$, or applying $S(\mathrm{i}=1)$ and $O(\mathrm{i}=1)$ but not $C(\mathrm{i}=0)$ and vice versa. Therefore, we decided to use the multinomial logistic regression, with the corresponding formula:

$Z_{i}\left(S_{i} C_{i} O_{i}\right)=\beta_{0}+\beta_{1}$ LandR $+\beta_{2}$ Fert $+\beta_{3}$ Eros $+\beta_{4}$ Eng $+\beta_{5}$ Inc $+\beta_{6}$ Cred $+\beta_{7} E d u c+\beta_{8}$ Sex $\beta_{9}$ Age $+\varepsilon_{i}$

\subsection{Results and discussions}

\subsubsection{Household factors}

The survey results indicate that out of 147 household heads (number of household heads after data cleaning), $95.2 \%$ are male and the remaining (4.8.\%) are female. With regard to the age of the respondent household heads, the mean age is 42,6 years, with a minimum and maximum of 22 and 85 years, respectively. On average, in the two provinces, 58.3\% and $7.3 \%$ of the respondents have attended primary and secondary school respectively. The average family size is about 5.8 persons per household, indicating that the survey respondents have rather large families. In terms of farming engagement, $64 \%$ of the household heads declared to be fully engaged in agriculture and $33.2 \%$ are mainly offfarm engaged and participate in agriculture only in the period that requires abundant labor.

Next to these personal characteristics, about a third of the farmers in the research area cultivated on plots with steep slopes (25.8\%) and very steep slopes (8.7\%) (Table 2.1). Plots located in marsh areas were not taken into account in this study since farmers have only very small plots in these areas or no plots at all.

\subsubsection{Farmers' motivation to invest in SLM}

Although farmers are aware of the benefits of land registration (to have a property title), the majority of them $(85,6 \%)$ did not register their land. The reason why farmers don't register their property is due to the fact that most of the lands are inherited from father to son $(81,9 \%)$ and the owners think that the tenure right is automatically acquired. When farmers are asked about the benefits of land registration, $80 \%$ of them stated that land registration reduces land conflicts, while $49.4 \%$ confirmed that it increases the chance of credit access, and $31 \%$ believed that land registration motivates potential land buyers.

In terms of investments in SLM in relation to soil erosion, the survey results indicate that among farmers who experienced erosion on the farm (89\%), more than half $(52 \%)$ have applied all practices $\left(\mathbf{S}_{1} \mathbf{C}_{1} \mathbf{O}_{1}\right)$ farm (Table 2.2). Soil erosion is positively and significantly associated with investments in SLM $\left(\gamma^{2}=8.454 ; p=0.015\right)$. This implies that the investment in SLM tend to rise when farmers perceive soil erosion occurring on their farm. 
Table 2. 1. Main characteristics of the households in the study areat

\begin{tabular}{lllll}
\hline & & Gitega & Muyinga & Average \\
\hline Gender household head (HHH) (\%)¥ & Male & 96 & 94.4 & 95.2 \\
& Female & 4 & 5.6 & 4.8 \\
\hline Mean age of the HHH (years) & & 44.4 & 41.2 & 42.8 \\
\hline Education level HHH & Illiterate & 5.3 & 16.7 & 11 \\
& Read and write & 22.7 & 25 & 23.8 \\
& Primary school & 66.7 & 50 & 58.3 \\
& secondary school & 5.3 & 8.3 & 7.3 \\
\hline Engagement of HHH in farming (\%) & Full engaged & 58.7 & 69.4 & 64.0 \\
& Partially engaged & 40.0 & 26.4 & 33.2 \\
\hline Average family size & & 5.7 & 5.9 & 5.8 \\
\hline Persons generating income & & 2.2 & 1.8 & 2 \\
\hline Slope of the farm plots (\%): & Flat & 28 & 6.9 & 17.4 \\
& Moderate slope & 28 & 68.1 & 48 \\
& Steep slope & 28 & 23.6 & 25.8 \\
& Very steep slope & 16 & 1.4 & 8.7 \\
\hline
\end{tabular}

+ Values in the table are presented in percentage and average $(N=147)$

$\neq H H H=$ Household head; \%=Percentage

Table 2.2 Farmers' investments in different combination of conservation practices in the study areat

\begin{tabular}{l|lll|l}
\hline & \multicolumn{2}{|l|}{ Types of investments $\$$} & Total \\
\cline { 2 - 4 } & $\mathrm{S}_{1} \mathrm{C}_{1} \mathrm{O}_{1}$ & $\mathrm{~S}_{1} \mathrm{C}_{0} \mathrm{O}_{1}$ & $\mathrm{~S}_{0} \mathrm{C}_{1} \mathrm{O}_{1}$ & \\
\hline \# of respondents & 77 & 32 & 38 & 147 \\
\% of respondents & 52.4 & 21.8 & 25.9 & 100 \\
\hline
\end{tabular}

+ Values in the table are presented in number and percentage of respondents $(N=147)$

I SCO symbolizes soil and water conservation practices; chemical fertilizers; and Organic fertilizers

respectively (1 means that a farmer applies such practice and 0 , otherwise)

\subsubsection{Farmers' ability to pay SLM}

According to the results of this study, the 2015 annual income generated from farm activity ranged on average from 7,874 BIF (US\$4.96) up to 58,268 BIF (US\$36.68) and came mainly from the sale of beans, coffee, and maize. The average income from non-farm activities was 211,408 BIF (US\$133.10), essentially from the sale of livestock, small trade, and from money received from relatives (e.g. remittance). Furthermore, the findings indicate that more than half of the respondents (56.5\%) accessed credit. The average credit size amounted 111,321 BIF (US\$70.07), however, the majority of these loans (51.7\%) did not exceed 20,000 BIF (US\$12.58). This is due to the scarcity of the credit market for agriculture. Among the farmers who accessed credit, $71.3 \%$ received it from a VSLA, $11.1 \%$ from their friends, $8 \%$ from non-government organizations and only $4.6 \%$ from banks.

The findings furthermore show that among the farmers who accessed a credit, $56.6 \%$ of them applied all practices $\left(\mathrm{S}_{1} \mathrm{C}_{1} \mathrm{O}_{1}\right)$, while $43.4 \%$ have applied only two categories of practices (22.9\% for $\mathrm{S}_{1} \mathrm{C}_{0} \mathrm{O}_{1}$ and $20.5 \%$ for $\mathrm{S}_{0} \mathrm{C}_{1} \mathrm{O}_{1}$ ) (Table 2.3).

Table 2.3 Access to credit and farmers' decision-making to invest in SLM in the study areat

\begin{tabular}{lll|lll|l}
\hline & & & \multicolumn{3}{l|}{ Type of investments } & \multirow{2}{*}{ Total } \\
\cline { 3 - 6 } & & & $\mathrm{S}_{1} \mathrm{C}_{1} \mathrm{O}_{1}$ & $\mathrm{~S}_{1} \mathrm{C}_{0} \mathrm{O}_{1}$ & $\mathrm{~S}_{0} \mathrm{C}_{1} \mathrm{O}_{1}$ & \\
\hline $\begin{array}{l}\text { Did you ask and get } \\
\text { credit? }\end{array}$ & Yes & \# of respondents & 47 & 19 & 17 & 83 \\
& & \% of respondents & 56.6 & 22.9 & 20.5 & 100 \\
& \multirow{2}{*}{ No } & \# of respondents & 30 & 13 & 21 & 64 \\
& & \% of respondents & 46.9 & 20.3 & 32.8 & 100 \\
\hline
\end{tabular}

+ Values in the table are presented in number and percentage of respondents $(N=147)$

I SCO symbolizes soil and water conservation practices; chemical fertilizers; and Organic fertilizers respectively (1 means that a farmer applies such practice and 0 , otherwise).

There is a positive and significant relationship $\left(\gamma^{2}=2.892 ; p=0.024\right)$ between access to credit and investment in SLM. The investments in SLM (preferably in $\mathbf{S}_{1} \mathbf{C}_{1} \mathbf{O}_{1}$ ) increased for farmers who have better access to credit. This shows that access to credit is a key factor in investing simultaneously in all relevant SLM practices. On the question of how the credit was allocated, $39 \%$ farmers indicated that the credit was used for agricultural activities (32\% for buying inputs and 7\% for constructing SWC, needed to pay the workforce and for setting up contour-lines) followed by trade and health care by $19 \%$ and $18 \%$ respectively. 


\subsubsection{Costs associated to land management practices in the study area}

The cost associated to land management investments in the study area are presented in table 2.4. The findings indicate that soil and water conservation practices are less expensive than organic and chemical fertilizers because the investment is mainly in labor and they are applied once on a certain plot (and then need maintenance only). However, organic and inorganic fertilizers are often used three times per annum corresponding to the three gricultural seasons in Burundi, and thus much more expensive. The big difference between both is that organic fertilizers are often produced on the farm (requiring labor and the righ skills/knowledge), while chemical fertilizer needs to be purchased, and thus, requiring cash. The government's policy to subsidize chemical fertilizers has therefore made a significant contribution to reducing the costs of chemical fertilizers.

Table 2.4 Cost associated to sustainable land management practices in the study area

\begin{tabular}{lll}
\hline Types of SLM practicest & Average cost/farmer (BIF) $\neq$ & Average cost/farmer (US\$) $\neq$ \\
\hline Contour-lines & 8,814 & 5.44 \\
\hline Ditches & 7,380 & 4.64 \\
\hline SWC practices (total) \& & 16,194 & 10.08 \\
\hline Crop residues & 1,357 & 0.85 \\
\hline Mulch & 8,487 & 5.34 \\
\hline Compost & 16,828 & 10.60 \\
\hline Manure & 30,903 & 19.45 \\
\hline Organic fertilizer (total) & 57,575 & 36.24 \\
\hline Limestone & 85 & 0.05 \\
\hline KCIף & 1,361 & 0.85 \\
\hline DAPף & 25,141 & 15.82 \\
\hline Urea & 11,138 & 7.00 \\
Chemical fertilizer (total) & 36,284 & 23.72 \\
\hline
\end{tabular}

TSLM: Sustainable land management

BIF: Burundian Franc and USS: United States Dollars and values are in average $(N=147)$

Here, SWC means soil and water conservation

KCl means Potassium Chloride and DAP means Diammonium Phosphate
2.3.5 Factors influencing farmers' investments in land management: empirical analysis

Estimates of the multinomial logistic regression analysis are presented in table 2.5.

Table 2.5. Factors influencing farmers' investments in land management in the study area

\begin{tabular}{lllll}
\hline $\begin{array}{l}\text { Dependent } \\
\text { variablest }\end{array}$ & Predictors $\neq$ & & Wald & Exp.(B)
\end{tabular}




\begin{tabular}{|c|c|c|c|c|}
\hline $\begin{array}{l}\text { Dependent } \\
\text { variablest }\end{array}$ & Predictors & Wald & Exp.(B) & $\%$ \\
\hline \multirow[t]{3}{*}{ Case processing§ } & $\mathrm{S}_{1} \mathrm{C}_{1} \mathrm{O}_{1}$ & & & 52.4 \\
\hline & $\mathrm{S}_{1} \mathrm{C}_{0} \mathrm{O}_{1}$ & & & 21.8 \\
\hline & $\mathrm{S}_{0} \mathrm{C}_{1} \mathrm{O}_{1}$ & & & 25.9 \\
\hline
\end{tabular}

Although farmers in different focus group discussions had expressed that land registration influences investments in SLM, the survey results show that this variable is not statistically significant in distinguishing the groups $\left(\mathrm{S}_{0} \mathrm{C}_{1} \mathrm{O}_{1}\right)$ and $\left(\mathrm{S}_{1} \mathrm{C}_{0} \mathrm{O}_{1}\right)$ from the group $\left(\mathrm{S}_{1} \mathrm{C}_{1} \mathrm{O}_{1}\right)$ (category reference). This also holds for the remaining predictors namely income, soil

tDependents variables are defined by three categories namely $S_{1} C_{1} O_{1}, S_{1} C_{0} O_{1}$, and $S_{0} C_{1} O_{1}$ where SCO symbolizes Soil and water conservation practices; Chemical fertilizers; and Organic fertilizers respectively (1 means that a farmer applies such practice and 0 , otherwise). The category reference is $S_{1} C_{1} O_{1}$.

FValues of Predictors are presented by the Wald coefficient, the level of significance (sig.) and the $\operatorname{Exp}(B)$ in distinguishing categories $\mathrm{S}_{1} \mathrm{C}_{0} \mathrm{O}_{1}$ and $\mathrm{S}_{0} \mathrm{C}_{1} \mathrm{O}_{1}$ from reference category $\left(\mathrm{S}_{1} \mathrm{C}_{1} \mathrm{O}_{1}\right)$. $\mathrm{HHH}$ means Household heads. ${ }^{*}: p<=0.10 ; * *: p<=0.05 ; * * *: P<=0.001$; $\S$ values of case processing are in percentage of respondents $(N=147)$.

The three main categories of practices $\mathrm{S}_{1} \mathrm{C}_{1} \mathrm{O}_{1}, \mathrm{~S}_{0} \mathrm{C}_{1} \mathrm{O}_{1}$ and $\mathrm{S}_{1} \mathrm{C}_{0} \mathrm{O}_{1}$ were used as dependent variables, with $\mathrm{S}_{1} \mathrm{C}_{1} \mathrm{O}_{1}$ as reference level.

The model fit is based on the statistical significance of the final chi-square (Bayaga, 2012). In this study, the probability of the model chi-square $(18, N=147)$ was significant at $p=0.029$. Multi-collinearity was tested and no violations were detected (the variance inflation factor of each predictor was less than 2).

The independent variables soil erosion and engagement of the household head in farming are statistically significant in distinguishing category $\mathrm{S}_{1} \mathrm{C}_{0} \mathrm{O}_{1}$ from reference category $\mathrm{S}_{1} \mathrm{C}_{1} \mathrm{O}_{1}$ $(p<0.05)$. Hence, the survey respondents who experienced erosion on their farm were more likely to be in the group of survey respondents who applied all three practices $\left(\mathrm{S}_{1} \mathrm{C}_{1} \mathrm{O}_{1}\right)$, rather than in the group who applied only SWC practices and organic fertilizers $\left(\mathrm{S}_{1} \mathrm{C}_{0} \mathrm{O}_{1}\right)$. In addition, household heads who are "fully engaged" in farming prefer to apply combined land management practices (i.e. organic, chemical fertilizers and SWC practices) than those not fully engaged $(p<0.001)$.

Credit uptake is significant in distinguishing category $S_{0} C_{1} O_{1}$ from category $S_{1} C_{1} O_{1}(p<0.05)$, meaning that the survey respondents whogot credit were more likely to be in the group of survey respondents who applied all practices $\left(\mathrm{S}_{1} \mathrm{C}_{1} \mathrm{O}_{1}\right)$ rather than in the group of survey respondents who applied only fertilizers without investing in SWC practices $\left(\mathrm{S}_{0} \mathrm{C}_{1} \mathrm{O}_{1}\right)$. The "education level" of the household head is a personal factor that also influences SLM investments. Respondents with primary level were more likely to be in the group of respondents who applied $\mathrm{S}_{1} \mathrm{C}_{1} \mathrm{O}_{1}$ than in $\mathrm{S}_{0} \mathrm{C}_{1} \mathrm{O}_{1}$. In the same way, households with older household heads were more likely to be in the group of respondents who applied $S_{1} C_{1} O_{1}$ than $S_{0} C_{1} C_{1}(p=0.050)$.

\subsection{Discussion}

Without a thorough understanding of the factors that eventually lead to conservation investments, policy makers and extension agents may not be able to communicate effectively with farmers (Kifle et al., 2016). In this study, predictors that significantly influenced SLM investments were soil erosion, farming engagement of the household head (motivational factors), access to credit (ATP), age and education level of household head (personal factors).

According to the findings, farmers who experienced soil erosion on their farm were more likely to invest in all practices together, rather than only in SWC practices or organic fertilizers. However, these results contradict findings in the Blue Nile (2002) and in the Central Rift Valley of Ethiopia (2012) where neither investments in water erosion control nor in soil fertility control were found to be associated to farmers' experience of soil erosion or soil fertility depletion (Adimassu \& Kessler, 2012; Bewket \& Sterk, 2002). For this study, the positive correlation $(p=0.025)$ between experiencing soil erosion on the farm (hence being aware of it) and investments in SLM could also be attributed to previous activities of the local SCAD project, since the survey farmers had already received trainings on integrated farm planning (PIP) and were therefore supposed to be quite aware of land degradation.

The results of multinomial logistic regression revealed that farmers who had access to credit were more likely to be in the group of farmers who applied SWC, chemical and organic fertilizers together, rather than in the group of farmers who applied only chemical and organic fertilizers. Findings from a study carried out in Tanzania stipulated that households with good access to support services, particularly credit, tend to invest more in SLM on their upland fields (Nyanga et al., 2016). This might be associated to the impact of soil erosion being usually more frequent in highlands where farmers invest more to restore soil fertility. The same notification came from research carried out recently in Ethiopia where farmers with higher financial capital (including credit) invested more in SLM as compared to farmers with lower financial capital (Adimassu \& Kessler, 2012). Findings from Zambia confirmed that farmers' investments in land management are minimal due to their limited access to credit (Ngombe et al., 2014). In addition, similar results were reported in Ethiopia, where 
credit access influenced positively and increased the probability of SLM adoption (Kirui, 2017). The findings of this research also confirm what was found in Central Nepal, in which the use of credit influences the adoption of improved soil conservation technologies (Tiwari et al., 2008). For this research, given that farmers have developed the culture of savings and loans through a VSLA, the structures once consolidated could be a channel to access to credits for smallholders who are insolvent for financial institutions.

The age, as well as the time spent by the household head on agricultural activities also positively influenced investments in SLM. These findings are consistent with those from Kenya, where age was found positively associated to the adoption of SWC; i.e. older farmers are likely to easier adopt SWC practices than younger farmers (Alufah et al., 2012). Presumably older farmers (and those who are full engaged in farming) are likely more aware of problems associated to farming and as a result more receptive to land management practices.

It was hypothesized that higher educated farmers are more receptive to land management practices. However, the results indicate that farmers with basic knowledge (primary level) were more likely to apply integrated land management practices than those with secondary level or illiterate ones. These results can be explained by the fact that the most educated ones aspire other jobs and do not consider agriculture as their business; contrarily to the farmers with primary level education who have a keen interest to invest in land management and are more committed to enhance farm productivity.

\subsection{Conclusion}

This paper assessed motivational, economic, and personal factors that influence SLM investments. In this study, SLM investments were divided into three groups namely soil and water conservation, organic and chemical fertilizers. Out of the nine major factors analysed, five triggered farmers to invest in SLM practices: occurrence of soil erosion on the farm, access to credit, age, education level, and engagement in farming of the household head. In analysing these findings, three main lessons were learned.

Firstly, farmers' access to credit is positively associated to investments in all three groups of SLM practices together: soil and water conservation practices, as well as chemical and organic fertilizers. Hence, credit does not only contribute to buying (expensive) chemical fertilizers, but farmers use it also for manpower payment to construct soil conservation practices such as contour-lines and diversion ditches, as well as to purchase organic fertilizer elsewhere. Providing farmers access to credit is thus an essential element in preventing land degradation.

Secondly, older farmers and those fully engaged in farming are more likely to invest in SLM than the younger ones and those partially engaged. Having more experience in farming, and thus being more aware of the needs of the land and its erosion and fertility problems, is therefore a driver of investments in SLM.

Thirdly, education is crucial to SLM, as it enhances farmers' knowledge and skills related to causes and solutions of land degradation. This study shows that even a minimum literacy (primary level) is already sufficient to make a difference in farmers' capabilities and selfreliance to find solutions and invest more in SLM. Interestingly, when accessing higher levels of education farmers tend to aspire an exit from agriculture and invest less in their land.

It is clear that the implementation of SLM practices - as a solution to land degradation and a driver of more food security - is beneficial to the whole nation. However, the cost associated to investments in SLM remain a big challenge for farmers in the study area. Investing in SLM is thus not a concern of small farmers alone, but the role of the government and other partners is crucial. We therefore recommend policy makers in Burundi to improve access to credit markets in rural areas, as this will motivate farmers to invest in their farm and deal with land degradation problems. Together with enhanced efforts to strengthen smallholders' capacities concerning SLM and their agri-entrepreneurial skills, this enhances more integrated solutions which eventually will be more effective. 


\subsection{Introduction}

Exposure to adverse weather and climate change increasingly affects the livelihoods of the rural population and challenges their food security and economic development (Bobojonov \& Sommer, 2011), especially of those farmers who depend on subsistence agricultural and lack access to alternative livelihoods (Meijer et al., 2015).

Beyond weather variability and climate change, other factors such as market conditions, seed availability and labor supply, also play a decisive role in shaping farmers' responses to risk associated to farming (Mertz et al., 2009). Farmers are therefore perceived as risky borrowers, which reduces their access to credit (i.e. credit rationing) and raises interest charges, with the net effect of these limitations being that farmers are trapped in lowproductivity farming (Hazell et al., 2010). Increased adverse weather conditions as droughts and floods are therefore likely to exacerbate existing gaps, making the poor more vulnerable and leaving many rural farmers in a cycle of poverty. Risks can potentially have significant implications on stakeholders, investments and development in the agricultural sector (Giertz et al., 2015). Moreover, agricultural risks are the principal cause of transient food insecurity, creating a poverty trap for millions of households across the developing world that enforces a vicious cycle of shock and recovery (Choudhary et al., 2016). diseases affecting crop production and the risk of hail (experienced by 78 and $85 \%$ of farmers respectively). Based on a risk perception index (RPI), differences in risk perception were observed between both provinces. Drought risk and pests and diseases affecting crops were perceived to be most severe in Gitega with a RPI of 0.55 and $0.50(N=75, P \leq 0.05$,) respectively, whereas drought and flooding risks were perceived to be most severe in Muyinga with a RPI of 0.59 and $0.49(N=72, P \leq 0.05)$ respectively. Farmers who experienced risk in the past also perceived the risk as more important now (flooding for instance: $r=0.35$, $P \leq 0.01)$ and were more inclined to coping with it $(B=0.96, P \leq 0.05)$. However, given that most farmers only undertake measures after an event has taken place (ex-post measures), it is essential for the government to provide farmers better access to information on climate variability, and to train farmers in order to encourage adoption of climate smart adaptation strategies. Furthermore, for those risks that cannot be prevented by farmers or for which coping strategies under study are insufficient, social protection mechanisms like an agriinsurance should be encouraged.

\section{Based on:}

Ndagijimana, M., Kessler, A., Asseldonk van, M. 2020. Analysing risk experience, risk perception and coping strategies in Burundian agriculture. Natural Resource Forum, a United Nations Sustainable Development Journal (Submitted)

A comprehensive risk analysis of a business such as farming entails questions on the importance of risk as perceived by farmers and how to deal with it (Wauters et al., 2014). These perceptions and farmers' experiences with risks influence their risk responses (Flaten et al., 2005). Many scholars in the world have studied the behavior of farmers in coping with agriculture risks and management measures taken (Biswas et al., 2015). Generalisation is complicated since the risks farmers are confronted with, and subsequently adopt coping strategies, vary by farming system, agro-climatic region, local policy, and institutional setting. The assessment of farmers' perception and how they react to risk are crucial to better understand their decision-making when faced with risk (Flaten et al., 2005), and contributes to the formulation of more appropriate policies to help overcome risk associated with farming (Asravor, 2018). This linkage to policy-making is particularly important considering the increase in risk due to climate changes (Alcamo et al., 2007). Governments can facilitate farmers' better access to extension services that provide them information and training on improved farm management and climate information, enabling them to adapt to longterm climate change (Coulibaly et al., 2015). This study was carried out in Burundi with the objectives to 1 ) assess the historic risk exposure associated to farming and farmers perceptions of these risks; and 2) assess the relationship between risk experience, risk perception and coping strategies in the study area. 


\subsection{Methodology}

\subsubsection{Study area}

The study was performed in four districts (communes) of Gitega province (districts of Bukirasazi and Makebuko) and Muyinga province (districts of Butihinda and Giteranyi). These districts belong to the pilot area of a project referred to as "Fanning the Spark" which was carried out from 2014-2017 in the framework of supporting farmers to enhance food security at village level based on agriculture risk adaptation and investments in crop production. Beneficiaries were trained by means of an integrated farm planning approach which developed families' competencies and visions.

Gitega is located in the central part of Burundi and its capital is the second biggest city after Bujumbura. The yearly average rainfall is about $1179 \mathrm{~mm}$ and the temperature ranges between 21 and $31^{\circ} \mathrm{C}$. Gitega counts on average 176 rainy days in a year, with December as the rainiest month (www.weatherbase.com, 2015). The population density is 349 inhabitants $/ \mathrm{km}^{2}$ which is a density higher than the national average ( 247 inhabitants $/ \mathrm{km}^{2}$ ) (MFPDE, 2006a).

Muyinga is located in the North-East part of Burundi and borders in the east with Tanzania and in the north with Rwanda. The yearly average rainfall is $1146 \mathrm{~mm}$ and the temperature ranges between 17 and $27^{\circ} \mathrm{C}$. Muyinga counts 156 days of rain per year with April as the rainiest month (MFPDE, 2006b). Crop production in these two provinces is generally based on limited use of chemical fertilizers and farmers face serious problems related to access to credit. The main cash crop in the study area is coffee. However, farmers face market problems for their food crops, with volatile prices especially during sowing season (high input prices) and harvest periods (low prices of harvested products). Therefore, young farmers rely on the casual work in Tanzania (mainly for farmers from Muyinga) and in other provinces to compensate for low income from agriculture.

\subsubsection{Sampling and data collection}

The sample consisted of 160 participants randomly selected from a population of farmers in eight villages of the mentioned four districts, and a structured household survey was conducted in 2016 to collect quantitative data. The household head was interviewed, and if absent, the spouse completed the questionnaire. The questionnaire was administered by a group of bilingual enumerators, after having performed a training to ensure that Planning-in-Burundi.htm questionnaire's translation and interpretation were similar among the enumerators. The questionnaire comprised four main modules and captured risk experience ${ }^{4}$, risk perception agricultural investments, and the types of coping strategies adopted by farmers. Next to quantitative data on the above specified subjects, qualitative data were collected through focus group discussions (FGDs). In total, eight FGDs were conducted, i.e. one per village. The purpose of the FGDs was to complete information collected from individual farmers. Additional information related to the risk management strategies applied were collected at this stage. After data collection and cleaning we obtained data on 147 households for the analysis.

\subsubsection{Risk experience, risk perception, coping strategy and data analysis}

Risk experience is the fact or state of having been affected by the risk (Saguye, 2017). Prior to the survey, a discussion with farmers was organized to identify the most dominant risks associated with farming in their respective areas. Eight main risks ${ }^{5}$ were identified from literature and these focus groups, and farmers were asked if they had already experienced them or not during the past five years. This was a binary variable with 1 if the risk occurred and 0 otherwise. First of all, the ranking of the eight most prominent risk factors under study was established and then, the relationship between different experienced risks was analyzed by using the Pearson correlation coefficient. The relationship was tested in order to analyze the inter-dependence of different risks.

Risk perception on its turn reflects the decision-maker's interpretation of the likelihood of exposure to the risk and is defined as a decision-maker's assessment of the risk inherent in a particular situation (Mahul \& Pennings, 2004). Thus, it is a combination of the probability of the occurrence of an uncertain event and the consequential negative impact (Slovic et al., 1982). In this study, risk perception of eight risks was analysed by using the risk perception index (RPI). The RPI ranges from 1 (weak) to 4 (very severe) and is calculated as an absolute frequencies of each choice (Signorino \& Beck, 2014):

$$
R P I=\left(\sum_{i} n_{i} \pi_{i}\right) / N * 4
$$

where $n_{\mathrm{i}}$ represents the absolute frequency of the $i^{\text {th }}$ mode; $\Pi_{\mathrm{i}}$ represents the weight assigned to the $i^{\text {th }}$ mode (that is, weak $=1$, moderate $=2$, severe $=3$, very severe $=4$ ) and $N$ is the total number of observations.

\section{Risk and shock are interchangeably used in this study.}

5 Weather risks (drought, flooding, early exit rain and hail); market risks (input price and output price); and production risks (pests/diseases affecting crops and stored products). The pests/diseases affecting crops and stored products are referred to as "pests/dis. crops" and "pests/dis. storage" for all figures and tables. 
Coping strategies depend on the nature of risk, available strategies, financial aspects and farmers' livelihoods; they therefore differ from one household to another. To gauge the coping strategies among farmers in the study area, farmers were asked two types of questions (i) how did the household cope with each risk factor in the past? and (ii) if the same event would happen today, what three coping strategies are you most likely to resort to? Coping strategies mostly used in the study area were identified during different focus group discussions before the start of the survey. In addition, based on the agricultura context in Burundi, but also on other studies on risk management (Kahan, 2013; Coulibaly et al., 2015; Amjed et al., 2018), 27 different coping strategies were identified. These were grouped into five categories to help farmers identify better which were applicable to them and to facilitate data recording and analysis.

The association between risk experience (eight risk factors), risk perception (eight risk factors) and coping strategies (five categories) was measured by means of Pearson correlation.

Table 3.1. Classification of households coping strategies to shocks

\begin{tabular}{|c|c|}
\hline Category & Coping strategies \\
\hline Farm investments & $\begin{array}{l}\text { Use of ashes for stored produce, use of adapted crops, use of pesticides, } \\
\text { early sowing, use of tobacco sap for growing crops, leave affected crops, } \\
\text { irrigation, belated sowing }\end{array}$ \\
\hline Assistance & $\begin{array}{l}\text { Assistance by friends, government, churches and NGO, or borrowing money } \\
\text { from friends, credit from formal or informal institutions }\end{array}$ \\
\hline Asset depletion & $\begin{array}{l}\text { Sale of animals or growing crops, sale of a part of land (plots), sale of other } \\
\text { assets of members of the households (radio, television, cloths, jewellery, } \\
\text { phones) }\end{array}$ \\
\hline Savings & Use of precautionary savings \\
\hline Consumption adjustment & $\begin{array}{l}\text { Reduce food expenditure, reduce non-food expenditure, consume less } \\
\text { expensive food, use of stored produce }\end{array}$ \\
\hline
\end{tabular}

\subsubsection{Empirical analysis with path analysis}

Path analysis was used to test the farmers' behavior when facing agricultural risks in the study area. The construction of the model is presented in Figure 3.1. Based on this construction, we analyze the relationship between risk experience, risk perception, and coping strategies. Path analysis applies regression analysis and allows a more structural interpretation of statistical dependencies. The 'one way road' (arc with one head $\rightarrow$ ) means natural (or causal) dependency, while the arc with two heads ( $\leftrightarrow$ ) indicates the absence of prior information about the direction of (causal) dependency (it is assumed to be correlated). Thus, the independent variables (risk experience and risk perception) are modelled as being correlated, having both direct effects on coping strategies (endogenous variable). In the below model, applying a coping strategy may be influenced by external factors out of the set model, including their measurement error. These factors are denoted by ' $\mathcal{E}$ ' in the model.

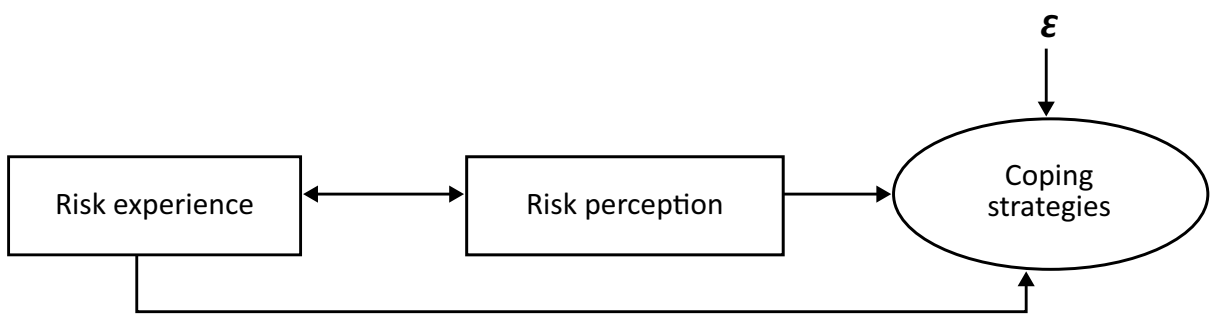

Figure 3.1. Structural relationships in coping strategies

\subsection{Results}

\subsubsection{Risk source in the study area}

The four risks most experienced by farmers from Gitega were flooding (91\%), hail (85\%), pests and diseases affecting crops (80\%), and drought (75\%), whereas those in Muyinga were drought (89\%), pests and diseases affecting crops (78\%), fluctuating input prices (57\%) and fluctuating output prices (44\%). In Gitega, also some other risks were more experienced than in Muyinga such as early exit rains (61\%), pests and diseases affecting stored products (63\%) and output price fluctuations (56\%) (see Figure 3.2). 


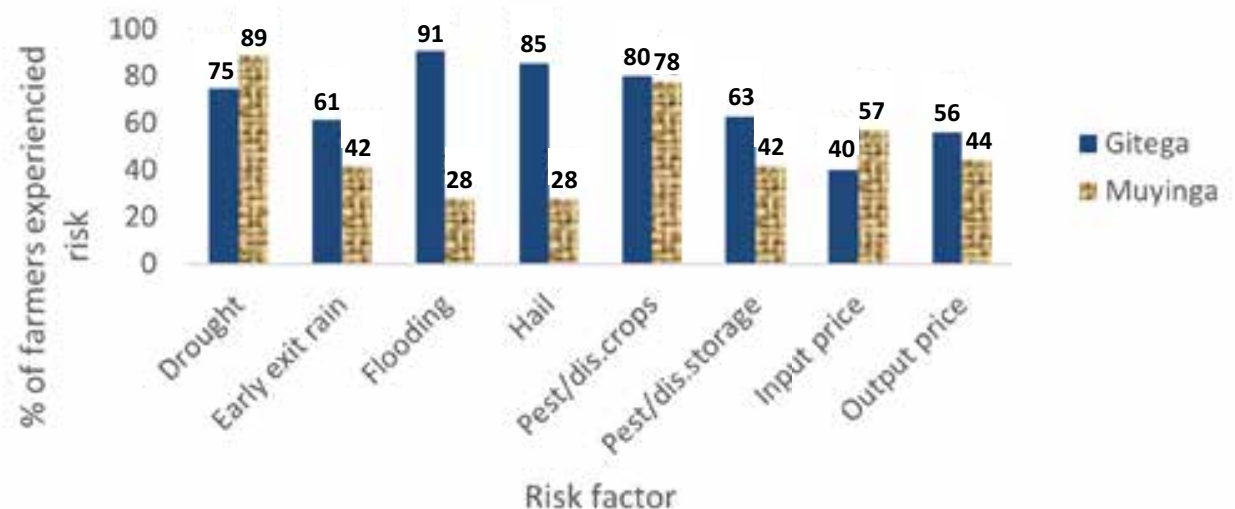

Risk factor

Figure 3.2. Percentage of farmers experiencing identified risks in the study area: Gitega (N=75); Muyinga $(N=72)$

The correlation between the identified risks has been tested to analyze for their interdependence. Several risks are statistically significant and positive correlated (others negative) as depicted in Table 3.2.

Table 3.2. Correlation between the main risk factors

\begin{tabular}{lllllllll}
\hline & Drought & Flooding & Hail & $\begin{array}{l}\text { Early } \\
\text { exit rain }\end{array}$ & $\begin{array}{l}\text { Pest/dis. } \\
\text { crops }\end{array}$ & $\begin{array}{l}\text { Pest/dis. } \\
\text { storage }\end{array}$ & $\begin{array}{l}\text { Input } \\
\text { price }\end{array}$ & $\begin{array}{l}\text { Output } \\
\text { price }\end{array}$ \\
\hline Drought & 1 & & & & & & & \\
\hline Flooding & -.030 & 1 & & & & & & \\
\hline Hail & -.056 & $.553^{* *}$ & 1 & & & & & \\
\hline Early exit rain & -.001 & $.208^{*}$ & $.181^{*}$ & 1 & & & & \\
\hline Pest/dis. crops & $.185^{*}$ & .019 & .159 & .101 & 1 & & & \\
\hline Pest/dis. storage & $.181^{*}$ & $.220^{* *}$ & .138 & $.223^{* *}$ & $.342^{* *}$ & 1 & & \\
\hline Input price & $-.174^{*}$ & $-208^{*}$ & -.126 & .008 & .032 & .049 & 1 & \\
\hline Output price & $-.225^{* *}$ & .019 & .047 & -.007 & -.047 & .006 & $.470^{* *}$ & 1 \\
\hline
\end{tabular}

$*, *$ denote significance at $5 \%$ and $1 \%$ respectively

For instance, relative strong positive and significant correlations were found between flooding and hail $(r=0.553, P \leq 0.05)$, and a moderate correlation between pests and diseases affecting crops and stored products $(r=0.342, P \leq 0.05)$, as well as between input and output price fluctuations $(r=0.470, P \leq 0.10)$. The strong correlation between hail and flooding means that the occurrence of both (or neither of them) at the same time in the study area is more likely than of only one of them (Sulewski \& Kloczko-Gajewska, 2014). The positive and significant relationship between pests and diseases affecting crops and stored products is explained by the fact that some pathogenic germs are harvested with crops and may be harmful once the crops are stored. In addition, the survey results indicate that a drought had a direct impact on pests and diseases affecting both crops $(r=0.185, P \leq 0.10)$ and stored produce $(r=0.181, P \leq 0.10)$. Farmers in the study area affirmed that pests thrived very well during the dry season.

Furthermore, drought and output price are statistically significant and negative correlated $(r=-0,225 ; P \leq 0,05)$ meaning that the frequency of drought has an impact on the overal price of the harvested products because of the produce quality. In most of cases however this correlation was relatively weak in strength $(r<0.30)$.

\subsubsection{Risk perception in the study area}

The farmers' risk perception levels were different according to the (regional) nature of the risk. Based on the risk perception index (RPI), from the total respondents (N=75) in Gitega, drought, pests and diseases that affect crops and stored products were perceived by farmers to be the three main risks, with an RPI of $0.55,0.50$, and 0.34 respectively (see Figure 3.3). In Muyinga drought and pests and diseases affecting crops also figured among the top two perceived risks (with an RPI of 0.59 and 0.47 respectively), but in this study area flooding scored high also. Hence, there are some clear differences in risk perception between the two study areas. Given that significant correlations between perceived risk factors are similar to the earlier presented values for experienced risk factors, these are not reported here.

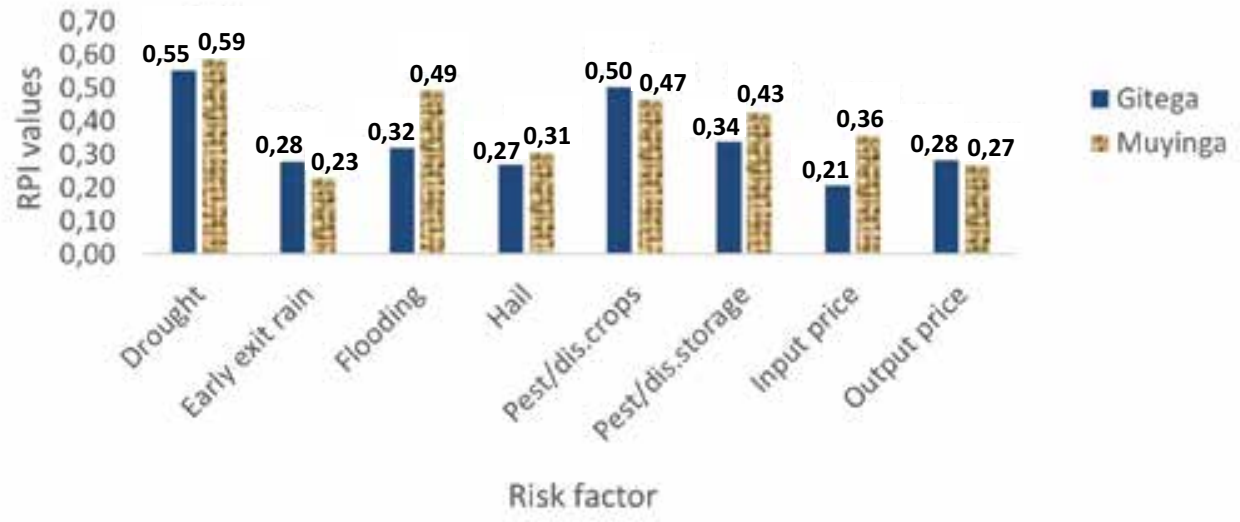

Figure 3.3. Risk perception in the study area: Gitega $(N=75)$; Muyinga $(N=72)$ 
Furthermore, the Pearson correlation coefficient was used to test the correlation between risk experience and (transformed) 6 risk perception. Correlation values reveal that having experienced a specific risk in the past does not imply that it is necessarily perceived as more severe now. We see in Table 3.3 that this is only the case for flooding $(r=0.35, P \leq 0.01)$, hence, the more experience farmers have with flooding the more severe they currently perceive flooding as a risk. However, Table 3.3 also shows that some past experiences with certain risk can lead to perceiving another risk currently as more severe. This is for instance the case between experiences with flooding and the current risk perception of hail $(r=0.21$, $\mathrm{P} \leq 0.05)$, as hail is often followed by flooding. The results of this study also point out the relationship between experiencing hail or early exit rains in the past and the perception of price fluctuations of inputs (with respectively $r=0.25$ and $r=0.24, P \leq 0.05$ ). The early exit of rain reduces production and makes the input price unaffordable by farmers. Furthermore, the results revealed a significant and negative relationship between the occurrence of hail and pests and diseases in crops $(r=-0.17, P \leq 0.05)$. The negative coefficient means that the more farmers experience hail, the less severe pests and diseases are perceived in crops.

Table 3.3. Correlation between risk experience and risk perception

\begin{tabular}{|c|c|c|c|c|c|c|c|c|}
\hline \multirow[b]{2}{*}{ Experience } & \multicolumn{8}{|c|}{ Perception } \\
\hline & Drought & Flooding & Hail & $\begin{array}{l}\text { Early } \\
\text { exit rain }\end{array}$ & $\begin{array}{l}\text { Pest/ } \\
\text { dis.crops }\end{array}$ & $\begin{array}{l}\text { Pest/ } \\
\text { dis.storage }\end{array}$ & $\begin{array}{l}\text { Input } \\
\text { price }\end{array}$ & $\begin{array}{l}\text { Output } \\
\text { price }\end{array}$ \\
\hline Drought & 0,03 & 0.06 & -0.05 & 0.03 & 0.15 & 0.19 & -0.03 & -0.16 \\
\hline Flooding & 0.01 & $0,35^{* *}$ & -0.06 & -0.02 & -0.08 & -0.17 & 0.11 & 0.02 \\
\hline Hail & -0.01 & $0,21^{*}$ & 0.18 & 0.08 & $-0.17^{*}$ & - 229 & $0,253^{*}$ & 0.11 \\
\hline Early exit rain & 0.12 & -0.14 & 0.01 & 0.00 & 0.02 & 0.02 & $0,243^{*}$ & 0.10 \\
\hline Pest/dis. crops & 0.14 & -0.05 & 0.05 & -0.11 & -0.07 & 0.03 & -0.08 & -0.15 \\
\hline Pest/dis. storage & 0,19 & 0.03 & -0.09 & -0.05 & -0.07 & -0.04 & 0.12 & 243 \\
\hline Input price & 0.04 & -0.09 & 0.11 & 0.21 &,- 203 & -0.14 & -0.02 & 0.15 \\
\hline Output price & -0.02 & 0.08 & 0.02 & 0.21 & -0.07 & -0.07 & -0.02 & 0.19 \\
\hline
\end{tabular}

* ** denote significance at $5 \%$ and $1 \%$ respectively

\subsubsection{Coping strategies in the study area}

Respondents listed the three main strategies that their household resorted to when faced a particular risk. Different strategies are used to cope with the same shock, but also a same strategy is often used for different shocks. For instance, when faced with drought, $33 \%$ of the respondents resorted to the strategy of farm investment (which was also used by $75 \%$ of the farmers in case of pests and diseases affecting stored products) (Table 3.4)

In addition, $26 \%$ of respondents adjusted their consumption when affected by hail and $77 \%$ used this strategy also for coping with price fluctuation of outputs. In line with some other study results in Africa (Coulibaly et al., 2015), results from this study indicate that ex-post coping strategies are the dominant mechanisms used by most households in the study area. However, most of these coping strategies are survival mechanisms with limited mid and long-term effects. This can be due to the poor access to credit by farmers and underfinancing of agriculture in the study area. In dealing with the problems related to access to credit, most respondents resort to assistance, mainly by borrowing cash from their "village savings and loans associations" (VSLAs). However, respondents also stated that these financial structures have limited capacity to serve all famers applying for credit at the same time (when all applicants are affected by a given systemic risk). A more closer look at farm investments also revealed the use of very original mechanisms originating from farmers' expertise. Examples are the use of ashes for stored products and pulverization with tobacco saps for specific risks such as pests and diseases that affect both crops and stored products.

Furthermore, the risk management adoption level depends on the nature of the risk. When faced with pests and diseases that affect stored products, $75 \%$ of the households resorts to farm investments (mainly with the use of ashes or tobacco saps). However, when facing price fluctuations (low output price), farmers adjust their consumption patterns by reducing expensive food and/or consume the stored product. Some households (about 5-15\% depending on the risk) even did not do anything when facing risk associated with farming.

Respondents indicated that although some of the strategies used in the past are a kind of survival strategy, they keep using the same strategies because they do not have other alternative and effective strategies. Farmers are in general not satisfied by the undertaken actions in the past, results indicated that $77.6 \%$ of the respondents disliked the used strategies; i.e. they would prefer to use another strategy to cope with these risks. 
Table 3.4. Risk management adoption

\begin{tabular}{lllllll}
\hline & \multicolumn{2}{l}{ Risk management } & & & & \\
\cline { 2 - 7 } Risk experience & $\begin{array}{l}\text { Farm } \\
\text { Investment }\end{array}$ & Assistance & $\begin{array}{l}\text { Asset } \\
\text { depletion }\end{array}$ & Saving & $\begin{array}{l}\text { Consumption } \\
\text { adjustment }\end{array}$ & $\begin{array}{l}\text { No coping } \\
\text { strategy }\end{array}$ \\
\hline Drought & 33 & 15 & 16 & 85 & 24 & 4.2 \\
\hline Flooding & 16 & 28 & 14 & 11 & 21 & 11 \\
\hline Hail & 1 & 28 & 14 & 11 & 26 & 11 \\
\hline Early exit rain & 41 & 11 & 5 & 2.6 & 25 & 15 \\
\hline Pest/dis. crops & 55 & 10 & 2 & 1 & 14 & 18 \\
\hline Pest/dis. storage & 75 & 5 & 1 & 3 & 5 & 10 \\
Input price & 1 & 17 & 14 & 44 & 13 & 11 \\
Output price & 0 & 9 & 5 & 3 & 77 & 5 \\
\hline
\end{tabular}

Note: data in table are frequencies in percentage

In order to react effectively to different risks associated with farming, survey respondents also reported the necessity to be trained on risk management measures (18.4\%), to get better access to financial services like credit (13\%) and be timely informed about climate variability (9\%). Almost $82 \%$ of all farmers reported that risks associated with farming have increased over the last ten years due to climate variability.

In addition, based on a three-point Likert scale, results from descriptive statistics indicated that some shocks demotivate farmers to invest, especially for the shocks for which it is very difficult to take prevention measures (ex-ante measures) such as drought, flooding and hail. These three risks score the highest in both study areas. The respondents indicated that when these shocks occur they often loose the entire harvest and investments made; i.e. farmers do not have mechanisms to limit damage in these situations. However, as expressed by farmers, risks for which farmers do have coping strategies available motivate them to invest in agricultural. This is the case for pests and diseases that affect crops as well as price fluctuations of inputs and outputs. In addition, results indicated that on average, nearly 1 in 5 respondents in Gitega, representing 21.8\% and nearly 1 in 3 respondents in Muyinga, representing $31.3 \%$ do not change any practice and continue as usual (Table 3.5 ). This group of people is often referred to as "laggards", i.e. persons who are not receptive to change by arguing that their peers and parents did the same in the past. They are reluctant to innovate and wait for the results from the first innovators (risk takers) before undertaking any action.
Table 3.5. Farmers' decision making on agricultural investments under risk occurrence

\begin{tabular}{llll}
\hline \multirow{2}{*}{ Risk experience } & \multicolumn{3}{l}{ Farmers' decision to invest in agriculture (Gitega and Muyinga) } \\
\cline { 2 - 4 } & Increase (\%) & Decrease (\%) & Neutral(\%) \\
\hline Drought & $27(28)$ & $61(53)$ & $11(20)$ \\
\hline Flooding & $19(26)$ & $55(37)$ & $26(37)$ \\
\hline Hail & $11(32)$ & $58(32)$ & $32(35)$ \\
\hline Early exit rain & $38(45)$ & $33(24)$ & $29(31)$ \\
\hline Pest/dis. crops & $58(44)$ & $30(22)$ & $12(33)$ \\
\hline Pest/dis. storage & $42(55)$ & $42(13)$ & $17(32)$ \\
\hline Input price & $50(53)$ & $29(15)$ & $21(33)$ \\
\hline Output price & $44(55)$ & $29(15)$ & $27(30)$ \\
\hline
\end{tabular}

Note : Values for Muyinga are in brackets; (Gitega $N=75$; Muyinga $N=72$ )

\subsubsection{Results from path analysis}

As above mentioned in the methodology, a path analysis was used to test the relationship between risk experience, risk preference and coping strategies (farmers' behaviour). The farmers' coping strategies are different from one experienced risk to another. For instance, the effect of experiencing early exit of rains is statistically significant $(\beta 4=-0.22, P \leq 0.05)$ and its coefficient is negative indicating that the more a farmer has experienced early exit rains, the lower his willingness to undertake measures in terms of farm investments. Furthermore, experiencing pests and diseases affecting stored products is statistically significant $(\beta 6=0.35$, $\mathrm{P} \leq 0.05$ ) and its coefficient positive, meaning that the more farmers have experienced pests or diseases that affect stored products, the more they invest in agriculture. In addition, experiencing drought and input fluctuations are statistically significant $(\beta 1=-0.36 ; \beta 7=-0.37$, $\mathrm{P} \leq 0.05$ ) and coefficients negative, indicating that the more farmers experience drought or input fluctuation, the more they try to do something in dealing with these risks rather than doing nothing (negative correlation) (see Table 3.6).

The majority of farmers in the study area resort to using some locally known strategies, but coping strategies are different one to another according to the perceived risk Furthermore, drought perception is statistically significant $(\beta 1=0.96, \mathrm{P} \leq 0.05)$ and its coefficient positive, indicating that the more severe the drought is perceived, the more farmers resort to saving strategies (see Table 3.7). 
Table 3.6. Relationship between risk experience and coping strategies

\begin{tabular}{lllllllllll}
\hline \multirow{2}{*}{ Risk Management } & Coefficients $(\boldsymbol{\beta})$ & & & & & & & & \\
\cline { 2 - 11 } & $\beta 0$ & $\beta 1(\mathrm{D})$ & $\beta 2(\mathrm{~F})$ & $\beta 3(\mathrm{H})$ & $\beta 4(\mathrm{EE})$ & $\beta 5(\mathrm{PDC})$ & $\beta 6(\mathrm{PDP})$ & $\beta 7(\mathrm{IP})$ & $\beta 8(\mathrm{OP})$ & R2-Adj \\
\hline Farm Investment & 2.63 & 0.11 & 0.01 & 0.02 & $-0.22^{*}$ & -0.03 & $0.35^{*}$ & -0.12 & 0.08 & 0.03 \\
Assistance & 3.12 & 0.07 & -0.13 & -0.18 & -0.03 & 0.1 & 0.01 & -0.23 & 0.18 & 0.02 \\
Asset depletion & 3.30 & -0.24 & 0.11 & -0.06 & -0.19 & 0.13 & -0.12 & -0.05 & 0.15 & 0.02 \\
Saving & $1.82^{*}$ & -0.18 & 0.02 & 0.11 & -0.08 & 0.1 & 0.18 & 0.03 & 0.15 & 0.05 \\
$\begin{array}{l}\text { Consumption } \\
\text { adjustment }\end{array}$ & $2.49^{*}$ & 0.2 & -0.12 & 0.17 & 0.04 & -0.05 & $0.33^{*}$ & -0.24 & $0.16^{*}$ & 0.17 \\
Nothing & 2.00 & $-0.36^{*}$ & 0.01 & -0.09 & 0.05 & 0.17 & 0.24 & $-0.32^{*}$ & 0.18 & 0.19 \\
\hline
\end{tabular}

*denotes significance at 5\%; Abbreviations: $D=d$ drought; $F=$ flooding; $H=$ hail; $E E=$ Early exit rain; $P D C=$ pests and diseases that affect crop; $P D P=$ pests and diseases that affect stored products; IP= price fluctuation of inputs; $O P=$ price fluctuation of outputs; 60 is the intercept.

Table 3.7. Relationship between risk perception and coping strategies

\begin{tabular}{lllllllllll}
\hline & \multicolumn{1}{l}{ Coefficients ( $\beta$ ) } \\
\cline { 2 - 11 } Risk Management & $\beta 0$ & $\beta 1(\mathrm{D})$ & $\beta 2(\mathrm{~F})$ & $\beta 3(\mathrm{H})$ & $\beta 4(\mathrm{EE})$ & $\beta 5(\mathrm{PDC})$ & $\beta 6(\mathrm{PDP})$ & $\beta 7(\mathrm{IP})$ & $\beta 8(\mathrm{OP})$ & R2-Adj \\
\hline Farm Investment & $8.4^{*}$ & -0.89 & 0.69 & 0.25 & 0.09 & -0.37 & -0.43 & -1.8 & 0.75 & 0.5 \\
Assistance & -3.71 & 0.91 & 1.43 & 0.86 & 0.1 & -0.47 & 0.92 & -1.25 & -0.8 & 0.07 \\
Asset depletion & 9 & n.a & n.a & 0 & 1.29 & -0.14 & -0.22 & -1.22 & -0.94 & n.a \\
Saving & -2.07 & $0.96^{*}$ & 0.56 & -0.46 & -0.46 & 0.77 & -0.28 & 0.54 & -0.43 & 0.08 \\
$\begin{array}{l}\text { Consumption } \\
\text { adjustment }\end{array}$ & 11.11 & 0.86 & 0.93 & 0.49 & -0.43 & -0.75 & 0.75 & -0.3 & -1.24 & 0.07 \\
Nothing & $5.9^{*}$ & 1.53 & -0.59 & 0.12 & 0.05 & -0.9 & 0.04 & 0.67 & -1.86 & 0.19 \\
\hline
\end{tabular}

"denotes significance at 5\%; n.a means that any farmer in the study who perceives drought and flooding has resorted to asset depletion as coping strategy. Abbreviations: $D=$ drought; $F=$ flooding; $H=$ hail; $E E=$ Early exit rain; $P D C=$ pests and diseases that affect crop; $P D P=$ pests and diseases that affect stored products; IP= price fluctuation of inputs; $O P=$ price fluctuation of outputs; $\beta 0$ is the intercept.

Farmers are afraid of the impact of drought in the case it happens again. However, taking a certain coping strategy depends on the nature of the risk but also on other factors like the availability or accessibility of the strategy. For instance, when faced with early exit rain or drought, farmers could resort to irrigation mechanism, but the lack of dams in the study area prevent farmers to take such actions.

\subsection{Discussion}

This paper captured eight risks associated with farming, of which flooding and drought were found to be the most experienced risks by Burundian farmers. These results partly confirm earlier findings in Burundi in a food security study, which point to the fact that deficit water, plant diseases, and heavy rains were the main risks that affect agriculture (Paridaens et al., 2012).

The results in this study from the risk perception analysis showed that the main perceived risk factors were drought, hail, and input price fluctuations. These results are similar to those from a study from Ivory Coast where a majority of farmers stated drought, pests/disease, and price fluctuation as important risk sources and most severe (Kouamé, 2012). The analysis of correlation between past experience and risk perception indicated that experiencing a given risk did not lead automatically to perceive the risk as more severe. Findings from another study from Poland came to a similar conclusion concerning the existence of interdependence of some risks related to agricultural (Sulewski \& Kloczko-Gajewska, 2014). The results of this study on how risks influence farmers' decisions to invest in farming are quite interesting, since some risks increased the farmers' willingness to invest. When farmers from the study area were asked why they keep investing despite the risk, they responded that investing in agriculture is like a lottery: either the weather is favourable and you win (good harvest) or adverse and you lose (deprived or no harvest at all). In all cases, farmers rather rely on expected profits in good conditions (return on investment) than on taking into account occasional losses. Evidences from India through a study on why farmers sometimes even seem to like taking risks, came partly to similar findings, showing the existence of a relationship between risk-loving behavior and wealth and assets (Maertens et al., 2014). Hence, farmers who are afraid of taking risks try to limit possible losses even if it means reducing the likelihood of gains (i.e. risk averse). Farmers are willing to accept higher risks to obtain a higher income (Kahan, 2013), but in general they balance expected profits and risks depending on their risk attitude (level of risk aversion). Similar situations were found in this study where some farmers preferred to reduce investments for risks beyond their control or do not like to make any changes in order to minimize eventual losses associated to risk. Farmers are feeling comfortable with their usual gains and losses rather than investing in new actions that could lead to additional benefits.

The results of the path analysis point out some relationships between past experiences, risk perception and coping strategies. When facing drought, farmers resort mainly to adaptations to their crops (farm investment), reduction of expenditures for non-food production and reduction of consumption of more expensive products (consumption adjustment) These results partly confirm those from a study conducted in Tanzania which showed 
that reducing consumption is the most important reported strategy when facing drought (Traerup \& Mertz, 2011). The link between these three variables above mentioned cannot be generalized based on the results of this study. The fact that farmers resort to mechanisms like reducing consumption, reducing food intake as well as non-food expenditures indicate the lack of alternative strategies to cope with risks. The use of some inappropriate strategies might be due to the misinterpretation of the level (and in somehow the real cause) of risk perception. An early study on risk perception and personal behavior stated that the poor risk perception, or the misinterpretation of actual levels of risk, will consequently lead to inappropriate behavior by individuals (Arezes \& Miguel, 2008)

It has been noticed that most of the used strategies are survival mechanisms with short impact and mostly applied ex-post. This is in the same line with results from Malaw where it was found that different strategies adopted by farmers to cope with the impact of the interaction of different stressors were largely dominated by ex-post reactive coping strategies (Coulibaly et al., 2015). Unfortunately, many of ex-post strategies undertaken were counter-productive since some of them consisted in selling assets thereby hampering future income and investments. Also previous studies indicated that when farmers are unable to deal with risks associated to farming ex-ante, they resort to measures like stocking crops, and selling assets and jewellery among others (Kouamé, 2012). Hence, especially in developing countries, farmers frequently resort to strategies with short-term effects (survival mechanisms) when confronted with unexpected events (Coulibaly et al., 2015).

Farmers in the study areas resorted to adjust their consumption mainly in case of deprived output prices. Prior research conducted in Burundi in 2013 stated that when faced to input price fluctuations, drought or flooding, households resort to selling assets, depleting savings, and adjusting their consumption including reducing the number of meals per day (Mupfasoni et al., 2013). Furthermore, smallholders, due to their small operations and limited financial capabilities, find it difficult to adopt sophisticated coping strategies to overcome yield and income instabilities at farm level (Ullah et al., 2017). In the same way, irrigation is not feasible without government or other stakeholders participation due to the high cost of dam construction. Some local and rather new strategies found in this study (such as the use of ashes) show the farmers' creativity in terms of coping strategies. Such innovations should be enhanced and scaled-up if proven to be effective because of being less expensive or sometimes even not costing anything, and because they correspond to the local context of farmers.

\subsection{Conclusion and policy implications}

This paper examined the risk experience, perception and the coping strategies in Gitega and Muyinga provinces in Burundi. The study area is exposed to different and uncontrollable risk factors such as drought, flooding, hail, pests and diseases, and price fluctuations. Experienced risks differ between locations, for instance, pests and diseases that affect crops are most experienced and most severe in Gitega but less in Muyinga. Furthermore, the risks associated to farming have increased over the past decades according to the farmers.

Different risks affect farmers' behavior differently. Some risks motivate farmers to invest in agriculture while others reduce their willingness to invest. Risks for which farmers are not able to take prevention measures (ex-ante measures) such as drought, flooding and hail demotivate farmers to invest in agriculture. Thus, the motivation or demotivation to invest in agriculture depend on the nature of the risk, personal financial ability to respond and other external factors like farmers awareness concerning coping strategy mechanisms.

Furthermore, farmers are aware about the most frequent risks in the study area, but the way farmers respond is frequently inadequate because the most used coping strategies have limited effects.

It is therefore essential for the government to encourage the access to services that will make available information on climate variability, and to train farmers on better risk management strategies which are crucial to adapt to long term climate variability. For risks to which farmers are not able to respond effectively, the Burundi government should stimulate social protection mechanisms like an agri-insurance, as it has done some years ago when dealing with input price fluctuations by subsiding fertilizers. 



\subsection{Introduction}

Smallholders must make complex financial decisions, and often exploit only a limited range of financial instruments available to them, to address their varying needs. The available formal financial instruments, such as banking facilities or micro-finance, are often expensive and risky, or lack necessary flexibilities (Karlan et al., 2017). When formal financial institutions are not available, smallholders use more informal and flexible mechanisms instead.

A household survey and focus group discussions were conducted to quantify the genera determinants of an index-based crop insurance adoption under limited liabilities in Burundi, and specifically the effect of existing Village Savings and Loan Associations (VSLAs). The survey sample comprised of 40 crop insurance adopters, 40 non-adopters and 40 drop-outs in Bukirasazi and Makebuko communes of Gitega province.

The results indicated that saving money (by VSLAs) for upcoming premium payments and regularly VSLA meetings attendance increase insurance adoption with relative risk ratio $(R R R)=0.21, p \leq 0.001)$ and $(R R R=0.01, p \leq 0.01)$, respectively. In addition, VSLAs' members with more knowledge in land management (RRR=0.07, $p \leq 0.05)$, crop management (RRR=0.05, $p \leq 0.001)$ and integrated farm planning $(R R R=0.03, p<0.05)$ were more likely to adopt the crop insurance. Furthermore, smallholders being aware and less appreciative limited liability were more likely inclined to adopt crop insurance with $R R R=0.12(p \leq 0.01)$ and $R R R=0.01$ ( $p \leq 0.001)$, respectively.

Given the importance of VSLA in fostering crop insurance adoption, we recommend strengthening VSLAs in their operation, save for upcoming premium payments as jointly agreed and set in their constitution, and encourage smallholders to run their farms with integrated farm planning. Due to limited knowledge of smallholders about the mode of crop insurance operation, a more extensive capacity building coupled to a coaching by experts in this domain is more than a necessity.

\section{Published as:}

Ndagijimana, M., Asseldonk van, M., Kessler, A., Ndimubandi, J. (2020). Effect of Village Savings and Loan Associations on adoption of index-based crop insurance under limited liabilities. J. Agr. Rural Develop. Trop. Subtrop. 121 - 1 (2020) 23-33. https://doi.org/ 10.17170/kobra-202002281031.
The widespread use of informal financial networks, mostly savings-led village groups (of which the rotating savings and credit associations (ROSCAs) is a typical example), is a testament to this (Conning \& Udry, 2005, Karlan et al., 2017). A Village Savings and Loan Association (VSLA) is a group of people who save together, take loans (credits) from the deposited savings, and share generated interests by loans according the rules and regulations made by and for the members of the group. The main objective of VSLAs is to assess the savings made, analyse the loans to give to applicants and exchange information related to the organisation.

A VSLA may have an additional social or solidarity fund, which is a fund managed by the group that can be accessed by members in the form of an interest-free loan or cash grant in case of an emergency (Karlan et al., 2017).

Emergency can manifest itself following high crop yield losses or reduced quality or a combination of these (Roth \& McCord, 2008). A multi-peril crop insurance can play an important role in hedging against these implications of adverse weather and climate change (Mahul \& Stutley, 2010). However, stand-alone crop insurance may attract little demand and may not be seen as a scalable value proposition (Falco et al., 2014). Index-based microinsurance products offer a more financially sustainable mechanism by tackling adverse selection and moral hazard, and reducing the risk faced by agricultural households. While there are some examples of success, by and large smallholders have been reluctant to hedge substantial amounts of risk with this instrument (Cole et al., 2012). However, there is increased interest in risk management and bundling crop insurance to promote agricultural investments and access to credit, and to provide financial stability to smallholders and other actors in the agri-value chain (Dick \& Wang, 2010).

In the rural area smallholders are often disconnected to potential insurance companies. Although demand for micro-insurance solutions for smallholders in developing countries is (relatively) substantial, the supply side faces several constraints and challenges which prevent the private sector from becoming involved in these solutions on a large scale (Levin \& Reinhard, 2007). Therefore, many input suppliers (such as those selling seeds and 
fertilisers) could sell on credit, but they have limited capacity to handle the covariate risk associated with agriculture (Hazell et al., 2010). Most of the banks are also reluctant to finance agricultural activities, only some micro-finance institutions are beginning to become involved in granting credits to farmers organised in cooperatives (i.e., aggregated demand). However, if smallholders are not safeguarded against the unforeseen weather hazards, they prefer to invest less in agriculture, instead of running the risk to lose it all. In general, risk and uncertainty impede innovations and induces risk-averse and low-return investments (Zimmerman \& Carter, 2003).

Index insurance is often promoted as a solution to many barriers that are thought to limit the supply of formal insurance coverage to smallholder farmers and livestock owners in developing countries (Jensen \& Barret, 2016). However, in the presence of basis risk, a risk averse and/or ambiguity averse individual can still have no or limited appetite in indexbased insurance (Belissa et al., 2019).

In 2017, an index-based insurance program was implemented in Burundi. This indexbased insurance was preferred by smallholders and insurers since it deals with asymmetric information (manifesting itself in adverse selection and moral hazard) and pay-outs are based on an index whose degree of occurrence and magnitude cannot be influenced by insurers (in addition to the advantages of low transaction costs). Advocates of index insurance argue that it can overcome unfeasible loss assessment by conventional means, particularly where there are many small-scale farmers or where insurance markets are underdeveloped (World Bank, 2015; Fisher et al., 2019).

Smallholders opted for a mutual approach (owned by themselves) with limited liability meaning that in the case of excessive systemic climate shocks, which influence the majority of the insured at the same time, the compensation should be less than the agreed conventional pay-out. Limited liability was socially considered to be valuable by the members of the VSLA because it reduced the need for excessive levels of retention and reinsurance, and associated transaction costs, compared to unlimited liability (Harrington \& Niehaus, 1999).

The main objective of this study was to explore the determinants of index-based crop insurance adoption under limited liability with particular attention to the effects of VLSAs on adoption, as the crop insurance was implemented through these social and financia structures. Three groups of respondents were considered for this study namely adopters, non-adopters and drop-outs.

In terms of achievements, the insurance continues to operate although the underwriting rate is not as high as at the beginning of the program. An insurance management committee has been set up and two farmers per rainfall station (i.e. 12 farmers for the six stations) have been trained and therefore have the capacity to collect daily rainfall data that serve as a reference for the indemnification in case of excessive or deficit rainfall

\subsection{Crop insurance in Burund}

The crop insurance in Burundi is organised via a mutual structure named Micro-insurance and Finance Cooperative (MAFICO). MAFICO is an independent mutual which promotes agricultural insurance, health insurance, micro saving and credit schemes. It is owned and managed by local smallholders, also represented in the executive board (Ndagijimana et al., 2017). Burundi smallholders preferred to set up a mutual agri-insurance company themselves based on mutual solidarity and limited liability principles, hence without involvement of an external (re-)insurance company. As this insurance is developed under a mutual approach, the insured are responsible of any change regarding the terms and conditions. MAFICO is technically supported by a private Income Security Expertise Company (ISECOM) which delivers technical assistance in terms of management, program development, awareness raising, and all aspects related to the monitoring and evaluation. ISECOM's support is essential since farmers have limited competencies to manage a complex program like a crop insurance. All aspects related to the crop insurance are managed by a crop insurance committee which reports to MAFICO's executive committee. The committee works in close collaboration with the manager of MAFICO who is the person in charge of all MAFICO's daily activities.

A crop insurance pilot study was conducted in 2017 in cropping season B (Februrary - May) with 257 participants from selected VSLAs in four communes (Bukirasazi, Makebuko, Butihinda and Giteranyi) in two provinces in Burundi, namely Gitega and Muyinga. Piloted VSLAs were participatory selected based on a certain number of criteria such as a high adoption level of integrated farm planning (PIP) and a subscription to the health insurance scheme. The latter was only required for famers from Gitega province. After the analysis of these criteria, $17 \%$ of VLSAs were selected among 200 existing VSLAs in the two provinces, that is 13 VSLAs from Gitega and 21 from Muyinga. In their mode of operation, VSLA members agreed that $50 \%$ of their savings and generated interest would be used for a credit fund (investment), 30\% progressively put aside to pay the insurance premium and the remaining $20 \%$ would be shared among the members to be used for family needs. However, some VSLA members preferred not separating the savings as set in their constitution meaning that this $30 \%$ for premiums was not saved by all VSLAs. 
The index-based crop insurance product covered both drought and excessive rainfall, as they were selected by smallholders as the major weather stresses that hamper agricultura production. It was decided by smallholders' representatives to measure rainfall using groundbased stations. Six rain gauges were installed and twelve smallholders, i.e. two smallholders per rain gauge site, appointed to collect rainfall data each day at 8.00 AM for the covered seasons. The selection criteria for collectors was to be literate (able to read and write) and have at least primary education. Another criterion was the attitude of the collector such as being intrinsically motivated, participating in different meetings organised by MAFICO, and being responsible with exemplarity in the village. Before rainfall data collection, the 12 collectors were trained on how these data should be collected. The training was offered by the Institut Géographique du Burundi (IGEBU). The reason to appoint two smallholders per rain gauge was to share the work load and as a back-up in case one of them was hindered (e.g. due to illness, travel, and other social commitments) at the time of data collection. The two collectors agreed on the collection timeline and if one was not available, he should inform his colleague to do the recording in his place to avoid missing data. Every month, the collected data were submitted to IGEBU for verification and validation. During the verification process, data were compared to those from IGEBU reference stations to check coherence. The differences noticed were automatically corrected. After the verification, IGEBU validated the rainfall data and allowed their use as reference to determine the pay-outs.

The implemented crop insurance program in Burundi operated under limited liabilitie meaning that in case of extreme systemic climate shocks, which affect the majority of insured at the same time, the insurer will set a limit on pay-outs (Ndagijimana et al., 2017). Given this limited liability, in case of extreme shocks are incurred at portfolio level (i.e., losses exceeding retention level of MAFICO), the insurer pays each affected smallholder only $80 \%$ of the premiums received (the rest is allocated for transaction cost). In years without (or limited) losses, the insured remain the owner of (part of) their contributions not used for pay-outs. A part of the remaining amount, determined by the crop insurance members general assembly, may be used building a reserve (i.e. retention) or premium discounts for those who continue the insurance cover in the subsequent year.

The premium and pay-out are calculated based on the recurrence interval of drought and excessive rainfall (i.e. the trigger value), the agreed percentage of pay-out (i.e. tick value) and the invested amount. As such the insurance coverage is input based and not yield based. Climate studies were carried out in each of the pilot zones to determine the recurrence interval of the two perils. Recurrence intervals were based on 30-year historical rainfall data analysed by the Information Processing Centre of the Department of Hydrometeorology in IGEBU. Based on the smallholders' preferences elicited at focus group meetings, the original design was refined in terms of coverage based on recurrence interval per peril per season.
In Burundi, smallholders grow crops in three seasons, namely season A (SeptemberJanuary), season B (February-May) and season C (June-September). The crop insurance only focused on the two first cropping seasons which are alternatively affected by the two perils (drought and excessive rainfall) covered by the insurance program. During season $C$, farmers grow crops in marshlands or swampy areas. In Muyinga province, the recurrence interval for drought and excessive rainfall, in Season B, was set at $20 \%$ and $23 \%$, respectively. In Gitega province, the probability of recording a drought was set at $13 \%$ and at $43 \%$ for excessive rainfall. Smallholders agreed that premiums were to be paid 5 days preceding the concerned season and pay-outs (if any) 30 days after the covered period.

Prior to launching the pilot program an awareness raising campaign was organised to explain how the crop insurance works, how to set up a board committee, and how to assign the rainfall data collectors. Initially, smallholders' participation in the first crop insurance campaign (season B 2017) was relatively high due to these awareness campaigns. Two years later the crop insurance program ceased in Muyinga province but continued in Gitega province, managed by the farmers themselves with support from MAFICO. In Muyinga province MAFICO is not yet implemented. Therefore, this study only includes smallholders from two communes of Gitega province, namely communes of Bukirasazi and Makebuko. Gitega province is geographically located in the central part of Burundi. During the insurance piloting stage, the total premium and pay-out for the four relevant seasons in Gitega were estimated at 740,190 $\mathrm{BIF}^{7}$ (404.93 US\$) and 504,400 BIF (275.94 US\$) respectively, resulting in a loss ratio of $69 \%$ (Table 4.1). On average, $10 \%$ of the premiums were reserved to account for incurred transaction costs. In addition, in $50 \%$ of the seasons, liability was limited meaning that the expected pay-outs were capped in accordance with the smallholders' agreement as set in the insurance policy.

However, even at the end of support, 162 farmers (75\%) continued the program for the next season which indicated the commitment to crop insurance program. Fortunately, after three seasons, impressive results are still noticed since the crop insurance program extended without support, and 96 smallholders (45\%) are still involved in the crop insurance which is a promising situation for insurance implementation in Burundi, particularly in Gitega province. Furthermore, a crop insurance board committee is operating, 12 smallholders acquired skills in rainfall data collection, smallholders are aware of the benefits of crop insurance, and local government officers appreciated this innovative approach of addressing climate related risks.

7 BIF: Burundian Francs, 1 US\$=1,827.929 BIF (https://www.brb.bi/, exchange rate on 18th of June 2019). 
Table 4.1.Key indicators of the crop insurance performance in the study area (Gitega)

\begin{tabular}{|c|c|c|c|c|c|c|c|c|}
\hline Season & $\begin{array}{l}\text { Number } \\
\text { insured }\end{array}$ & $\begin{array}{l}\text { Total } \\
\text { Amount } \\
\text { insured } \\
\text { (BIF) }\end{array}$ & $\begin{array}{l}\text { Average } \\
\text { amount } \\
\text { insured } \\
\text { per farm } \\
\text { (BIF) }\end{array}$ & $\begin{array}{l}\text { Total } \\
\text { premium } \\
\text { (BIF) }\end{array}$ & $\begin{array}{l}\text { Average } \\
\text { premium } \\
\text { per farm } \\
\text { (BIF) }\end{array}$ & $\begin{array}{l}\text { Total } \\
\text { pay-outs } \\
\text { (BIF) }\end{array}$ & $\begin{array}{l}\text { Pay-outs } \\
\text { limited } \\
\text { due to } \\
\text { limited } \\
\text { liability } \\
\text { (Yes, No) }\end{array}$ & $\begin{array}{l}\text { Loss } \\
\text { ratio }^{8} \\
\text { (\%) }\end{array}$ \\
\hline \multicolumn{9}{|l|}{$\begin{array}{l}\text { During the pilot } \\
\text { study }\end{array}$} \\
\hline Season B 2017 & 215 & $2,535,940$ & 11,795 & 959,500 & 4,463 & $1,012,898$ & Yes & 106 \\
\hline \multicolumn{9}{|l|}{ Post-pilot study } \\
\hline Season A 2018 & 162 & $2,677,360$ & 16,527 & 856,966 & 5,290 & 267,736 & No & 31 \\
\hline Season B 2018 & 148 & 933,968 & 6,311 & 909,786 & 6,147 & 549,357 & No & 60 \\
\hline Season A 2019 & 96 & 250,140 & 2,606 & 234,515 & 2,443 & 187,612 & Yes & 80 \\
\hline $\begin{array}{l}\text { Average (Season B } \\
\text { 2017-Season A } \\
\text { 2019) }\end{array}$ & & $1,599,352$ & & 740,192 & & 504,401 & & 69 \\
\hline
\end{tabular}

\subsection{Methodology}

\subsubsection{Sampling frame and data collection}

The sampling consisted of 120 smallholders selected from 13 VSLAs from Bukirasazi and Makebuko communes (Gitega province). These 120 smallholders consisted of 40 current crop insurance adopters by the time of study (i.e., season A 2019), 40 non-adopters and 40 drop-outs. Information was collected through a household survey with a structured questionnaire, which was administered by enumerators who were fluent in Kirundi (the local language in Burundi). The questionnaire was divided into two main modules focusing on VSLA participation and on crop insurance adoption, respectively. For the module on VSLA, data collected were related on savings deposited and credits received, the appreciation of VSLA activities by its members (in terms of knowledge learned in land management and

8 The loss ratio is the ratio between the pay-outs and collected premium by season. In this study, the loss ratio for the season B 2017 exceeding 100 percent means that farmers from Gitega were paid-out from premium collected in Muyinga and Gitega (joint participation) because the trigger 'excessive rainfall' occurred in Gitega exceeded the normal precipitation. For the season B 2017, the loss ratio in Gitega was 106\% (41\% in Muyinga), and the los ratio for the two pilot areas amounted to $91 \%$. In addition, in the first crop insurance campaign high transaction costs were incurred including additional expenses, among others, the opening of a bank account dedicated to crop insurance and frequent awareness training. crop management), the use of the integrated farm plan (PIP) in the farming system, the role of VSLAs within the insurance adoption (savings for the insurance premium) among others. For the module related to crop insurance adoption, questions captured constraints preventing crop insurance adoption and scaling-up, benefits of insurance and knowledge of crop insurance management (from premium payment up to claim handling). For closed questions in the survey, different Likert-scales were used to quantify data and categorize answers (nominal, ordinal and interval) (Schroeder et al., 2013).

In addition to the household survey, focus group discussions (FGDs) were used to gathe information related to how the VLSA could be re-organised to increase the level of crop insurance adoption and scaling-up. Particularly, the index design and the limited liability of the mutual approach were discussed in-depth during the FGDs. In total, three FGDs (of 10 participants each) were conducted, i.e. one per group (adopters, non-adopters and dropouts).

\subsubsection{Empirical framework and data analysis}

One-way analysis of variance (ANOVA) was used to compare means for the three different categories of survey respondents (i.e. adopters, non-adopters, and drop-outs). In addition, crop insurance adoption was fitted using a multinomial logistic regression model with variables associated to VSLAs, index design and limited liabilities, and those specific to the respondent as predictors.

We tested the hypothesis that smallholders' commitment to VSLAs is positively associated with the crop insurance adoption (H1), in terms of saving collectively for premium payments, meeting attendance frequency, farming with the integrated farm planning approach (PIP), and the change in knowledge due to received trainings. It is important to note that the PIP approach was rolled-out through each of the villages involved in this study, with a high level of participation also among the VSLA members. Having been trained via the PIP approach implies that families have made a visionary integrated farm plan (the PIP) which is developed for the whole farm by the farmer family and drawn on a map, and which aims at transforming small-scale subsistence farms into more productive and sustainable farms, based on sound natural resource management (land, water and the crops/vegetation) Changing smallholders' mind-sets and making them aware that they can transform thei reality by conscious collective action is at the core of the PIP approach (Kessler et al., 2016) while real impact at farm level and beyond remains scattered. As a consequence, many Sub-Saharan African countries continue experiencing soil nutrient mining and insecure and insufficient agricultural production. Since technology-driven projects at the plot level failed to bring ISFM to scale, a different approach is needed. This paper describes a bottom-up 
approach developed in Burundi, the "PIP approach". It starts at farmer family level with the creation of an integrated farm plan (Plan Inte'gre' de Paysan in French-PIP.

Moreover, we tested the hypothesis that the index design and limited liability approach hamper crop insurance adoption ( $\mathrm{H} 2$ ), both in terms of awareness and appreciation.

We estimated determinants of crop insurance adoption by referring to Heyi-Damena $\&$ Mberengwa (2012). Therefore, the distribution function for the probability of adoption $\left(\rho_{i}\right)$ is given by:

$\rho_{i}=1 / 1+e^{-A_{i}}$

where $\rho_{\mathrm{i}}$ is the probability of adopting crop insurance for $i^{\text {th }}$ smallholder $\left(1-\rho_{\mathrm{i}}\right)$, otherwise and $A i$ is a function of $n$ exogenous variables and for this study is expressed by:

$A_{i}=\alpha+\mu_{i} X_{i}+\varphi_{i} \Delta_{i}+\gamma_{i} K_{i}+\varepsilon_{i}$

where $A_{\mathrm{i}}$ is the dependent variable which is a categorical variable with a value of:

- 1 - if the smallholder reported to use the crop insurance, hereafter 'adopter',

- $\quad 2$ - if the smallholder reported to have never used the crop insurance, hereafter 'nonadopter',

- $\quad 3$ - if the smallholder reported to have used the crop insurance but gave up using it after a given period, hereafter 'drop-out'.

$X_{i}$ is the vector of covariates affecting crop insurance use/adoption including variables linked to VSLA such are:

- $\quad$ Saving collectively for premium payments ( $1=$ smallholders allows VSLA to put aside money for insurance, 0 otherwise),

- Meeting attendance ( $1=$ not one, $2=$ attended $25 \%$ of planned meetings by respective VSLA, $3=50 \%, 4=75 \%, 5=100 \%$ of planned meetings)

- Change in knowledge due to the trainings received through VSLAs which was expressed by three variables namely:

- knowledge in land management $(1=$ much decreased, $2=$ less decreased, $3=$ no change, 4 = increased, 5 = much increased),
- knowledge in making a business plan $(1=$ much decreased, $2=$ less decreased $3=$ no change, $4=$ increased, $5=$ much increased),

- knowledge in crop management $(1=$ much decreased, $2=$ less decreased, $3=$ no change, 4 = increased, $5=$ much increased).

- Having created a PIP for the farm ( 1 = household created a PIP for the farm, 0 otherwise).

$\Delta_{i}$ is the vector associated to index design and limited liabilities (LL).

The index design was determined by:

- the smallholders' awareness of pay-out-based index ( $1=$ smallholder is aware that the pay-out is index -based rather than incurred losses, 0 otherwise),

- smallholder's appreciation of the pay-out-based index, by asking them if the pay-out based on index rather than incurred losses is a problem ( $1=$ like, $0=$ dislike).

The limited liability (LL) was elicited by:

- the smallholder's awareness of $\mathrm{LL}(1=$ smallholder is aware that the insurance is an index based limited liability, 0 otherwise) and

- smallholder's appreciation of LL ( $1=$ not at all appreciated, $2=$ not appreciated $3=$ indifferent, $4=$ appreciated, $5=$ much appreciated)

Finally, $K_{i}$ is a vector associated to variables related to the respondents

- The sex of the respondent ( $1=$ male, $2=$ female) and

- Education of the respondent ( $0=i$ illiterate, $1=$ primary, $2=$ secondary, $3=$ university)

$\mu_{i}, \Psi_{i}$ and $\gamma_{i}$ are respectively the corresponding vectors of parameters (slopes) and $\varepsilon_{i}$ is the error term.

We interpreted data from multinomial logistic regression by using the relative risk ratio (RRR) which is obtained by exponentiation of the multinomial logit coefficient ( $\left.e^{\text {coeff }}\right)$. 


\subsection{Results}

4.4.1 Relationship between variables linked to VSLA members and crop insurance adoption

The community-based financial structures referred to as VSLAs were the entry point of the implemented crop insurance scheme in the study area. A one-way ANOVA group was performed to compare the differences in key VSLAs membership variables between crop insurance adopters, non-adopters and drop-outs.

Results indicated that the mean difference (MD) in saving collectively for premium payments was statistically different between the adopters and non-adopters ( $M D=0.675, p \leq 0.01$ ) and between the adopters and drop-outs $(M D=0.225, p \leq 0.05)$. This means that for farmers who consent with their VSLAs to collectively save for premium payments were more likely to adopt the crop insurance. In addition, results also indicated that regular attendance to VSLAs' planned meetings was found statistically different between the adopters and nonadopters $(M D=0.550, p \leq 0.01)$, meaning that farmers who regularly attended planned VSLA meetings were more likely to adopt the crop insurance (compared to those participating more irregularly), even if they discontinued the crop insurance program after one or more seasons. For instance, $65 \%$ of the adopters participated in all planned VSLA meetings against $32.5 \%$ drop-outs.

Next, a significant difference was found in knowledge of land management between the adopters and non-adopters ( $M D=0.500, p \leq 0.01)$, meaning that the knowledge level of land management might influence crop insurance adoption. For the same variable knowledge of land management also the non-adopters and drop-outs differed significantly (MD=-0.650, $\mathrm{p} \leq 0.01)$, but also for knowledge in crop management ( $M D=-0.350, p \leq 0.05)$. Hence, even if farmers drop-out from the crop insurance, the trainings received through VSLAs play a big role in initial crop insurance adoption, with their focus on integrated and effective solutions to cope with low production including risks associated to farming. For the variable having a working PIP, the adopters were found to be significantly different from the non-adopters ( $M D=0.500, p \leq 0.01$ ) and from the drop-outs ( $M D=0.350, p \leq 0.01)$. The PIP approach, with its focus on transforming small-scale subsistence farm households into more productive and sustainable farms, thus triggers farmers to adopt the crop insurance.

The results also revealed that the adopters were significantly different from the nonadopters $(M D=0.225, p \leq 0.01)$ and the non-adopters from drop-outs $(M D=-0.175, p \leq 0.01)$ for the variable awareness of pay-out-based index. According to the drop-outs, they left the insurance program because of the pay-outs received being considered too low compared to the engaged investments. Similarly, awareness of limited liability was found significantly different between the adopters and drop-outs $(M D=0.300, p \leq 0.01)$ and between non adopters and drop-outs ( $M D=0.325, p \leq 0.01)$.For the variable limited liability appreciation, the adopters were found significantly different from the non-adopters $(M D=1.850, p \leq 0.01)$ and from the drop-outs $(\mathrm{MD}=0.625, \mathrm{p} \leq 0.05)$, meaning that appreciation of limited liability stimulated crop insurance adoption.

For the education of the respondent, the adopters were found significantly different from the non-adopters $(M D=0.550, p \leq 0.01)$ and from the drop-outs $(M D=0.350, p \leq 0.05)$ meaning that educated persons were more likely to adopt crop insurance. In general, most important differences in means were found between adopters and non-adopters, and between adopters and drop-outs. The group of non-adopters did not differ a lot from the group of drop-outs for most of the analysed variables.

The results from focus group discussion suggested that the main crop insurance limitations that hamper the adoption and scaling up are a lack of sufficient information on crop insurance in the community, lack of coaching by experts in the field, and lack of interest of crop insurance by some smallholders. In addition, the location of rain gauges does not favour all smallholders in the same way because drought or excessive rainfall can hit one colline (smallest administrative unit in Burundi) in the community and this is not accounted for at the time of pay-out analysis because only average of the whole season is considered.

Furthermore, the pay-out is always small compared to the incurred losses (used fertilisers, seeds, time and ultimately yield) and thus smallholders still have difficulties to manage climate-related disasters. In addition, participants in the group discussion suggested that there should be a national climate insurance fund where farmers and the government can contribute (i.e., blending insurance with public disaster relief).

In terms of improving crop insurance adoption, respondents in the group discussions suggested that other actors such as non-governmental organisations involved in agricultura development, as well as ministries in charge of agriculture and in social protection should be involved in crop insurance management to improve its adoption and get tangible results.

\subsubsection{Determinants of crop insurance adoption in the study area}

Multinomial logistic regression was fitted to identify the factors that influence crop insurance adoption by comparing non-adopter and drop-out groups with the reference group of adopters (Table 4.2). The goodness of fit test was analysed by using, among others, the 
Chi-square coefficient $\left(x^{2}\right)$. According to the results, $\chi^{2}=82.32, p \leq 0.001$ and $R^{2}{ }_{\text {adj }}$ to $68.68 \%$ suggesting that the observed data were consistent to the expected one.

The independent variables saving collectively for premium payments (1), VSLA meeting attendance (2), knowledge in land management (3), knowledge in crop management (5), having a working PIP (6), appreciation of limited liability (10), and education (12) were found statistically significant in distinguishing non-adopters from adopters $(p \leq 0.05)$ (Table 4.2). Furthermore, by comparing adopters and drop-outs, the independent variables saving collectively for premium payments (1), having a working PIP (6), and awareness of limited liability (9) were found statistically significant in distinguishing drop-outs from adopters $(p \leq 0.05)$. Multicollinearity was checked by using the variance inflation factor (VIF) and correlation between aforementioned independent variables did not cause problems with the fit and the interpretation of the results.

The relative risk ratio (RRR) for non-adopters relative to adopters is expected to decrease by a factor of $0.21(p \leq 0.01)$ given other variables in the model are held constant for the variable saving collectively for premium payments. For the same variable, the RRR for dropouts relative to adopters would be expected to decrease by a factor of 0.08 ( $p \leq 0.01)$. In addition, for the variable meeting attendance, for one additional VSLAs' meeting attended, the RRR for non-adopters relative to adopters would be expected to decrease by a factor 0.01 ( $p \leq 0.01$ ). In other words, smallholders who attended planned VSLA meetings are more likely to adopt the crop insurance.

Next, smallholders who stated that their knowledge in land management improved due to the VSLAs' trainings were more likely to adopt the crop insurance ( $R R R=0.07, p \leq 0.05)$ and are more likely to be in the group of adopters rather than in the group of non-adopters. Furthermore, the RRR for non-adopters relative to adopters would be expected to decrease by a factor of 0.05 ( $p \leq 0.01$ ) for the variable knowledge in crop management holding constant other variables in the model. Smallholders who had a working PIP (running the farm with PIP approach) were more likely to keep adopting crop insurance rather than to never adopt it $(R R R=0.03)$. For the same variable, smallholders with a PIP were more likely to be in the group of adopters rather than in the group of drop-out. In other words, the RRR for dropouts relative to adopters would be expected to decrease by a factor of $0.07(p \leq 0.01)$.

For the awareness of limited liability variable, the RRR for drop-outs relative to adopters would be expected to decrease by a factor of 0.12 , which means smallholders who are aware of limited liability were inclined to adopt crop insurance $(p \leq 0.01)$. In addition, smallholders who appreciate limited liability were more inclined to adopt the crop insurance $(p \leq 0.01)$
Table 4.2. Multinomial logistic regression analysis of factors influencing crop insurance adoption

\begin{tabular}{|c|c|c|c|c|}
\hline Variables related to & Variables* & RRR & Robust Std. Error & P-values \\
\hline \multirow{6}{*}{ VSLAs } & 1 & 0.21 & -4.2 & $<0.01$ \\
\hline & 2 & 0.01 & -2.71 & 0.01 \\
\hline & 3 & 0.07 & -1.96 & 0.05 \\
\hline & 4 & 8.67 & 1.02 & 0.31 \\
\hline & 5 & 0.05 & -2.92 & $<0.01$ \\
\hline & 6 & 0.03 & -2.37 & 0.02 \\
\hline \multirow{2}{*}{ Index design } & 7 & 0.32 & -0.93 & 0.35 \\
\hline & 8 & 116.81 & 1.51 & 0.13 \\
\hline \multirow{2}{*}{ Limited liability } & 9 & 15.99 & 1.19 & 0.23 \\
\hline & 10 & 0.01 & -3.6 & 0.00 \\
\hline \multirow{4}{*}{ Control } & 11 & 1.02 & 0.26 & 0.79 \\
\hline & 12 & 0.07 & -2.01 & 0.05 \\
\hline & 13 & 102340 & 4.37 & $<0.01$ \\
\hline & Drop-outs & & & \\
\hline \multirow{6}{*}{ VSLAs } & 1 & 0.08 & -2.56 & 0.01 \\
\hline & 2 & 0.21 & -1.68 & 0.09 \\
\hline & 3 & 4.88 & 1.7 & 0.09 \\
\hline & 4 & 0.62 & -0.74 & 0.46 \\
\hline & 5 & 1.08 & 0.14 & 0.89 \\
\hline & 6 & 0.07 & -3.74 & $<0.01$ \\
\hline \multirow{2}{*}{ Index design } & 7 & 0.97 & -0.02 & 0.98 \\
\hline & 8 & 0.61 & -0.48 & 0.63 \\
\hline \multirow{2}{*}{ Limited liability } & 9 & 0.12 & -2.78 & 0.01 \\
\hline & 10 & 0.83 & -0.55 & 0.58 \\
\hline \multirow{8}{*}{ Control } & 11 & 1.02 & 0.51 & 0.61 \\
\hline & 12 & 0.28 & -1.64 & 0.1 \\
\hline & 13 & 894.05 & 1.22 & 0.22 \\
\hline & Number of obs & 120 & & \\
\hline & Wald chi2(24) & 82.31 & & \\
\hline & Prob>chi2 & 0 & & \\
\hline & Pseudo R2 & 0.6868 & & \\
\hline & Log pseudo likelihood & -41.296443 & & \\
\hline
\end{tabular}

Reference category is Adopters; $N=120$ (adopters $=40$, non-adopters $=40$, drop-outs $=40$ ); $R R R$ : relative risk ratio * 1: Saving collectively for premium payments, 2: Meeting attendance, 3: Knowledge in land management, 4: Knowledge in business plan, 5: Knowledge in crop management, 6: Having a working PIP, 7: Awareness of pay-out based index, 8: Appreciation of pay-out based index, 9: Awareness of limited liability, 10: Appreciation of limited liability, 11: Sex of the respondent, 12: Education of the respondent, 13: constant 
Finally, for one additional education level attended, the RRR for non-adopters relative to adopters would be expected to decrease by a factor $0.07(p \leq 0.05)$. In other words, educated smallholders are more likely to adopt crop insurance.

Other variables like knowledge in business plan, index design and the sex of respondent were not significant to distinguish adopters from non-adopters and drop-outs.

\subsection{Discussion}

This study explored the determinants that influence the adoption of an index-based crop insurance under a limited liability mutual approach. Data analysis consisted in comparing adopters, non-adopters and drop-outs. It was hypothesized that smallholders' commitment to VSLAs in terms of saving collectively for premium payments, meeting attendance frequency, farming with the integrated farm planning approach, and the change in knowledge due to received trainings through VSLAs are positively associated with crop insurance adoption.

Findings indicated that members of VSLAs who save money collectively for premium payments and who attended VSLA meetings regularly were more likely to adopt the crop insurance. VSLAs as financial structures could thus have a prominent role in crop insurance adoption: once a VSLA is structured with a better saving system and well-organised, it could pave the way for crop insurance adoption. Moreover, aggregating demand via VSLA's will likely reduce transaction costs for reaching smallholders. An alternative approach is to (re) insure the aggregate level, e.g. covering a crop credit portfolio at VSLA level or portfolio of VSLA's (Herbold, 2011).

Next, smallholders who stated that their knowledge in both land and crop management had improved due to the VSLAs' trainings (organised during the PIP approach implementation) were more likely to adopt crop insurance. These results are similar with those from India where the probability of crop insurance adoption was found higher for farmers with some formal trainings in agriculture (Aditya et al., 2018). Trainings are considered as a crucial motivator in helping smallholders to improve their knowledge in terms of risk management including the use of crop insurance. These results are consistent with those of Dercon et al. (2013) who indicated that trainings addressing on-farm risk-sharing increased insurance uptake in Ethiopia.

In addition, VSLAs' smallholders who had a PIP and implemented it, were more likely to keep adopting crop insurance rather than to drop out or never adopt it. This relationship between having a vision and a plan and crop insurance adoption could be explained by the fact that smallholders with a working PIP invest in integrated land management including crop diversification and are likely aware of risks associated to farming; as a result, they are more receptive to risk management by adopting crop insurance. A risk-averse farmer would be more willing to buy agricultural weather index insurance (Jin et al., 2016). Through focus group discussions, respondents indicated that the implementation of the PIP approach improved the way of farming and enhanced investments in the farm (including the adoption of crop insurance).

Furthermore, smallholders who are aware of and less appreciate limited liability were more inclined to adopt crop insurance and thus limited liability hampers crop insurance adoption. According to the results from India, farmers' adoption of crop insurance is low mainly on account of lack of awareness about insurance products (Aditya et al., 2018). During the group discussions, farmers stated that they are proud of their mutual insurance because it is not only an innovation in their community but that they are also the first to have experimented this approach across the country. However, they regret that they do not have a good grasp of all the issues inherent to the functioning of the insurance, which limits its extension in the community. In addition, non-adopters and drop-outs stated that the limited liability associated to the index-based insurance is the main obstacle to crop insurance adoption since in most cases the insured receives less than losses incurred. Indeed, yield losses are never entirely correlated to what a weather index predicts (Turvey \& Kong, 2010; Xu et al., 2018), and it is thus possible with the index based insurance that an insured farmer is paid-out without having losses or otherwise that a farmer is affected by a shock and not paid-out (because the pay-out is only triggered if the shock has occurred and the agreed threshold reached). Although index insurance lowers transaction costs compared to indemnity insurance, it introduces basis risk, which is the difference between actual loss and the pay-out on an insurance contract (Fisher et al., 2019). Indexbased insurance in combination with limited liability compounds basis risk. Nevertheless, the index-based insurance as implemented in the study area is an innovative approach, since the insured farmers are at the same time insurers and can decide the insurance fund as they see fit (and making decisions on index design, retention level, reinsurance and limited liability).

Finally, the control variable education was found significantly associated to crop insurance adoption. In order words, educated smallholders are more likely to adopt the crop insurance. This result is similar to the results from Belissa et al. (2019) in a study on risk and ambiguity aversion behaviour in index-based insurance uptake in Ethiopia. Education enhances farmers' knowledge and skills related to risk associated to farming and might influence the understanding of the functioning of crop insurance. In addition, similar results were 
reported in a study on challenges, opportunities, and prospects for index-based insurance uptake in sub-Sahara Africa where literacy was found positively correlated with index-based insurance uptake (Ntukamazina et. al, 2017).

\subsection{Conclusion}

Using data from a household survey, this study analysed the extent to which VSLAs influence index-based crop insurance adoption under limited liability. By analysing the findings, four main lessons were learnt.

Firstly, saving collectively for premium payments is crucial for crop insurance adoption. This study shows that smallholders who consent with their VSLA to save for premium payments are more likely to adopt the crop insurance. To increase the crop insurance adoption, VSLAs should endorse to save money as set in their constitution and approved by the VSLA members. Saving enables smallholders to pay premiums in lean periods coinciding with large family investments, namely the payment of agricultural inputs and school fees.

Secondly, regular attendance in the planned VSLA meetings was found as a positive driver of crop insurance adoption. The results from this study indicate that the level of participation in these VSLA meetings demonstrates the commitment that participants have towards the activities developed and those planned within the VSLA, including for this case the crop insurance program.

Thirdly, smallholders who run their farm with a PIP (i.e. who have a vision and a plan and implement this plan) are more likely to invest in integrated land management and therefore are more receptive to the innovative tools that reduce risk exposure, in this case the crop insurance program. In addition, knowledge in land and crop management is also key driver in crop insurance adoption.

Fourthly, according to the findings, smallholders who are aware of and less appreciate limited liability were more inclined to adopt the crop insurance that means the limited liability hampers crop insurance adoption.

Even though a proportion of the smallholders from the study area continue adopting the crop insurance, managing this program is not a concern of smallholders alone, and the contribution from the Burundi government and other stakeholders by subsidizing premiums is more than a necessity. VSLA structures should remain the entrance point of crop insurance implementation, but given the low knowledge level of its members in terms of crop insurance operation, capacity building coupled to a coaching program by crop insurance experts would be a great intervention of the public sector. 


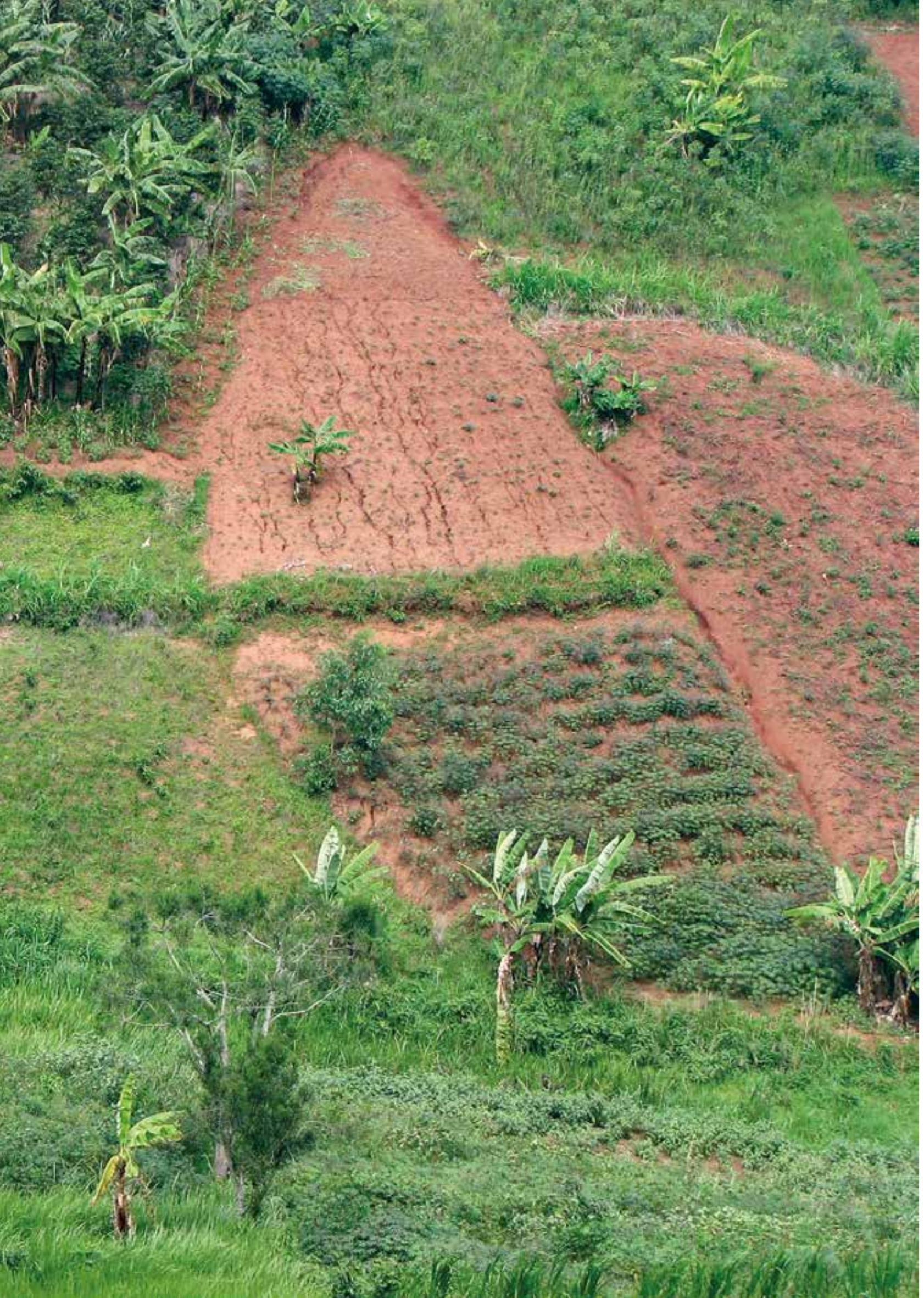

Chapter 5

Analysing the links between index-based crop insurance adoption and agricultural investments in Burundi 
This paper analyses the links between index-based crop insurance (IBI) adoption and agricultural investments based on a cross-sectional sample of 40 crop insurance adopters and 40 non-adopters from two communes located in Gitega province in Burundi. Analysed agricultural investments variables included use of fertilizers, applying crop diversification, and use of land and crop management practices in the most recent year and in the year before IBI implementation started. The results from multivariate analysis indicate that adopters use $36 \%$ more chemical fertilizers and invest 18\% more in chemical fertilizers than non-adopters $(p \leq 0.01)$. Adopters apply more land management practices also, in which they invest $15 \%$ more than non-adopters $(p \leq 0.01)$. Furthermore, adopters change crop management practices over time by $38 \%$ and their knowledge in crop management practices increased by $23 \%$ ( $p \leq 0.01)$. Differences between adopters and non-adopters are however not statistically significant for crop diversification strategies and for the use of organic fertilizers. Hence, in order to be more effective and beneficial to farmers, other actions are also needed to encourage farmers to invest in their farm. Particularly promising in Burundi in this respect is to empower and train farmers by means of the Integrated Farm Planning approach, as well as to enhance farm inputs availability and to promote smart agri-entrepreneurial programs. In order to enhance agricultural development, the Burundi government should have a more prominent role in fostering farmers' agricultural investments and in supporting IBI adoption.

\section{Based on:}

Ndagijimana, M., Kessler, A., Asseldonk van, M., Ndimubandi, J. (2020). Analysing the links between index-based insurance adoption and agricultural investments in Burundi. International Journal of Agricultural Management (Accepted).

\subsection{Introduction}

Weather-related shocks are a major threat to the livelihoods of vulnerable farmers in lowincome, arid and semi-arid regions of the world (Jensen et al., 2018). In response, crop insurance products have been piloted in, for example, Sub-Saharan Africa (SSA) to protect low income farmers against climate related risks (Churchill, 2008, Ntukamazina et al., 2017) However, implementing traditional indemnity-based crop insurance schemes in a viable way with substantial outreach is hampered by information asymmetry (causing moral hazard problems and adverse selection) as well as associated transaction costs to address those problems. Agricultural index-based insurances (IBIs) tackle this moral hazard and adverse selection, given that they are based on a verifiable and independent measurement of a variable that impacts crop development (Sinha \& Tripathi, 2016). Hence, the advantage of an IBI is that farmers are paid-out based on indices rather than appraised losses. IBIs are therefore considered a potential solution to the long-standing problem of low rates of crop insurance adoption, especially in risk-prone regions of SSA (Carter et al., 2015).

Nevertheless, the main challenge of the IBI lies in the method of compensation in the event of a climatic shock. This arises partly from the spatial discrepancy between the measured risks at a specific meteorological station and the occurrence of weather shocks at the location of the insured farm. For instance, it may rain more than the trigger level for drought insurance at the meteorological station but not at the insured location, with the result that a farmer is not compensated for drought losses. In this case, no payments are done (or payments are lower), even though the farmer has paid the insurance premium (Carter et al., 2014). More spatial targeted IBIs can be designed by using satellite-based information (to limit spatial basis risk), but some elements of basis risks still remains. The basic risk is the difference between actual loss and the pay-out on an insurance contract (Fisher et al., 2019).

Most farmers appear to be reluctant to opt for an IBI with inherent basic risks (Smith \& Goodwin, 2006). Yet the growth of IBIs, primarily weather-index insurances but also areayield index crop insurances, has been remarkable in the developing world over the past decade (Bobojonov, et al., 2013, Sinha \& Tripathi, 2016). An IBI is regarded as a major innovation that could revolutionize access to formal insurance for millions of farmers and related individuals in the near future (Carter et al., 2014). However, ambiguous evidence feed the debate on IBIs and to what extent they represent an opportunity for development, especially in a dynamic and changing environment (Sabatini, 2017).

An insurance program enables farmers to take more risk, which they would not have taken in the absence of it (Aditya et al., 2019), leading them to invest more in viable activitie and use more inputs (He, et al. 2016). Increased investments have been found in several 
empirical IBI studies. For example, Karlan et al. (2014) investigated the impact of an IBI on income enhancing agricultural investments in a randomized control trial in Ghana and found a strong response. Also in a field study in Kenya IBI uptake contributed to investments in chemical fertilizers and adoption of improved seeds, as well as to higher yields (Sibiko \& Qaim, 2017). Studies in the Philippines (He et al., 2016) and in the USA (Chang \& Mishra, 2012; Claassen et al., 2017) also revealed a positive effect of IBI adoption on the use of chemical fertilizers. In a review study comprising several field studies in developing countries it was shown that farmers with an IBI increased agricultural investments (Carter et al. (2014).

However, there are also studies that find no effect or even the opposite. Babcock and Hennessy (1996) found that farmers in lowa (USA) with a yield and revenue insurance are likely to use less chemical fertilizers. Similar effects were found in Kansas (USA) where farmers with an index-based insurance used fewer inputs such as chemical fertilizer (Smith \& Goodwin, 1996) and improved seeds (Sibiko \& Qaim, 2017). Furthermore, also in the USA Quiggin et al. (1993) in a study on a multi-peril crop insurance found an insignificant effect of the insurance on the use of chemical fertilizers.

Although there are many studies that analyse the effect of crop insurances on fertilizer use, there are only few that focus on their effects on the use of land or crop management practices. Prokopy et al. (2019) studied adoption of agricultural conservation practices in the USA and found that a crop insurance is sometimes correlated with conservation practice adoption. However, findings from Beckie et al. (2019) revealed that the short-term nature of a crop insurance, being an annual expense, does not directly incentivize (more long-term) best management practices.

In summary, how insurance adoption affects input use and land management on the farm is still under debate. This paper aims to fill this gap by analysing the links between IBI adoption and agricultural investments in rural Burundi.

\subsection{Methodology}

\subsubsection{Context}

This study in Burundi was performed in two communes of Gitega province, namely Bukirasazi and Makebuko, located in the central part of Burundi. Annual and perennial crops are cultivated during the three main agricultural seasons: in the two rainy seasons $A$ (from
September to January) and B (from February up to May) and the dry Season C from June up to September (when crops are cultivated only in the marshlands).

Participatory meetings were organized with farmers to discuss the design of the insurance to be implemented. Farmers preferred the weather-based IBI rather than a conventional insurance (i.e. indemnity-based multi-peril crop insurance) since implementation was expected to be easier, cheaper and eliminated moral hazard problems. Moreover, a mutual approach was followed in which farmers are the insured and insurers at the same time. The mutual IBI is implemented and coordinated by a Micro-insurance and Finance Cooperative (MAFICO), which is an independent mutual that promotes an agricultural insurance, a health insurance, and micro saving and credit schemes. It is owned and managed by farmers, who are also represented in the executive board (Ndagijimana et al., 2017).

The IBI was launched in season B 2017 in the aforementioned two communes. Farmers were targeted on the basis of specific criteria such as belonging to a village saving and loan association (VSLA) with a high adoption level of land management practices, and a subscription to the health insurance scheme. Although the VSLAS' main objective is to promote savings and service loans to their members, it also constituted to save $30 \%$ of the contributions for an agricultural insurance (premium payment). Next to these savings for premium payments, VSLA members were trained on how to increase farm productivity through the implementation of the so-called Integrated Farm Planning (PIP) approach, which was introduced in the study area by the project "Fanning the Spark" in 2013. The approach implies that families make a visionary integrated farm plan (the PIP) which is developed and drawn on a map, and which aims at transforming small-scale subsistence farm households into more productive and sustainable farms, based on sound natural resource management (Kessler et al., 2016). The PIP approach works to some extent like a theory of change (Taplin et al., 2013), since it defines long-term goals and then maps actions to achieve the planned changes. The PIP approach focuses on the household and the farm as a 'farming system', where integration of practices and a diversity of crops and activities are crucial to make the household more resilient.

\subsubsection{Agricultural investments analysed in this study}

The term "investment" in this study includes both monetary and non-monetary expenditures. Thus, farm investment is the monetary value spent by the farmer to obtain certain farm inputs and the cost of implementing the farm practices based on the time used to do so. Four types of investments are considered for this study, namely investments in fertilizers, crop diversification, land management and crop management: 
- Fertilizer investments comprise organic and chemical fertilizers. Organic fertilizers are either manure from own livestock or purchased. In the study area, most farmers possess big and/or small livestock which provides manure. Chemical fertilizers are purchased from the communal or provincial extension services (as part of a subsidized public policy).

- Crop diversification investments comprise nine annual crops: beans, cassava, maize, potatoes, peanuts, peas, rice, soybean and sweet potatoes. These are the main staple crops in the study area, but also at national level, and are seasonally grown (mainly in season A and season B). Furthermore, eight vegetable crops were considered: amaranth, cabbage, carrots, marrow, onion, pepper, spinach, and tomato. Most of these crops are grown around the homestead in a vegetable garden, as well as in marshlands during season C (dry period). Finally, eight perennials were considered: avocado, banana, coffee, citrus/lemon, Japanese plum, mango, maracuja, pineapple. Most of these crops are cash crops and commercialized on the local market.

- Land management investments considered eight land management practices: agroforestry, basic compost pits (traditional, unroofed), improved compost pits (welldesigned and roofed), mulching, ploughing along the contour line, trenches on the contour lines (with or without vegetation on the bunds), and vegetative borders (hedges).

- Crop management investments covered eight crop management practices: kitchen gardens, continuous ridges, planting in triangle form, adequate crop spacing, crop rotations, mixed cropping, row cropping, and relay intercropping.

\subsubsection{Sampling and data collection}

The sample comprised 40 farmers who started with the IBI in 2017 and 40 farmers who were not involved. Farmers in both groups were randomly selected from VLSAs in the same areas to minimize the heterogeneity of agro-ecological characteristics which could influence farmers' decisions on the types of agricultural investments. Furthermore, some control variables were taken into account (i.e. gender, age and education of the respondent, and whether or not farming with the PIP approach). The farm-level household survey was complemented with focus group discussions (FGD) to interpret and strengthen individua information provided by farmers. In total, four focus group discussions were organized, with in each commune one FGD for the IBI adopter group and one for the non-adopter group.

\subsubsection{Description of variables and empirical analysis framework}

By means of a cross-sectional survey with recall estimates, we were able to consider two time periods, i.e. the time before the IBI implementation $\left(T_{0}=2016\right)$ based on recall estimates of the farmer and more recent estimates three years after IBI implementation $\left(T_{1}=2019\right)$ First a simple Difference-in-Difference (DD) test was used to analyse differences between the adopters and non-adopters. The DD model which estimates the average IBI effect was estimated for each agricultural investment under analysis by the following formula based on Shahidur et al. (2010)

$D D=E\left(Y_{1}^{T}-Y_{0}^{T} \mid T_{1}=1\right)-E\left(Y_{1}^{C}-Y_{0}^{C} \mid T_{1}=0\right)$

$Y_{t}^{T}$ and $Y_{t}^{C}$ are respectively adopters and non-adopters in time $T_{1}(=1)$ denoting the presence of the insurance program, and with $\mathrm{T}_{1}(=0)$ the time before the IBI started. The superscripts and ${ }^{C}$ represent beneficiary group (treatment) and non-beneficiary group (control).

The univariate regression equation is as follows:

$\mathbf{Y}_{\mathrm{j}}=\beta_{0}+\beta_{1}$ insurance $_{\mathrm{j}}+\mathrm{E}_{\mathrm{j}}$

$Y_{\mathrm{j}}$ is the dependent variable representing changes in the amount or costs of one of the gricultural investment used by farmer $j$ between 2019 and 2016 and $\mathrm{E}_{\mathrm{j}}$ is the error term. Insurance is a dummy variable indicating whether insurance was adopted or not.

Subsequently, by means of multivariate analysis control variables were taken into account in addition to insurance, The equation based on He (2016) becomes as follows:

$\mathrm{Y}_{\mathrm{j}}=\beta_{0}+\beta_{1}$ insurance $\mathrm{j}_{\mathrm{j}}+\beta_{\mathrm{j}} \mathrm{X}_{\mathrm{j}}+\mathrm{E}_{\mathrm{j}}$

$X_{j}$ is a vector including farmers' and farm management characteristics (control variables) that can potentially affect input use:

- $\quad$ Gender of the respondent ( 1 = Male, 2 = female $)$

- $\quad$ Age of respondent (number of years)

- Education of respondent 0 = illiterate, $1=$ attended primary school, $2=$ attended secondary school, 4 = attended university)

- $\quad$ PIP approach ( 1 = farmer runs his/her farm with PIP approach, 0 otherwise). 
We assume that $|\mathrm{B}|$ adoption has a positive effect on agricultural investments above mentioned. The four agricultural investments under analysis were assessed as follows:

- Changes in fertilizer use in this study cover both chemical and organic (either 'purchased' or 'own production') and were rated by farmers with a three point Likert scale ( $1=$ used less, $2=$ no change, $3=$ used more). The expenditures associated to purchasing fertilizers were derived from the market prices (normally fixed by the local sellers) and the amount purchased (kg). The amount of fertilizer used in this study refers to seasons A and B in 2019 to minimize errors from farmers who might not remember how many $\mathrm{kg}$ was purchased a long time ago.

- Changes in crop diversification investments were obtained by asking farmers for each crop if it was grown in 2016 and 2019, and if they had invested in new seeds/plants. The outcome could therefore be either a score of -1 if the crop was grown at T0 and no longer at T1; a score of 0 if no change happened between T1 and T0; or a score of 1 if the crop was grown at T1 whereas it was not at T0. Then, mean scores were calculated based on these three outcomes $[-1,0,1]$ concerning the changes over the study period (T0 and T1).

- Land management investments were analysed by evaluating (i) changes in different measures before (T0) and after (T1) the start of the IBI, and (ii) the costs associated to land management implementation. These costs were derived either by multiplying the cost of a daily manpower and the total number of days spent to implement the practice or multiplying the size of the implemented practices by the cost per unit. For the same reasons as with fertilizers, the cost of the land management implementation refers to the year 2019

- Crop management investments were analyzed by (i) the change in use of a given practice between T0 and T1, as well as (ii) the change in knowledge of practices since the start of the IBI (1 = no change, 2 = some increase in knowledge level, $3=$ substantial increase in knowledge level).

\subsection{Results}

\subsubsection{Fertilizer investments}

Total fertilizer use changed over time $(p \leq 0.05)$ between non-adopters and adopters as estimated in the univariate DD analysis. Approximately $26.1 \%$ of the adopters used more fertilizes compared to $17.8 \%$ of the non-adopters between $T_{0}$ and $T_{1}$, while $18.1 \%$ of the adopters used less fertilizer compared to $34.1 \%$ of the non-adopters (Table 5.1).
Table 5.1. Differences fertilizer use between adopters and non-adopters in $2019\left(T_{1}\right)$ compared to $2016\left(T_{0}\right)$

\begin{tabular}{llllll}
\hline $\begin{array}{l}\text { Category of } \\
\text { respondent }\end{array}$ & $\begin{array}{l}\text { Changes Fertilizers } \\
\left(\mathrm{T}_{1}-\mathrm{T}_{\mathbf{0}}\right)\end{array}$ & $\begin{array}{l}\text { Frequency } \\
(\%)\end{array}$ & $\begin{array}{l}\text { Mean } \\
\text { score }\end{array}$ & Std. Dev. & DD \\
\hline Adopters & & $1.70^{* *}$ & 0.88 & $0.01^{* *}$ \\
& Used less & 18.1 & & & \\
& No changes & 58.8 & & & \\
& Used more & 26.1 & & & \\
Non-adopters & & & $1.69^{* *}$ & 0.75 & \\
& Used less & 34.1 & & & \\
& No changes & 48.1 & & & \\
& Used more & 17.8 & & & \\
\hline
\end{tabular}

Test $T_{1}-T_{0}, D D:{ }^{*} p \leq 0.05,{ }^{* *} p \leq 0.01 . N=80$ (adopters $=40$, non-adopters $=40$ )

Concerning organic fertilizers, the non-adopters did not significantly differ from the adopters, mainly because farmers in the study area predominantly used organic fertilizer produced by owned livestock rather than purchasing it. For chemical fertilizers (Table 5.2), the adopter differed significantly $(p \leq 0.01)$ from the non-adopters: BIF 56,370 (US\$ 30.84$)^{9}$ versus BIF 37,755 (US\$ 20.65), i.e. a difference of BIF 18,615 (US\$10.19).

Table 5.2. Differences in fertilizer investments between adopters and non-adopters in 2019

\begin{tabular}{lllll}
\hline Fertilizers & $\begin{array}{l}\text { Category of } \\
\text { responden }\end{array}$ & Mean & Std. Dev. & DD \\
\hline Organic fertilizer: & Adopters & 2.50 & 27.38 & 0.83 \\
quantity purchased (in kg) & Non-adopters & 1.67 & 18.25 & \\
$\begin{array}{llll}\text { Organic fertilizer: } \\
\text { quantity own production (in kg) }\end{array}$ & Adopters & 1,099 & 1,594 & 392.74 \\
& Non-adopters & 706.26 & 1,342 & \\
$\begin{array}{llll}\text { Organic fertilizer: } \\
\text { cost (in BIF) }\end{array}$ & Adopters & 100 & 1,095 & 33.33 \\
\hline Chemical fertilizer: & Non-adopters & 66.67 & 730.29 & \\
used (in kg) & Adopters & 49.36 & 52.07 & $19.71^{* *}$ \\
& Non-adopters & 29.65 & 39.88 & \\
$\begin{array}{l}\text { Chemical fertilizer: } \\
\text { costs (in BIF) }\end{array}$ & Adopters & 56,370 & 55,231 & $18.62^{* *}$ \\
\hline
\end{tabular}

DD: difference-in-difference, ${ }^{* *} p \leq 0.01 . N=80$ (adopters $=40$, non-adopters $=40$ ).

9 At the time of writing (Mid-June, 2019): 1 US\$ was approximatively equivalent to BIF 1827.929 


\subsubsection{Crop diversification investments}

By comparing adopters and non-adopters at $\mathrm{T}_{0}, 67.2 \%$ of adopters cultivated all nine annual crops versus $57.2 \%$ of the non-adopters. By using the difference-in-difference test for analysing the degree of crop diversification in disaggregated form (annual crops, perennial crops, and vegetable crops) during the two periods $\left(\mathrm{T}_{1}\right.$ and $\left.\mathrm{T}_{0}\right)$, the results of the "mean investment scores" indicate that adopters replaced some annual ( $D D=-0.05)$ and perennial crops $(\mathrm{DD}=-0.05)$ by vegetable crops $(\mathrm{DD}=0.01)$. However, changes over time between adopters and non-adopters showed no statistically significant differences (not only at disaggregated form but also as a whole) (Table 5.3)

Table 5.3 Differences in crop diversification between adopters and non-adopters in year 2019 (T1) and 2016

\begin{tabular}{lllllll}
\hline & & \multicolumn{3}{l|}{ Frequency (\%) } & & \\
\hline Type of crops & $\begin{array}{l}\text { Category of } \\
\text { respondent }\end{array}$ & $\mathrm{T}_{0}$ & $\mathrm{~T}_{1}$ & $\begin{array}{l}\text { Mean } \\
\text { investment } \\
\text { score }\end{array}$ & Std. Dev. & DD \\
\hline Annual crops & Adopters & 67.2 & 63.1 & -0.04 & 0.09 & -0.05 \\
& Non-adopters & 57.2 & 58 & 0.01 & 0.33 & \\
\multirow{2}{*}{ Perennial crops } & Adopters & 37.8 & 35.9 & -0.02 & 0.25 & -0.05 \\
& Non-adopters & 26.3 & 26.6 & 0.03 & 0.27 & \\
Vegetable crops & Adopters & 30.6 & 33.4 & 0.03 & 0.01 & 0.01 \\
& Non-adopters & 20.9 & 22.5 & 0.02 & 0.12 & \\
All types of crops & Adopters & 45.2 & 44.1 & -0.01 & 0.18 & -0.02 \\
& Non-adopters & 34.8 & 35.7 & 0.01 & 0.12 & \\
\hline
\end{tabular}

$N=80$ (adopters $=40$, non-adopters $=40$ )

\subsubsection{Land management investments}

Over time, significant differences were found between the adopters and non-adopters in overall land management practices $(p \leq 0.01)$ meaning that adopters were $8 \%$ more likely to apply land management practices than the non-adopters. Of the individual practices the use of vegetation borders and ploughing along counter lines were the most significant ones $(p \leq 0.01)$.

However, the results show also that the number of non-adopters applying basic compost pits and contour line without vegetation decreased at $\mathrm{T}_{1}$ compared to $\mathrm{T}_{0}$ (the mean investment scores are negatives). This suggests that these two 'basic' practices have been replaced by the more 'modern' ones i.e. basic compost pits were replaced by improved compost pits and contour lines were planted with vegetation. The cost associated to the implementation of these land management practices was also found statistically significant between both groups ( $p \leq 0.01$ ). Adopters invest more in land management (BIF 14,728; US\$ 8.05) than non-adopters (BIF 7,434; US\$ 4.06), hence a difference of BIF 6,843 (US\$ 3.99) (Table 5.4).

These results show that, in general, the implementation of land management practices in the study area requires little investments. This is linked to the average size of the farm (cultivated area) which is small in Burundi (74.3 acres per household) and in the study area (73.5 acres per household) (ISTEEBU, 2015).

Table 5.4. Differences in land management investments between adopters and non-adopters in year 2019 $\left(T_{1}\right)$ and $2016\left(T_{0}\right)$

\begin{tabular}{|c|c|c|c|c|c|c|}
\hline \multicolumn{7}{|c|}{ Frequency (\%) } \\
\hline Land management practices & $\begin{array}{l}\text { Category of } \\
\text { respondent }\end{array}$ & $T_{0}$ & $\mathrm{~T}_{1}$ & $\begin{array}{l}\text { Mean } \\
\text { investment } \\
\text { score }\end{array}$ & Std. Dev. & DD \\
\hline \multirow[t]{2}{*}{ Agroforestry } & Adopters & 51.7 & 87.9 & $0.36^{*}$ & 0.48 & $0.16^{*}$ \\
\hline & Non-adopters & 51.9 & 72.2 & $0.20^{*}$ & 0.49 & \\
\hline \multirow[t]{2}{*}{ Basic compost pit } & Adopters & 79.3 & 84.5 & 0.05 & 0.46 & 0.07 \\
\hline & Non-adopters & 67.9 & 66 & -0.02 & 0.29 & \\
\hline \multirow[t]{2}{*}{ Improved compost pit } & Adopters & 40.4 & 78.9 & $0.38^{*}$ & 0.4 & $0.18^{*}$ \\
\hline & Non-adopters & 28.8 & 46.3 & $0.20^{*}$ & 0.49 & \\
\hline \multirow[t]{2}{*}{ Contour lines only } & Adopters & 34.5 & 38.2 & 0.04 & 0.47 & 0.09 \\
\hline & Non-adopters & 27.1 & 22 & -0.05 & 0.39 & \\
\hline \multirow[t]{2}{*}{ Contour lines + vegetation } & Adopters & 60.7 & 94.6 & 0.34 & 0.51 & 0.05 \\
\hline & Non-adopters & 17.9 & 56.1 & 0.39 & 0.49 & \\
\hline \multirow[t]{2}{*}{ Mulching } & Adopters & 26.3 & 48.3 & 0.21 & 0.41 & 0.11 \\
\hline & Non-adopters & 16.9 & 27.1 & 0.10 & 0.3 & \\
\hline \multirow[t]{2}{*}{ Ploughing along contour line } & Adopters & 50 & 90 & $0.40^{* *}$ & 0.50 & $0.34^{* *}$ \\
\hline & Non-adopters & 0 & 6.3 & $0.06^{* *}$ & 0.25 & \\
\hline \multirow[t]{2}{*}{ Vegetation borders } & Adopters & 29.6 & 44.4 & $0.15^{* *}$ & 0.35 & $0.15 * *$ \\
\hline & Non-adopters & 20 & 20 & $0.00^{* *}$ & 0.00 & \\
\hline \multirow{2}{*}{$\begin{array}{l}\text { All land management } \\
\text { practices }\end{array}$} & Adopters & 50.7 & 68.1 & $0.17^{* *}$ & 0.43 & $0.08^{* *}$ \\
\hline & Non-adopters & 34.9 & 44.2 & $0.09^{* *}$ & 0.37 & \\
\hline \multirow{2}{*}{$\begin{array}{l}\text { Cost of land management } \\
\text { practices (T1) (BIF) }\end{array}$} & Adopters & & & $14,278^{* *}$ & 43,800 & $6,843 * *$ \\
\hline & Non-adopters & & & $7,434^{* *}$ & 30,248 & \\
\hline
\end{tabular}

Test $T_{1}-T_{0}$ and $D D:{ }^{*} p \leq 0.05,{ }^{* *} p \leq 0.01 . N=80$ (adopters $=40$, non-adopters $=40$ ) 


\subsubsection{Crop management investments}

The overall analysis of crop management investments reveals that adopters have doubled $(p<0.01)$ these practices over time $\left(42.6 \%\right.$ in $T_{0}$ versus $84.5 \%$ in $\left.T_{1}\right)$, while investments were less profound for non-adopters.

Findings from the DD test indicate that adopters are $38 \%$ more likely to invest in all crop management practices together $(p \leq 0.01)$. Specifically, adopters are significantly different from non-adopters in the use of crop spacing $(p \leq 0.01)$, crop rotation $(p \leq 0.05)$, mixed intercropping $(p \leq 0.05)$, continuous ridges $(p \leq 0.01)$, use of triangle $(p \leq 0.10)$, and row intercropping ( $p \leq 0.05)$ ((Table 5.5)

Table 5.5. Differences in crop management investments between adopters and non-adopters in year 2019 $\left(T_{1}\right)$ and $2016\left(T_{0}\right)$

\begin{tabular}{|c|c|c|c|c|c|c|}
\hline \multirow[b]{2}{*}{ Crop management practices } & \multirow[b]{2}{*}{$\begin{array}{l}\text { Category of } \\
\text { respondent }\end{array}$} & \multicolumn{4}{|c|}{ Frequency (\%) } & \multirow[b]{2}{*}{ DD } \\
\hline & & $\mathrm{T}_{0}$ & $\mathrm{~T}_{1}$ & $\begin{array}{l}\text { Mean } \\
\text { investment } \\
\text { score }\end{array}$ & $\begin{array}{l}\text { Std. } \\
\text { Dev. }\end{array}$ & \\
\hline \multirow[t]{2}{*}{ Crop spacing well-used } & Adopters & 50 & 94.7 & $0.45^{* *}$ & 0.50 & $0.39 * *$ \\
\hline & Non-adopters & 21.9 & 28.1 & $0.06^{* *}$ & 0.25 & \\
\hline \multirow[t]{2}{*}{ Crop rotations well-planned } & Adopters & 52.5 & 90 & $0.38^{*}$ & 0.49 & $0.25^{*}$ \\
\hline & Non-adopters & 29 & 41.9 & $0.13^{*}$ & 0.34 & \\
\hline \multirow{2}{*}{$\begin{array}{l}\text { Mixed intercropping well- } \\
\text { planned }\end{array}$} & Adopters & 31.4 & 54.3 & $0.23^{*}$ & 0.43 & $0.18^{*}$ \\
\hline & Non-adopters & 14.6 & 19.5 & $0.05^{*}$ & 0.22 & \\
\hline \multirow[t]{2}{*}{ Use of kitchen garden } & Adopters & 89.7 & 94.9 & 0.05 & 0.22 & -0.01 \\
\hline & Non-adopters & 13.9 & 19.4 & 0.06 & 0.23 & \\
\hline \multirow[t]{2}{*}{ Use of continuous ridges } & Adopters & 41.5 & 82.9 & $0.41^{*}$ & 0.5 & $0.35^{* *}$ \\
\hline & Non-adopters & 24.2 & 30.3 & $0.06^{*}$ & 0.24 & \\
\hline \multirow[t]{2}{*}{ Use of triangle } & Adopters & 50 & 82.5 & $0.33^{*}$ & 0.47 & $0.18^{*}$ \\
\hline & Non-adopters & 6.1 & 21.2 & $0.15^{*}$ & 0.46 & \\
\hline \multirow[t]{2}{*}{ Row intercropping well-planned } & Adopters & 33.3 & 42.4 & $0.09^{*}$ & 0.29 & $0.09 *$ \\
\hline & Non-adopters & 4.5 & 4.5 & $0.00^{*}$ & 0.00 & \\
\hline \multirow{2}{*}{$\begin{array}{l}\text { Relay intercropping well- } \\
\text { planned }\end{array}$} & Adopters & 27.3 & 33.3 & 0.06 & 0.24 & 0.06 \\
\hline & Non-adopters & 2.3 & 2.3 & 0.00 & 0.00 & \\
\hline \multirow[t]{2}{*}{ All crop management practices } & Adopters & 42.6 & 84.5 & $0.42^{* *}$ & 0.49 & $0.38^{* *}$ \\
\hline & Non-adopters & 12.7 & 17.2 & $0.04^{* *}$ & 0.23 & \\
\hline
\end{tabular}

Test $T_{1}-T_{0}$ and $D D:{ }^{*} p \leq 0.05,{ }^{* *} p \leq 0.01 . \mathrm{N}=80$ (adopters $=40$, non-adopters $=40$ )
Crop management knowledge has significantly improved for all practices for the adopters (positive mean knowledge score) based on the results from Table 5.6. On average, 55\% of the adopters recorded substantial changes in knowledge compared to only $6.5 \%$ of the nonadopters $(p \leq 0.01)$. Furthermore, only $27 \%$ of adopters stated to have the same knowledge level, while $81 \%$ of non-adopters remained on the same level as in 2016.

Table 5.6. Differences in crop management knowledge between adopters and non-adopters in year 2019 $\left(T_{1}\right)$ and $2016\left(T_{0}\right)$

\begin{tabular}{|c|c|c|c|c|c|}
\hline $\begin{array}{l}\text { Changes in } \\
\text { knowledge of crop } \\
\text { management }\end{array}$ & $\begin{array}{l}\text { Category of } \\
\text { respondent }\end{array}$ & T1 - T0 & $\begin{array}{l}\text { Frequency } \\
(\%)\end{array}$ & $\begin{array}{l}\text { Mean } \\
\text { knowledge } \\
\text { score }\end{array}$ & DD \\
\hline & Adopters & & & $2.28^{* *}$ & $0.23^{* *}$ \\
\hline & & No changes & 27.4 & & \\
\hline & & Some changes & 17.6 & & \\
\hline & & Big changes & 55.0 & & \\
\hline & Non-adopters & & & $2.05 * *$ & \\
\hline & & No changes & 81.5 & & \\
\hline & & Some changes & 12.1 & & \\
\hline & & Big changes & 6.5 & & \\
\hline
\end{tabular}

Test $T_{1}-T_{0}, D D: p \leq 0.01, N=80$ (adopters $=40$, non-adopters $=40$ )

Multivariate linear regression models were used to determine the link between the IB adoption and considered agricultural investment variables. Tests revealed a good fit of the models as indicated by for example Chi-square coefficient and $\mathrm{R}^{2}{ }_{\text {adj }}$ (Table 5.7). IBI adoption was found to have a positive and significant effect on the fertilizer investments (in amoun as well as the cost of fertilizers), on land management (in change of practices as well as the cost associated to the implementation of these practices), and on crop management (in change of practices and knowledge).

The findings indicated that adopters used more chemical fertilizers with 36\%-point $(p \leq 0.01)$ and invest $18 \%$ more than non-adopters $(p \leq 0.01)$. In addition, adopters were found to be more likely to change land management practices $(12 \%$ higher, $p \leq 0.01)$ and increased their investments by $15 \%$ (i.e. BIF 15 for BIF 100 invested) for the implementation of land management practices $(p \leq 0.01)$. Adopters were more likely to change crop management practices (38\% higher, $p \leq 0.01$ ) and their knowledge in crop management practices can be expected to increase by $23 \%(p \leq 0.01)$ 
Furthermore, male farmers invested $16 \%$ and $5 \%$ less in fertilizers and in land management respectively $(p \leq 0.05)$ than female farmers. Since Burundian men are not as much involved in field activities as women, they are less receptive to problems related to agriculture and therefore invest less in agriculture.

Moreover, higher educated respondents applied more crop diversification $(p \leq 0.05)$ than lower educated respondents. Finally, farmers who run their farm with a PIP approach were more likely to increase the amount of fertilizers ( $p \leq 0.05$ ), with the amount of fertilizers used being $22 \%$ higher for farmers running their farm with a PIP approach as compared to others who don't have a PIP.

Table 5.7. Results of multiple regressions analysis between adopters and non-adopters in year $2019\left(T_{1}\right)$ and $2016\left(T_{0}\right)$

\begin{tabular}{|c|c|c|c|c|c|c|c|}
\hline & \multicolumn{2}{|c|}{ Chemical fertilizer } & \multirow{2}{*}{$\begin{array}{l}\begin{array}{l}\text { Crop } \\
\text { diversification }\end{array} \\
\text { Change } \\
\text { in use } \\
\mathrm{T}_{1}-\mathrm{T}_{0}(\%)\end{array}$} & \multirow{2}{*}{$\begin{array}{l}\begin{array}{l}\text { Land } \\
\text { management }\end{array} \\
\text { Change } \\
\text { in use } \\
\mathrm{T}_{1}-\mathrm{T}_{0}(\%)\end{array}$} & \multicolumn{3}{|c|}{$\begin{array}{l}\text { Crop } \\
\text { management }\end{array}$} \\
\hline & $\begin{array}{l}\text { Quantity } \\
\text { (\%) }\end{array}$ & $\begin{array}{l}\text { Cost } \\
(\%)\end{array}$ & & & $\begin{array}{l}\text { Cost } \\
(\%)\end{array}$ & $\begin{array}{l}\text { Change } \\
\text { in use } \\
\mathrm{T}_{1}-\mathrm{T}_{0} \\
(\%)\end{array}$ & $\begin{array}{l}\text { Change in } \\
\text { knowledge } \\
\text { (\%) }\end{array}$ \\
\hline Constant & 1.02 & 1.11 & -5.35 & -4.50 & 2.35 & 0.01 & 1.25 \\
\hline Insurance adoption & $\begin{array}{l}0.36^{* *} \\
(0.02)\end{array}$ & $\begin{array}{l}0.18^{* *} \\
(0.140)\end{array}$ & $\begin{array}{l}0.02 \\
(0.01)\end{array}$ & $\begin{array}{l}0.12^{* *} \\
(0.04)\end{array}$ & $\begin{array}{l}0.15^{* *} \\
(0.04)\end{array}$ & $\begin{array}{l}0.38^{* *} \\
(0.04)\end{array}$ & $\begin{array}{l}0.23^{* *} \\
(0.56)\end{array}$ \\
\hline $\begin{array}{l}\text { Gender of the } \\
\text { respondent }\end{array}$ & $\begin{array}{l}-0.08 \\
(0.28)\end{array}$ & $\begin{array}{l}-0.16^{*} \\
(8009)\end{array}$ & $\begin{array}{l}-0.02 \\
(0.01)\end{array}$ & $\begin{array}{l}-0.02 \\
(0.38)\end{array}$ & $\begin{array}{l}-0.05^{*} \\
(0.03)\end{array}$ & $\begin{array}{l}-0.04 \\
(0.03)\end{array}$ & $\begin{array}{l}-0.03 \\
(0.06)\end{array}$ \\
\hline $\begin{array}{l}\text { Age of the } \\
\text { respondent }\end{array}$ & $\begin{array}{l}0.05 \\
(9.01)\end{array}$ & $\begin{array}{l}-0.10 \\
(0.24)\end{array}$ & $\begin{array}{l}-0.01 \\
0.01\end{array}$ & $\begin{array}{l}-0.04 \\
(0.01)\end{array}$ & $\begin{array}{l}-0.04 \\
(0.01)\end{array}$ & $\begin{array}{l}0.32 \\
(0.02)\end{array}$ & $\begin{array}{l}0.27 \\
(0.08)\end{array}$ \\
\hline $\begin{array}{l}\text { Education of } \\
\text { the respondent }\end{array}$ & $\begin{array}{l}-0.01 \\
(0,80)\end{array}$ & $\begin{array}{l}0.10 \\
(0.35)\end{array}$ & $\begin{array}{l}0.05^{*} \\
(0.01)\end{array}$ & $\begin{array}{l}0.09 \\
(0.03)\end{array}$ & $\begin{array}{l}-0.03 \\
(0.01)\end{array}$ & $\begin{array}{l}-0.06 \\
(0.02)\end{array}$ & $\begin{array}{l}0.13 \\
(0.05)\end{array}$ \\
\hline Having a PIP & $\begin{array}{l}0.22^{*} \\
(0.63)\end{array}$ & $\begin{array}{l}0.13 \\
(0.22)\end{array}$ & $\begin{array}{l}-0.05 \\
(0.01)\end{array}$ & $\begin{array}{l}0.06 \\
(0.02)\end{array}$ & $\begin{array}{l}0.01 \\
(0.02)\end{array}$ & $\begin{array}{l}-0.032 \\
(0.05)\end{array}$ & $\begin{array}{l}0.86^{* *} \\
(0.06)\end{array}$ \\
\hline$R_{\text {adj }}^{2}$ & 0.719 & 0.72 & 0.01 & 0.09 & 0.02 & 0.6 & 0.39 \\
\hline Prob $>\mathrm{Chi}^{2}$ & 0.00 & 0.00 & 0.18 & 0.01 & 0.00 & 0.03 & 0.00 \\
\hline Log likelihood & -101.84 & 51.16 & 0.15 & 40.30 & 57.41 & 12.10 & 69.02 \\
\hline Wald chi2 (8) & 15.77 & 4.72 & 1.50 & 2.99 & 5.04 & 8.86 & 9.84 \\
\hline
\end{tabular}

${ }^{*} p \leq 0.05,{ }^{*} p \leq 0.01$. Standard errors indicated in brackets. $N=80$ (adopters $=40$, non-adopters $=40$ )

\subsection{Discussion}

This study explored the links between IBI adoption and agricultural investments in Burundi by comparing adopters and non-adopters. It was hypothesized that adopters invest more than the non-adopters in fertilizers, crop diversification, land and crop management practices.

The findings indicated that IBI adopters invest much more in chemical fertilizers. However, The $|\mathrm{B}|$ adoption did not show any significant difference between adopters and nonadopters in terms of investment in organic fertilizers. This is due to the fact that farmers in the study area predominantly used organic fertilizer produced by owned livestock rather than purchasing it. Other constraint is hampering farmers to invest in organic fertilizers, such as its limited local availability as reported during the FGD meetings.

The effect of $\mid \mathrm{BI}$ adoption on crop diversification is not conclusive to prove that adopters diversify crops (particularly annual and perennial crops) more than non-adopters. Farmers in the FGD meetings (adopters and non-adopters) stated that the reason why they diversify vegetable crops more than annual and perennial crops is due to the fact that vegetable crops mature quickly (from one up to two months) and require less space. In addition, vegetables are more lucrative than annual crops because customers are available all year round regardless of the growing season. Furthermore, some awareness-raising campaigns on the promotion of vegetable crops were organized for farmers who participated in training courses as part of the PIP approach. The reason that annual crops are less diversified, according to farmers in the FGDs, is that in each cropping season particular annual crops are grown, and variation is therefore more difficult. Overall, the link between the IBI adoption and crop diversification was not clearly proven with these results, and hence, crop diversification is influenced by other factors among others farmer's motivation or preferences, seed availability and agroecological conditions. These results are partly consistent to the results from Carter et al. (2015) who stated that there are a number of agro-ecological and economic environments in which an index insurance is unlikely to have an impact on the adoption of agricultura technologies, either because risk is intrinsically low or high.

The results also revealed that the adopters invest much more in land management practices than non-adopters. Furthermore, the number of farmers using the basic compost pits and contour lines without vegetation has dropped over the study period and these were replaced by improved compost pits and contour lines with vegetation respectively. This transition from the more basic to the more modern land management practices observed for both adopters and non-adopters can be explained by the fact that improved land management practices were already promoted by the PIP approach before the start of the IBI implementation. This means that a considerable part of the 
farmers considered in this study (both adopters and non-adopters of the IBI) were already trained in the PIP approach and with the knowledge how to implement good agricultura practices, as well as improve existing ones. The PIP approach is strongly based on farmerto-farmer learning, and during participatory discussions non-adopters stated that they have strengthened some farming practices due to the good examples demonstrated by adopters within the implementation of land management practices. This "spill-over effect", which refers to a process in which people adopt a new product or practice when they come in contact with others who have adopted it (Young-Peyton, 2009; Rogers, 2003), is enforced and accelerated by the IBI implementation and adoption, as IBI adopters even faster recognize the benefits of better land management in terms of yield increase. During the FGD meetings with insured farmers, participants declared that the IBI has increased their commitment in land management because yield losses are lower for those who protected their lands than for those who didn't. Farmers refer to the excessive rainfall in Gitega in the first insured year, where - though all were paid-out the same amount (for the same event) - farmers confirmed that they noticed a net income difference between farmers who had protected their land by contour-lines (trenches) and others who did not. The first received pay-outs and were also able to harvest some of the crop, the latter received only pay-outs.

It was also found from this study that adopters changed crop management practices over time and their knowledge increased more than non-adopters. Farmers in FGD meetings reported that they have acquired some knowledge in land and crop management during the PIP approach introduction, but with the mutual crop insurance approach, their knowledge has improved even more because every time the insured farmers came together, they exchanged experiences and strengthened their knowledge. Farmers from group discussions said that learning through farmer groups (group learnings) allowed learners to better understand the practices as well as the best way to implement them. Furthermore, group learnings stimulated the use of improved farming techniques particularly land management as well as crop management. Group learning sometimes takes more time before getting tangible results for diffusion and adoption of practices. Young-Peyton (2009) said that people adopt once they see enough empirical evidence to convince them that the innovation is worth adopting, where the evidence is generated by the outcomes among prior adopters. In the community, IBI adopters are considered champions since they started and keep running an innovative program that didn't exist before and are convinced and self-confident to continue with it. In the FGD meetings they expressed that they want to demonstrate the difference with the rest of the community in terms of land and crop management. They argued that with these considerations, they want that their farms become like the farmer field schools where other community members will come to learn.
Looking at all investments made by farmers, according to the results from this study there is evidence of a causality effect between IBI adoption and agricultural investments, with adopter investing more in agricultural practices than the non-adopters. However, reverse causality could also be the case, i.e. that farmers who already invest in different farming practices are more willing to adopt the IBI. This can however not be verified with the results from this study. The fact that the early adopters were chosen on the basis of precise and specific criteria (i.e. selective method) could lead to an interpretation bias on reverse causality between the two variables i.e. agricultural investments and IBI adoption. Given the current setting it was not feasible to conduct a randomised control trial to estimate the impact more robustly.

\subsection{Conclusion}

Using cross-sectionally data from a household survey, this study analysed the links between index-based insurance (IBI) and agricultural investments in Burundi. By analysing the findings, three main lessons were learnt.

Firstly, IBI adoption increases investments in chemical fertilizers, as well as in land and crop management practices. Therefore, if well organized, the IBI could be a good tool to stimulate agricultural investments as it helps farmers to mitigate the adverse effects of weather risks.

Secondly, during the IBI implementation, the IBI non-adopters also invested substantially in farming practices, which is the result of the PIP approach being there before and the spill-over effect which is a result of the peer learning method that has enabled farmers to improve these farming practices. The PIP approach builds the foundation for sustainable change, with farmers becoming curious and willing to learn from others, because they are more aware and want to improve their investments. Once well organized and all having implemented a PIP, the peer learning method would be a key factor in the diffusion of innovation in the community; this should be promoted, because teachers and learners are familiar with each other and the knowledge transmission becomes easier and more costeffective.

Thirdly, although IBI is a tool with a high potential to stimulate agricultural investments, the adoption of IBI has not had significant effects on certain farming practices such as crop diversification and the use of organic fertilizers. These practices require either more substantial investments (for crop diversification) or the limited local availability (as is the case of organic fertilizers). Therefore, the IBI has its limitations and does not necessarily result in an overall improvement and progress towards more sustainable agriculture. 
Hence, next to an $\mid \mathrm{BI}$, additional activities are needed to further and more quickly transform Burundian agricultural towards sustainability

In that respect, in this paper we have seen that scaling-up the PIP approach is a promising option, as it enhances farm inputs availability and encourages farmers to invest more in land and crop management, including crop diversification. This requires action from the Burund government and other partners involved in land and crop management, and supporting IB adoption by farmers can play an important role in agricultural development. 


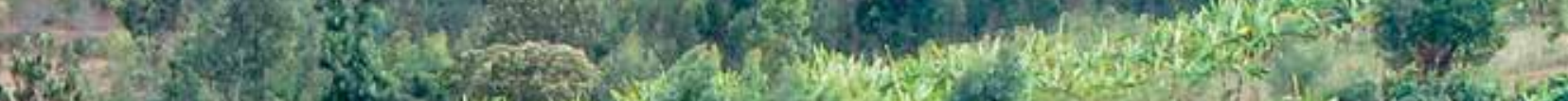

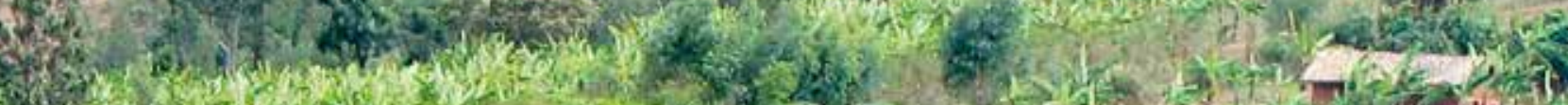

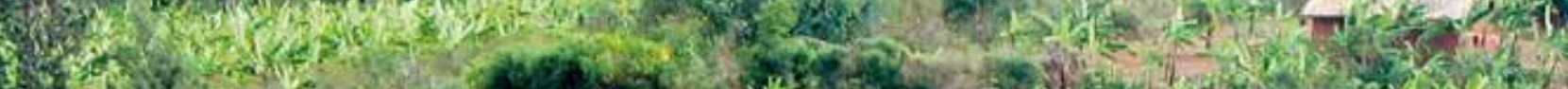

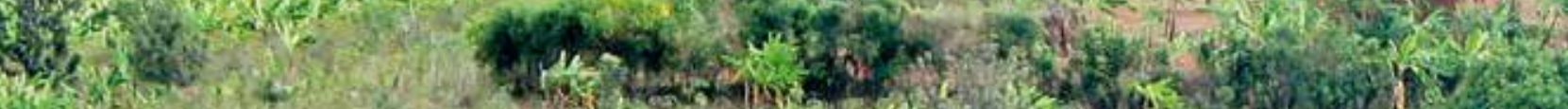

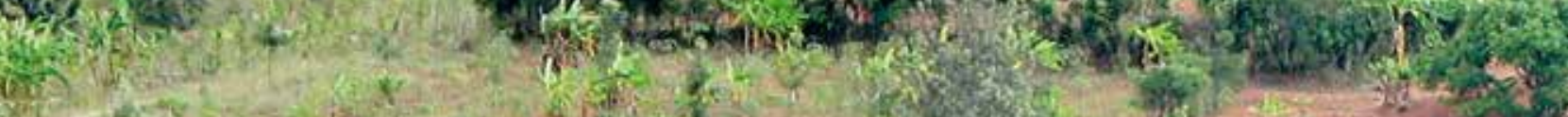

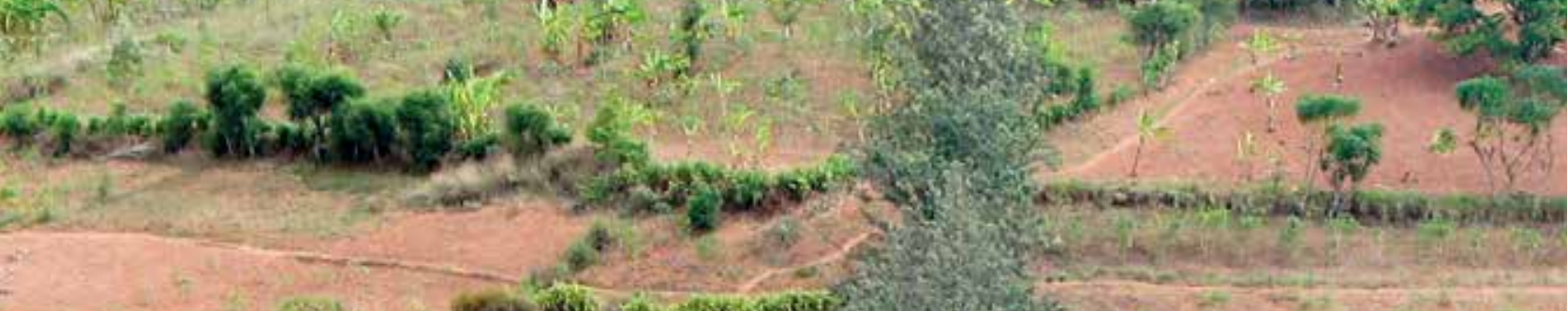

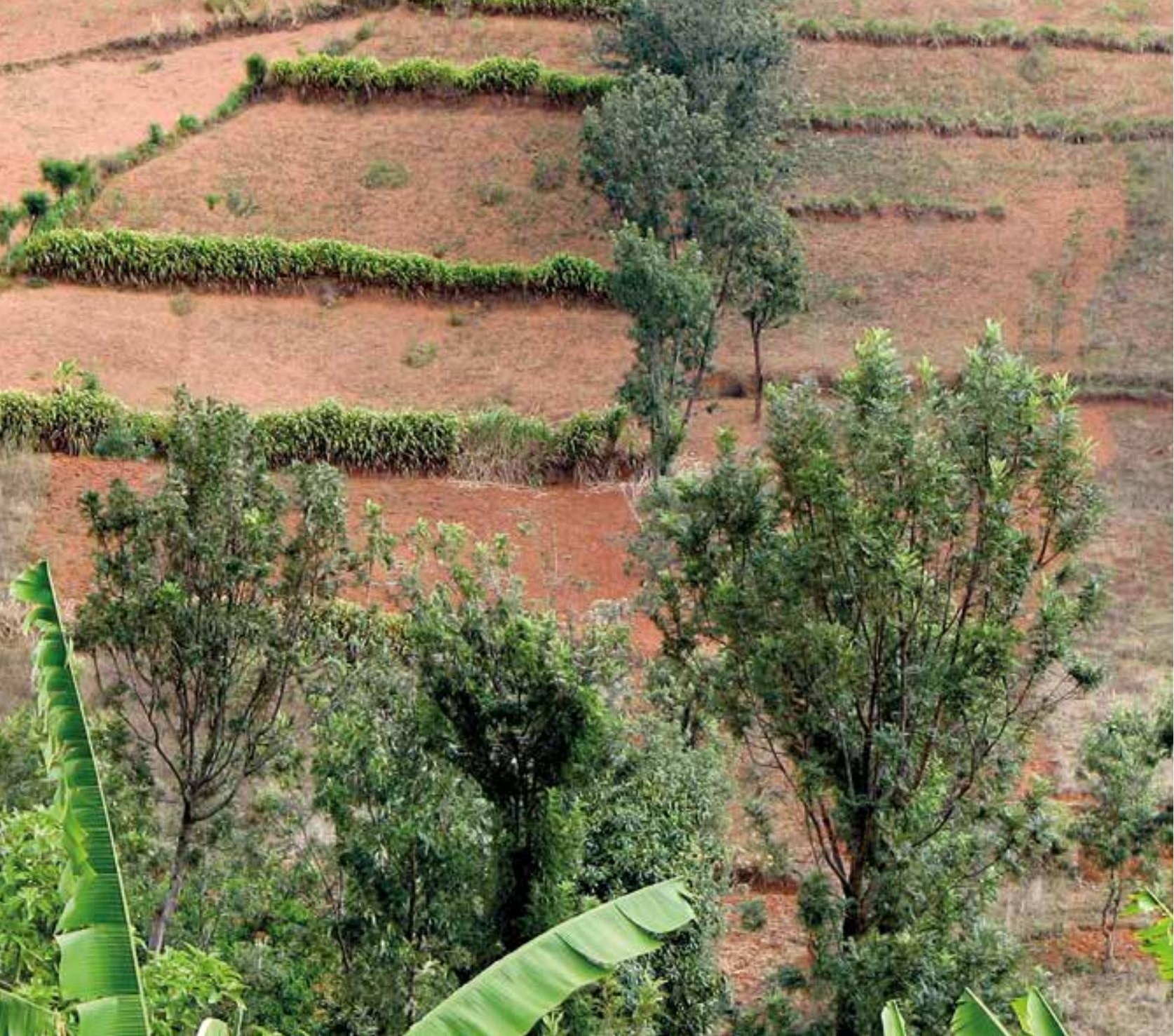

Chapter 6

Synthesis 


\subsection{Introduction}

This study entitled "Coping with risk and climate change in farming: exploring an indexbased crop insurance in Burundi" aims to shed light on factors influencing sustainable land management (SLM) investments and to what extent an index-based crop insurance (IBI) helps farmers to overcome risks associated to farming.

This research focused on factors influencing SLM investments by smallholder farmers, crop risk and perception (as experienced by farmers), effect of village savings and loan associations (VSLAs) on IBI adoption and the link between IBI adoption and agricultural investments in Burundi. Data were collected in two provinces of Burundi (Gitega and Muyinga) for Chapters 2 and 3, and only in Gitega for Chapters 4 and 5, based on both quantitative data collection (a survey with closed questions at household level) and qualitative methods (mainly focus group discussions).

Chapters of this thesis were elaborated based on the research questions as below described and connected as in the figure 6.1. Chapter 2 focused on factors influencing farmers investments on SLM to address land degradation in the study area, related to climate change effects on soil erosion and soil productivity. Chapter 3 analyzed risk experience and risk perception by farmers by highlighting the household coping strategies, pointing to the need for a more sustainable strategy. Thus, Chapter 4 introduced IBI, and provided insight into VSLAs and the extent to which these encourage the adoption of an IBI under limited liabilities; and Chapter 5 analyzed the links between the IBI adoption and agricultural investments by smallholder farmers.

Specifically, this study was meant to answer the following research questions:

- RQ1: What are the factors influencing SLM investments by smallholder farmers in Burundi?

- RQ2: To what extent do farmer household coping strategies in Burundi respond effectively to the severity of crop risks being experienced at the farm level?

- RQ3: What is the effect of VSLAs on the adoption of IBI under limited liabilities in rural Burundi?

- RQ4: What are the links between IBI adoption and agricultural investments by smallholder farmers in Burundi?

The results have been presented in the previous chapters and the structure connecting the different chapters of this thesis is presented in Figure 6.1 


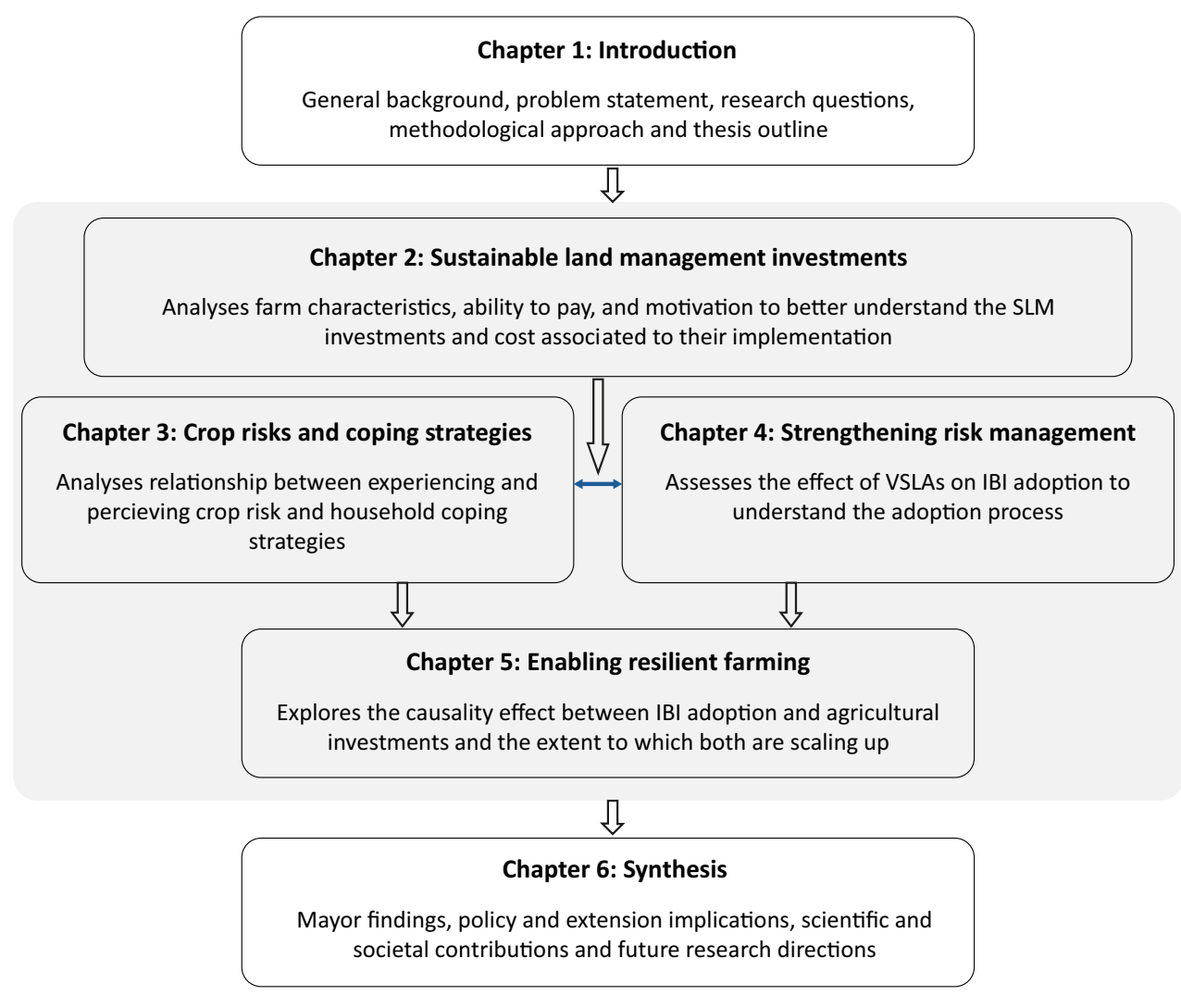

Figure 6.1. Synopsis of the analysis of SLM investments and the links between IBI adoption and agricultura investments

In the following section 6.2, the results from previous chapters (Chapter 2 to 5 ) are synthetized and discussed to address the research questions. Next, section 6.3 reflects on the core issues from the research findings whereas section 6.4 details the implications for policy making. Then, section 6.5 highlights in general terms the research contribution to science and society, section 6.6 presents the limitations of this study and gives recommendations for future research, while finally in section 6.7 we come to the general conclusions.

\subsection{Main findings of the research}

1) What factors are influencing sustainable land management investments? (Chapter 2)

The first research question gave attention to the drivers of SLM investments by farmers as implemented in the provinces of Gitega and Muyinga. Five key factors that positively influence SLM investments were identified on the basis of a multinomial logistic regression model: the occurrence of soil erosion on the farm, access to financial services like credit, education level and the age of the household head, as well as the engagement of the household head in farming. The results indicated that experiencing soil erosion on the farm increases farmers' willingness to invest in SLM, which is crucial in reducing negative effects associated with land degradation and advance towards sustainable agriculture. In addition, although the agricultural sector is less creditworthy in terms of bank financing due to the high level of climate risk associated with agriculture, the results of this study showed that the more credit farmers have access to, the more investments in SLM increase. Ngombe et al. (2008) came to the same conclusion by confirming that farmers' investments in SLM are minimal due to their limited access to credit. Furthermore, the level of education plays a major role in enhancing farmers' knowledge of the causes of and solutions to tackle soil degradation. The results of this study show that a minimum literacy level (i.e. primary education) is already sufficient to make a difference in farmers' capabilities to find solutions and invest more in SLM. Our study further revealed that older farmers and those who are fully engaged in farming are likely more aware of problems associated to farming and as a result more receptive to implement land management practices. Enhancing efforts to strengthen smallholder farmers' capacities concerning SLM in the context of climate change is therefore essential.

2) To what extent do farmer household coping strategies in Burundi respond effectively to the severity of crop risks being experienced at farm level? (Chapter 3)

The second research question investigated the relationship between experiencing and perceiving crop risks associated to farming and the undertaken coping strategies by households. The results indicate that the most frequently experienced risks are drought and excessive rainfall, whereas drought, hail, and input price fluctuations were perceived to be the most severe risks in the study area. It was noticed that some of these risks motivate farmers to invest in agriculture whereas others demotivate them, particularly those risks which farmers are not able to deal with ex-ante. However, the motivation or demotivation to invest in agriculture depends not only on the nature of the risk, but also on personal financial ability and other external factors, like farmers' awareness concerning coping strategies. Most of these coping strategies are survival mechanisms dominated by ex-post 
reactive responses with limited mid and long-term effects. This study showed that the kind of coping strategies chosen by a household depends mainly on the nature of the risk and the means available to the household to deal with it. Therefore, other more effective adaptation strategies to foster resilient agriculture are needed, such as an agricultural insurance for unpredictable risks that farmers cannot cope with.

3) What is the effect of VSLAs on the adoption of IBI under limited liabilities in Burundi? (Chapter 4)

The third research question aimed at evaluating the effect of VSLAs on IBI adoption. The results indicate that adoption of the IBI by VSLA members increases if they can save for upcoming premiums payment via their VSLA and if they regularly attend VSLA meetings. Hence, once a VSLA is structured with a better saving system and well-organised, it could pave the way for IBI adoption. Furthermore, we found that VSLAs' members with more knowledge on land and crop management, as well as those running their farm based on an Integrated Farm Plan (PIP), are more likely to adopt a crop insurance. This relationship between having a vision and a plan and adopting a crop insurance, could be explained by the fact that farmers working with a PIP already invest in integrated land and crop management and are more aware of risks associated to farming. As a result, they are more receptive to risk management by adopting the crop insurance. However, the low level of farmers' knowledge of how an insurance works is one of the major barriers to its adoption at community level. Hence, capacity building coupled to a coaching program by crop insurance experts would be essential to boost IBI adoption in Burundi.

4) What are the links between IBI adoption and agricultural investments by smallholder farmers in Burundi? (Chapter 5)

The fourth research question explored the links between the IBI adoption and agricultura investments, with a focus on integrated land management, including use of fertilizers, land and crop management as well as crop diversification. The results show that adopting an IBI increases agricultural investments in chemical fertilizers and in land and crop management practices, but had no significant effects on crop diversification and the use of organic fertilizers. The results also revealed that the adopters invest much more in land management practices, that they changed crop management practices over time, and that they increased their knowledge more than non-adopters. Interestingly, not only the IBI-adopters but also non-adopters invested substantially in farming practices over the past three years, which can be contributed to being involved in the PIP approach since three years, and the spill-over effect which is a result of the peer learning method that has enabled farmers to improve these farming practices. Once well-organized and working better together due to the PIP approach, the peer learning methods turn out to be a key factor in the diffusion of innovations in the community. This should be further promoted, because when fostering collaboration, knowledge transmission becomes easier and more cost-effective. Nevertheless, the results show that the IBI has its limitations and does not necessarily result in an overall improvement and progress towards more sustainable agriculture. Hence, nex to an IBI, additional activities are needed to further and more quickly transform Burundian agricultural towards sustainability.

\subsection{General discussion}

This section focuses on the potential of an IBI in fostering SLM by smallholder farmers and hence advance towards more sustainable agriculture. Firstly, we analyze the issues surrounding the IBI adoption and how to enable scaling-up. Next, we reflect on the potential of the IBI adoption in enhancing SLM. Finally, we discuss the potential role of group and peer learning methods in both the adoption and scaling-up of the IBI and the promotion of SLM practices for more sustainable agriculture.

\section{Index-based crop insurance issues}

An agricultural insurance is one way by which farmers can stabilize farm income and investments, as well as safeguard against disastrous effects of losses due to natural hazards (Aidoo et al., 2014). An IBI aims at limiting the high (transaction) costs associated with traditional insurances (i.e. the indemnity-based insurances). While positive impacts have been recorded where IBI products were adopted, their uptake has generally been low (Ntukamazina et al., 2017) and in most cases not sustainable (Carter et al., 2014). However, an IBI provides less-costly and more-transparent risk management than other alternative products, enabling farmers to make more productive investments and better manage crop risks (Cole et al. 2012)

The IBI in Burundi is a mutual-based approach implemented through VSLAs. The findings from Chapter 3 indicate that $45 \%$ of the IBI adopters still subscribe to the insurance 3 years after its launch in Burundi, even without further project support. Despite this considerable percentage, one wonders why some IBI adopters drop-out at some point, and why some farmers remain hesitant to adopt the IBI at all? This issue will be discussed in-depth in the next paragraphs. 
Previous studies that explored IBI uptake by smallholder farmers came to the conclusion that despite the IBI benefits, voluntary IBI uptake was much lower than was initially anticipated (Binswanger-Mkhize, 2012). Reasons for the low uptake of insurance products can be various, such as: inappropriate product design; lack of knowledge about product development; basic risk that remains; lack of agricultural insurance legislation; high premiums (making the product unaffordable); financial illiteracy; lack of trust in the insurer; or lack of qualified personnel in the area of agricultural insurances (Cartel et al., 2014 Takahashi et al., 2016; Ntukamazina et a.l, 2017, Mensah, et al., 2017). In Ethiopia, a study by Tadesse et al. (2013) revealed that nearby two-thirds of the households reported that they perceived the insurance as something designed for rich people who can afford to pay the insurance premium, similar to the case of a motor insurance. A study by Sibiko et al.(2018) in Kenya suggests that the reason why the weather index insurance is weakly adopted is that contracts are not yet sufficiently tailored to the needs and preferences of smallholder farmers. In most cases, and particularly in developing countries, an IBI is implemented by international organizations in consultation with local private actors (e.g., Burkina Faso, Ethiopia, Kenya, Rwanda, Tanzania) and sometimes with governments that subsidize risk premiums (e.g. in Uganda). Below we discuss the main strategies to be taken up in the context of fostering the uptake and scaling-up an IBI.

Firstly, in order to enhance IBI adoption by smallholder farmers, we need to find solutions to the main and underlying causes of the low uptake as stated above. One suggestion by Sibiko et al. (2018) is that offering contracts to small groups rather than individual farmers could increase IBI uptake and these groups can also be important platforms for learning about complex innovations, including novel risk transfer products (Sibiko et al., 2018). The results of our study show that farmers prefer a collective subscription through their VSLAs rather than an individual subscription. This is supported by findings from Dercon et al. (2014), who suggested that the uptake of a weather index insurance by Ethiopian farmers is higher when the insurance is channeled through group-based informal insurance schemes with appropriate training for group leaders. Our findings pointed out the outstanding role of VSLAs in fostering crop insurance adoption and thus, strengthening their mode of operation could increase the IBI uptake. Working in groups allows members to complement each other both financially and technically and achieve goals that could not be achieved on their own.

Secondly, it is well-known that in low income countries farmers are often cash constrained and would benefit from accessing a micro-credit - but uninsured loans may increase risk (Dercon \& Christiaensen, 2011; Karlan et al. 2014). Farming is a risky business in which money lenders are afraid of being unable to recover their loans and small farmers find themselves excluded from the credit market in favour of those in less risky occupations.
Thus, beyond reducing lenders' fears, linking insurance with credit will also allow service providers to use one distribution channel (reduce administration costs such as through the use of innovative tools - e.g. mobile phone) that may also help to further reduce interest rates and insurance premiums (Tadesse et al., 2015). Hence, increasing access to credits in rural areas might foster IBI uptake and scaling-up by smallholder farmers.

Thirdly, another issue to be tackled when scaling-up an IBI is the connection of the different partners, which might have different objectives and focus areas. Scaling-up IBI requires a consolidated synergy between several public and private actors (i.e. alignment of publicprivate partnerships). Partners include banks and micro-finance institutes (MFIs), mobile network operators, seed companies, government agencies, research institutions, insurance and reinsurance companies, and global donors like the Global Index Insurance Fund "GIIF" (Greatrex et al., 2015). The agricultural sector involves several actors in different links of the chain, and more synergy among these actors would make the IBI scaling-up easy and fast.

Fourthly and finally, the Social Protection Support Fund together with other safety-net programs currently being implemented in Burundi (e.g. the Merankabandi program World Bank program) is a complementing option to foster adoption and scaling-up of an IBI. Case studies from Ethiopia showed the attractiveness of linking an IBI with productive safety-net programs (food-for-work or cash-for-work) (Tadesse et al. (2015)). Thus, the Merankabandi program in Burundi could help cash-constrained smallholder farmers for risk premium payments. In the literature we also find that the social protection approach (particularly the safety-net programs) is a response to the cash constraints of the poor to invest in risk management and could contribute to enhancing wider uptake if the $|\mathrm{B}|$ is appropriate (Tadesse et.al, 2015).

Hence, although the IBI is a mechanism with great potential for farmers, particularly in developing countries, its scaling-up faces a number of barriers that are currently being researched by scientists. Many different mechanisms for scaling-up the IBI have been piloted without being able to achieve a generalized model. These evidences reveal that it is difficult to come to a global or generic mechanism to scale-up the IBI, because farmers' needs and preferences are quite different and the willingness of policy makers to promote the IBI is sometimes lacking in developing countries and particularly in Burundi. Therefore, in order to enhance the adoption of an IBI, insurance programs should take into account the level of risk exposure of the community, as well as the needs and capacities of farmers. This requires the involvement of different key actors in rural development, particularly financial and social welfare institutions. 


\section{Relationship between IBI adoption and SLM investments}

Highlighting the relationship between IBI adoption and SLM practices is crucial in the context of agriculture and climate change. Many studies have been conducted on either the adoption of insurances or the implementation of SLM practices in developing economies, but research focusing on the relationship between the IBI adoption and the implementation of SLM practices for the promotion of sustainable and more resilient agriculture is rare. Some of them, particularly those in the Horn of Africa and other parts of sub-Saharan Africa, highlight that there is an interlinkage between IBI adoption and implementing improved agricultural technologies (Carter, 2009), but without clarifying which agricultural technologies are adopted and to which extent. This leads to the question: is there a causality (or even reverse causality) effect between IBI adoption and SLM investments? Findings from our study indicate that IBI adoption increases investments in sustainable agriculture, particularly in chemical fertilizer, land and crop management practices (Chapter 5). Based on these results, we might conclude that there is reason to belief of a causality effect between the IBI adoption and SLM investments. However, there might also be a reverse causality, i.e. that farmers who already invest more in SLM are more eager to adopt the IBI. This is what we find in Chapter 4, where farmers with more knowledge on land and crop management are more likely to adopt the IBI. In addition, farmers who already run their farm with a PIP (i.e. who have a vision and a plan for their farm and invest in SLM) are more receptive to the innovative tools that reduce risk exposure, in this case the IBI program.

When reflecting on these results and on our research method, we know that the selection of early IBI adopters for this study was made on specific criteria, including being a PIP-farme with (in most cases) already existing land and crop management practices on their farm (i.e. farmers who manage their farm based on the trainings received from the PIP approach). The fact that this selection of IBI adopters was thus biased and covering farmers having already SLM practices implemented on their farm, makes that the reverse causality effect between IBI and SLM cannot be concluded with evidence. Therefore, the analysis of reverse causal effect needs further studies that take into account the heterogeneity of farmers, i.e. by including those who have not run their farms with the PIP approach, using randomised control trials.

Nevertheless, and regardless the direction of causality between IBI adoption and SLM investments, this study suggests that it is essential to explore a strategy for sustainable agriculture that strengthens the insurance mechanism for smallholder farmers while simultaneously promoting SLM practices. Our results show that farmers are very well capable of implementing SLM practices and managing an IBI at the same time, which could be substantial win-win opportunity to foster sustainable agriculture and enhance food security in Burundi. Decision-makers and extension services should therefore capitalize on the results of this pilot insurance study and start formulating with all other key stakeholders at institutional level an "insurance policy document" for rural Burundi.

\section{Group and peer learning methods in the adoption and scaling-up of the IBI and SLM practices.}

Group and peer-learning (i.e. farmer-to-farmer) methods are key elements that produced significant effects on the improvement of the knowledge level of learners. Our study finds that group learning stimulated also the use of improved farming techniques, particularly land and crop management. Recent studies also show that facilitated group learning (i.e. small group seminars) proved to be a more sustainable method in creating attitude and behaviour change in land management and therefore more sustainable development in the rural community (Murphy, 2012)

Peer learning should be mutually beneficial and involve the sharing of knowledge, ideas and experience between the participants (Boud, 2001). Although the peer-learning methods are more informal compared to the group learning ones, they have proven to be effective particularly in the scaling-up of the PIP approach which aims at transforming small-scale subsistence farm households into more productive and sustainable farms, based on sound natural resource management. As with the scaling-up of the PIP approach, this study highlighted the important role of both (facilitated) group learning and peer learning methods in disseminating an innovation like the IBI, and in promoting farm techniques such as land and crop management at the community level.

The introduction of the IBI at the community level was also carried out through the group learning methods with support from experts because farmers lacked required skills to better explain how IBI works. Hence, strengthening the capacity of farmers on the IBI functioning through the peer-learning extension methods would stimulate the IBI adoption and scalingup. Thus, learning is at the core of SLM and IBI adoption because when farmers are motivated to learn, then the adoption is more sustainable and will last.

Findings of this research indicated that the group learning as well as the peer-learning approaches allowed learners to better understand the practices as well as the best way to implement them, and that they stimulate the use of improved farming techniques. The joint implementation and scaling-up of IBI and SLM practices promises a better future for farmers, especially when accompanied by bottom-up learning approaches, and could promote sustainable agriculture. However, it also requires the presence of strong and creative decision-makers, who, unfortunately are still lacking in many developing countries. 


\subsection{Policy implications}

This section deals with policy implications resulting from the results of this study. The empirical results from Chapter 2 highlight motivational, economic, and personal factors that influence SLM investments. Most farmers in the study area are aware of soil degradation and are adapting their farming practices accordingly. These actions to cope with the adverse effects of land degradation require expenditures that, in most cases, are difficult to bear by the farmers' modest incomes. The results indicate that only about half of the farmers applied strategies combining water and soil management practices, organic and inorganic fertilizers. Facing the current rate of soil erosion in Burundi, it is however crucial that farmers intensify these integrated practices to make soils more productive and resilient. Although many farmers in our study areas are now trained in the principles of the PIP approach and understand the importance of integrated farm management, many others still don't have a functional PIP for their farm. It would be essential that farmers who already have a solid experience in creating a PIP for their farm are supported to organize capacity building sessions for those who are lagging behind, as this approach is the driving force for sustainable development and considers the vision of all members of the household. Furthermore, government and extension services should focus much more on raising awareness concerning environmental degradation, and on applying SLM practices specific to each region, taking into account the level of degradation. The Government of Burundi could capitalize on the results of the PIP approach by integrating its principles into its national reforestation and community works programmes.

However, this thesis makes clear that only the implementation of SLM practices may not be sufficient to address all risks associated with agriculture. Certain risks, which are less frequent but have more severe effects, such as long periods with rainfall deficits, pests and diseases affecting crop production, or hail and excessive rainfall, require the availability of insurance mechanisms for vulnerable smallholder farmers. Given that we found that most farmers undertake adaptation strategies after the event has taken place (ex-post measures such as selling assets or reducing household expenditures), we recommend the government to provide farmers better access to information on climate variability, and train farmers in order to encourage adoption of climate smart adaptation strategies and a crop insurance such as an IBI. The results from Chapter 4 indicate that the VSLAs, although dedicated to savings and credits among its members, once well organized, can increase the IBI adoption level. Given that savings for upcoming risk premium payments increase the IBI adoption, VSLA leaders should always set aside the share reserved for the insurance as stipulated in their legal constitution. Saving for insurance (for upcoming premium payments) by VSLAs is an innovative strategy of VSLAs in the study area. The Government of Burundi and stakeholders in the rural development sector should scale-up this innovation as it has been found that VSLAs can play the leading insurance role in areas where insurance companies are absent

Moreover, as the crop insurance programme is already part of Burundi's national socia protection policy, the Government of Burundi should strengthen its system of adaptation to climate variability through the effective implementation of this insurance programme. The government and its decentralized bodies should draw on the lessons learned from the pilot study on IBI carried out as part of this research. Based on these lessons, the policy makers should develop a policy paper on the IBI adoption and scaling-up with particular emphasis on the mutual approach as undertaken by farmers.

While analysing the links between IBI adoption and investing in SLM, we found that IBI adopters (even some non-adopters) better apply and integrate SLM practices in their farming activities due to the combination of group and peer-learning (farmer-to-farmer learning) methods. The findings from Kenya (Kiptot \& Franzel, 2015) also indicate that a farmer-tofarmer learning approach is the most effective extension method to trigger adoption and to facilitate the promotion of climate smart agriculture. To get tangible results from this learning approach, extension workers and experts should elaborate an extension model to support farmer-to farmer learning.

\subsection{Research contribution to science and society}

The results of this research provide several new insights that are of interest to the scientific world. This study brought a significant contribution to the existing literature in highlighting the process of implementing a new type of crop insurance which is less known than the traditional insurance systems: a crop insurance managed by farmers themselves (i.e., mutual approach). Agricultural insurance is a subject that is becoming more and more prevalent in some developing countries. The main idea of this study, which is the adoption of IBI under limited liability, is still missing from previous studies. This study brings this to the attention of the scientific world and the public in general, by highlighting the key determinants of the insurance adoption and its effect on agricultural investments.

Secondly, this research clearly shows the relationship between the VSLAs and IBI adoption and the extent to which VSLAs stimulate the adoption of an insurance. As we found in Chapter 4, VSLAs' trainings, the effective participation of VSLA members in organized meetings and the VSLAs' savings for upcoming risk premium payments are key drivers for the adoption of IBI. Furthermore, the empirical findings from Chapter 3 provide further 
insights into the farmers' decision-making process to implement SLM practices. This study provides innovative ideas to science since it is one of the few (if not the first) studies that shows the essential contribution of a VSLA in the adoption of IBI under limited liability by the community.

This study also provides an important contribution to society in promoting that SLM and an $|B|$ program are implemented jointly. The relationship between the IBI adoption and SLM practices are drivers in promoting and scaling-up sustainable and resilient agriculture. The fundamental question is to find the appropriate method, meeting the needs of the community, to disseminate these two programs in the community. Kaminski (2011) defined this method as the theory of diffusion of innovation based on community competences. The diffusion of innovations is a theory that seeks to explain how, why, and at what rate new ideas spread (Rogers,1962). This study points out the combination of group and peerlearning (farmer-to-farmer) methods as the keys of disseminating an innovation in the community and as result, an effective approach to scaling-up both IBI and SLM practices since it promotes the skills and knowledge of the farmers themselves. In addition, the diffusion of innovation theory is often regarded as a valuable change model for guiding technological innovation where the innovation itself is presented in ways that meet the needs across all levels of adopters (Kaminski, 2011). In this sense, the PIP approach can serve as a model in the extension of innovations, as knowledge and skills can be transferred and extended to the community level from ideas developed at the household level.

\subsection{Limitations of the study and recommendations for future} research

During this study, we were confronted with several limitations. First, the sample size was small for both the area covered (two provinces out of 18 Burundi provinces) and the population surveyed, and this may reduce the representativeness of the results and therefore may not be extrapolated to a large population. In addition, it followed an observational approach and not an experimental approach by means of a randomized control trial to reduce bias and provide a rigorous tool to examine cause-effect relationships between an intervention and its outcome.

Second, the first phase of data collection coincided with a political crisis in Burundi. This made the selection of farmers to be surveyed a rather difficult task because those who had been selected beforehand were sometimes replaced by those available because the former were exiled to neighbouring countries.
Third, the considered period for the evaluation of IBI effects on agricultural investments may limit the robustness of the results of this study. It is the first time that an IBI was introduced in Burundi. This means that the analysis of its level of adoption (Chapter 4) and its potentia effects on agricultural investments (Chapter 5) after only four agricultural seasons is only a first analysis and the findings could only be considered as preliminary results.

Therefore, the following recommendations are suggested for further research:

1. Investigate in-depth the causality and potential reverse causality between IBI adoption and SLM investments. This information is crucial to better understand whether the IB adoption was useful to trigger SLM investments or whether farmers with well-managed land were motivated to adopt crop insurance.

2. Develop a good and well-adapted IBI program that meets the real context of Burundian agriculture and the needs of farmers by involving all relevant actors. The scope of this IBI should be inspired on the lessons learnt from this study.

3. Investigate better crop risk management strategies to adapt to long-term climate variability. This could help policy makers to make better planning in terms of climate change adaptation.

4. Evaluate the long-term effects of the group and peer-learning approaches on $|B|$ adoption and scaling-up. This is important for agricultural extension services to better understand the category of groups to work with for sustainable impacts.

5. Determine the drivers of farmers' intrinsic motivation, particularly factors that drive individual farmers to implement SLM technologies integrated into the farming system.

\subsection{Overall conclusions}

This thesis provided detailed insights on the factors influencing SLM investments in Burundi. At the second stage, the thesis investigated the households' coping strategies to deal with risk associated to farming. Finally, the thesis analyzed the effect of VSLAs on the adoption of an IBI under limited liability and the link between the IBI adoption and agricultural investments. Based on the findings of this study, we can draw the following conclusions.

1. Burundian agriculture faces enormous risks related to climate change, and since farmers do not have sufficient means to implement appropriate adaptation strategies, they are forced to resort to survival strategies. For those risks that farmers cannot respond to effectively, a crop insurance (i.e., IBI) corresponding to the needs and wishes of farmers 
is a promising option. The government should participate by subsidizing risk premiums for low-income farmers.

2. In addition to their main role as a source of savings and credit for members, VSLAs were found to be essential community structures in stimulating the IBI adoption. Recognizing this undeniable role in IBI adoption, extension workers and partners working with VSLAs within their interventions should strengthen VSLAs in their functioning system.

3. Despite their low level of knowledge about how an insurance works, farmers in the study area were able to manage the IBI program themselves. It is therefore necessary that the Government of Burundi through its decentralized entities and experts supports this innovative spirit of $|\mathrm{B}|$ adopters by building the capacity of farmers on the IB functioning, and by actively supporting the further scaling-up of IBI in Burundi.

4. Facilitated group and peer learning methods are effective community-friendly approaches to disseminating an innovation. It is therefore essential that these approaches are well developed and used by decision-makers for the IBI adoption and scaling-up.

5. The $|\mathrm{B}|$ adoption has a positive effect on agricultural investments, but it remains essential that policy makers think about other actions in addition to the IBI to encourage farmers to invest in sustainable and integrated land management for a more resilient and productive agriculture.

6. Both monetary and non-monetary expenditures incurred in the implementation and maintenance of certain SLM practices remain major challenges faced by farmers in the study area. Decision-makers should therefore improve access to credit markets in rural areas to motivate farmers to increase investments in SLM practices on their farm to deal with land degradation problems and food insecurity. 


\section{Literature cited}

Adimassu, Z., \& Kessler, A. (2012). Farmers' investments in land management practices in the CRV of Ethiopia. Paper presented at the The 8th International Symposium Agro Environ 2012, Wageningen, 2012-05-01/2012-05-04, Wageningen University and Research.

Adimassu, Z., Kessler, A., Yirga, C., \& Stroosnijder, L. (2013). Farmers' perceptions of land degradation and their investments in land management: a case study in the Central Rift Valley of Ethiopia. Environmental Management, 51(5), 989-998. doi: 10.1007/s00267-013-0030-z.

Aditya, K. S., Khan, M. T. \& Avinash, K. (2018). Adoption of crop insurance and impact: Insights from India. Agricultural Economics Research Review, 31(2), 163-174. doi:10.5958/0974-0279.2018.00034.4.

Aidoo, R., Mensah, J. O., Wie, P., \& Awunyo-vitor, D. (2014). Prospects of crop insurance as a risk management tool among arable crop farmers in Ghana. Asian Economic and Financial Review Economic and Financial Review, 4(3), 341-354.

Alcamo, J., Moreno, J. M., Nováky, B., Bindi, M., Corobov, R., Devoy, R. J. N., Shvidenko, A. (2007). Impacts, Adaptation and Vulnerability. Contribution of Working Group II to the Fourth Assessment Report of the Intergovernmental Panel on Climate Change, Cambridge. Cambriddge University Press, 541-580.

Alufah, S., Shisanya, C. A., \& Obando, J. A. (2012). Analysis of factors influencing adoption of soil and water conservation technologies in Ngaciuma sub-catchment, Kenya. African Journal of Basic \& Applied Sciences, 4 (5): 172-185. doi: 10.5829/idosi. ajbas.2012.4.5.1112.

Amjed, I., M., Usman Zafar, M., Abbas, A., Khalid Bashir, M., Ali, A., \& Kousar, R. (2018). Farm risk sources and their mitigations: A case of cotton growers in Punjab. Pakistan Journal Agricultural Sciences. doi: 10.21162/PAKJAS/18.7070

Arezes, P. M., \& Miguel, A. S. (2008). Risk perception and safety behaviour: A study in an occupational environment. Safety Science, 46(6), 900-907. doi: 10.1016/j. ssci.2007.11.008.

Asravor, R. (2018). Smallholder farmers' risk perceptions and risk management responses: Evidence from the semi-arid region of Ghana. African Journal of Economic and Management Studies, 9 (3), 367-387.doi: https://doi.org/10.1108/ AJEMS-10-2017-0250.

Bahizi, O. (2011). L'agriculture et Indicateurs Economiques du Burundi, Burundi. Retrieved November 23, 2016, from http://www.eac.bi.

Baumont-Keita, C., Linzatti, R., Ferreras, E., Kromer, J., Murara, J., Hassane, M., Kinane, M. (2011). Burundi: Document de Strategie Pays 2012-2016. Retrieved from https:// www.afdb.org/fileadmin. 
Bayaga, A. (2012). Multinomial logistic regression: Usage and application in risk analysis. Journal of Applied Quantitative Methods, 5 (2), 288-297. 10p. 6 Charts.

Beckie, H. J., Smyth, S. J., Owen, M. D. K., \& Gleim, S. (2019). Rewarding best pest management practices via reduced crop insurance premiums. International Journal of Agronomy, 2019. https://doi.org/10.1155/2019/9390501.

Belissa, T.K., Lensink, R. \& Asseldonk, M. van (2019). Risk and ambiguity aversion behavior in index- based insurance uptake decisions: Experimental evidence from Ethiopia, Journal of Economic Behavior and Organization, doi:10.1016/j. jebo.2019.07.018.

Bewket, W., \& Sterk, G. (2002). Farmers' participation in soil and water conservation activities in the Chemoga watershed, Blue Nile basin, Ethiopia. Land Degradation \& Development, 13(3), 189-200. doi: https://doi.org/10.1002/ldr.492.

Binswanger-Mkhize, H. P. (2012). Is there too much hype about index-based agricultural insurance? Journal of Development Studies, 48(2), 187-200. https://doi.org/10.1 080/00220388.2011.625411.

Biswas, A. A. A., Hasan, M. M., Rahman, M. S., Sattar, M. A., Hossain, M. A., \& Faisal, M. (2015). Disaster risk identification in agriculture sector: Farmers' perceptions and mitigation practices in Faridpur. American Journal of Rural Development, 3(3), 60 73.

Bizoza, A. R. (2014). Three-stage analysis of the adoption of soil and water conservation in the highlands of Rwanda. Land Degradation \& Development, 25(4), 360-372. doi https://doi.org/10.1002/ldr.2145.

Bobojonov, I., \& Sommer, R. (2011). Alternative insurance indexes for drought risk in developing countries. Paper prepared for presentation at the EAAE 2011 Congress ETH Zurich. Zurich-Switzerland.

Boud, D. (2001). Making the move to peer learning. In Boud, D., Cohen, R., \& Sampson, J. (Eds) (2001). Peer Learning in High Education. Learning from and with each other. London: Kongan Page (now Routledge), 1-20.

Carter, R.M., Cheng, L., \& Sarris, A. (2015). Where and how index insurance can boost the adoption of improved agricultural technologies. Journal of Development Economics 118 (2016) 59-71.

Carter, M., De Janvry, A., Sadoulet, E., \& Sarris, A. (2014). Index-based weather insurance for developing countries: A review of evidence and a set of propositions for upscaling. Development policy, Ferdi working paper, (5), 1-33.

Chaminda, S. H. (2010). Motivation as a potential variable to explain farmers' behavioral change in agricultural technology adoption decisions. Economics and Management, 13(3), 62-70.

Chang, H. H., \& Mishra, A. K. (2012). Chemical usage in production agriculture: Do crop insurance and off-farm work play a part? Journal of Environmental Management, 105, 76-82. https://doi.org/https://doi.org/10.1016/j.jenvman.2012.03.038.
Cholo, T. C. (2018). Land fragmentation and sustainable land management as climate change adaptation strategy in Ethiopia. PhD thesis, Wageningen University, Wageningen, the Netherlands, ISBN: 978-94-6343-323-5, 134. doi:https://doi. org/10.18174/456352

Choudhary, V., P. D’Alessandro, S., Giertz, Å., Suit, K. C., Johnson, T. J., Baedeker, T., \& Caballero, R. J. (2016). Agricultural sector risk assessment : methodological guidance for practitioners (English). Agriculture global practice discussion paper World Bank Group (2016/01/01 ed., Vol. no. 10, pp. 130). Washington, D.C.

Churchill, C. (2008). Protecting the poor: a microinsurance compendium. Internationa Labour Organisation. https://doi.org/10.3362/1755-1986.2008.008.

Claassen, R., Langpap, C., \& Wu, J. (2017). Impacts of federal crop insurance on land use and environmental quality. American Journal of Agricultural Economics, 99(3), 592-613. https://doi.org/10.1093/ajae/aaw075.

Cole, S., Bastian, G., Vyas, S., Wendel, C. \& Stein, D. (2012). The effectiveness of microinsurance in helping small-holders manage weather-related risks. Retrieved from http://eppi.ioe.ac.uk.

Conning, J. \& Udry, C. (2005). Rural Financial Markets in Developing Countries. The Handbook of Agricultural Economics, 3, 1-86.

Coulibaly, J. Y., Gbetibouo, G., A., Kundhlande, G., Sileshi, G., W., \& Beedy, T., L. (2015). Responding to Crop Failure: Understanding farmers' coping strategies in Southern Malawi. Sustainability, 7, 1620-1636. doi: 10.3390/su7021620.

Dercon, S., Hill,R. V., Clarke, D., Outes-Leon, I. \& Taffesse, A.S. (2013). Offering rainfal insurance to informal insurance groups: Evidence from a field experiment in Ethiopia. Journal of Development Economics 106 (C): 132-143 doi: 10.1016/j. jdeveco.2013.09.006

Dick, W. J. A. \& Wang, W. (2010). Government interventions in agricultural insurance. Agriculture and Agricultural Science Procedia, 1, 4-12. doi: 10.1016/j. aaspro.2010.09.002.

Faham, E., Hosseini, S. M., \& Darvish, A. K. (2008). Analysis of factors influencing rura people's participation in national action plan for sustainable management of land and water resources in Hable-Rud Basin, Iran. American Journal of Agricultural and Biological Sciences, 3(2), 457-461.

Falco, S. Di, Adinolfi, F., Bozzola, M. \& Capitanio, F. (2014). Crop Insurance as a strategy for adapting to climate change. Journal of Agricultural Economics 65(2), 485-504. doi: 10.1111/1477-9552.12053

Fisher, E., Hellin, J., Greatrex, H. \& Jensen, N. (2019). Index insurance and climate risk management: Addressing social equity. Dev Policy Rev 37, 581-602. doi: 10.1111/ dpr.12387. 
Flaten, O., Lien, G., Koesling, M., Valle, P. S., \& Ebbesvik, M. (2005). Comparing risk perceptions and risk management in organic and conventional dairy farming: empirical results from Norway. Livestock Production Science, 95(1-2), 11-25. doi: http://dx.doi.org/10.1016/j.livprodsci.2004.10.014.

Greatrex, H., Hansen, J., Garvin, S., Diro, R., Le Guen, M., Sari, B., Osgood, D. (2015). Scalingup index insurance for smallholder farmers. CCAFS Report, 14(14), 1-32.

Giertz, A., Mudahar Mohinder, S., Gray, G., Rubaiza, R., Garpelin, D., \& Suit, K. (2015). Rwanda agricultural sector risk assessment. World Bank, NY.

Giger, M., Liniger, H., Sauter, C., \& Schwilch, G. (2015). Economic benefits and costs of sustainable land management technologies: An analysis of WOCAT's global data. Land Degradation\& Development, 29(4), 962-974. doi: https://doi.org/10.1002/ Idr.2429

Gujarati, D. N. (2005). Basic econometrics. 3rd Edition. McGraw Hill Campanies, Inc., New York.

Harrington, S. E. \& Niehaus, G., R. (1999). Risk management and insurance. Library of Congress Cataloging-in-Publication Data. ISBN 0-256-21018-7.

Hazell, P., Anderson, J., Balzer, N., Clemmensen, A. H., Hess, U., \& Rispolli, F. (2010). The potential for scale and sustainability in weather index insurance for agricultural and rural livelihoods. IFAD and WFP, Rome, 153pp.

Heltberg, R., \& Siegel, P. (2008). Climate Change: Challenges for Social Protection in Africa. Paper for conference on social protection for the poorest in Africa. Washington DC: World Bank.

Herbold, J (2011). Climate change and agriculture insurance: Industry vulnerability and implications for scaling up innovations. The (re)insurer's perspective. FARM annual conference (p. 29). Zurich: Munich RE.

Heyi Damena, D., \& Mberengwa, I. (2012). Determinants of farmers' land management practices: The case of Tole District, South West Shewa Zone, Oromia Regiona State, Ethiopia. Journal of Sustainable Development in Africa, 14(1), 1520-5509.

Hosmer, D., \& Lemeshew, S. (2000). Applied Logistic Regression 2nd Ed. A Wiley-Inter Science Publication. New York.

Jensen, D. N. \& Barret, B. C. (2016). Agricultural index insurance for development. Applied Economic Perspectives and Policy 39(2). doi:10.1093/aepp/ppw022.

Jensen, D. N., Mude, A. G., \& Barrett, B. C. (2018). How basis risk and spatiotempora adverse selection influence demand for index insurance: Evidence from northern Kenya. Food Policy, 74, 172-198. https://doi.org/https://doi.org/10.1016/j. foodpol.2018.01.002

Jin, J., Wang, W. \& Wang, X. (2016). Farmers' risk preferences and agricultural weather index insurance uptake in Rural China. International Journal of Disaster Risk Science7(4), 366-373. doi: 10.1007/s13753-016-0108-3.
Kahan, D. (2013). Managing risk in farming. FAO (Ed.) Retrieved from http://www.fao.org/ uploads/media/3-ManagingRiskInternLores.pdf.

Karlan, D., Savonitto, B., Thuysbaert, B. \& Udry, C. (2017). Impact of savings groups on the lives of the poor. Proceedings of the National Academy of Sciences 114(12), 30793084. doi:10.1073/pnas.1611520114.

Kessler, A., Duivenbooden van, N., Nsabimana, F. \& Beek van, L. C. (2016). Bringing ISFM to scale through an integrated farm planning approach: a case study from Burundi. Nutr Cycl Agroecosyst 105(3), 249-261. doi: 10.1007/s10705-015-9708-3.

Khanam, R., Bhaduri, D., \& Nayak, A. K. (2018). Crop diversification: an important way-out for doubling farmers' income. Indian Farming, 68(01), 31-32. Retrieved from https://icar.org.in/sites/default/files/Crop diversification.pdf.

Kifle, S., Teferi, B., Kebedom, A., \& Legesse, A. (2016). Factors influencing farmers decision in the use of introduced soil and water conservation practices in the lowland's of Wenago Woredo, Gedeo zone, Ethiopia. American Journal of Rural Developement 4(1), 24-30. doi: 10.12691/ajrd-4-1-4.

Kirui, O. (2017). Drivers of Sustainable land Management in Eastern Africa. Preprints, 2017050007. doi: 10.20944/preprints201705.0007.v1

Kotir, J. H. (2011). Climate change and variability in Sub-Saharan Africa: A review of current and future trends and impacts on agriculture and food security. Environment Development and Sustainability, 13(3), 587-605. doi:10.1007/s10668-010-9278-

Kouamé, E., B,H. (2012). Risk, risk aversion and choice of risk management strategies by cocoa farmers in western cote d'ivoire. 20, 35. Retrieved from: http://www.csae. ox.ac.uk/ conferences/2010-EDiA/papers/267-Kouame.pdf.

Levin, T. \& Reinhard, D. (2007). Microinsurance aspects in agriculture. Munich Re Foundation, 41. Available at: https://www.findevgateway.org/library/microinsurance-aspectsagriculture.

Maertens, A., Chari, A. V., \& Just, D. R. (2014). Why farmers sometimes love risks: Evidence from India. Economic Development and Cultural Change, 62(2), 239-274. doi: $10.1086 / 674028$

Mahul, O., \& Pennings, M. E. (2004). Introduction to the Special Issue on Risk Behavior of Market Participants. European Review of Agricultural Economics, Vol 31 (3) pp. 233-234.

Mahul, O. \& Stutley, J. C. (2010). Government Support to Agricultural Insurance-Challenges and Options for Developing Countries. World Bank, NY. doi: 10.1596/978-0-82138217-2.

McMurran, M. (2002). Motivation to change: Selection criterion or treatment need? In M.McMurran (Ed.), Motivating offenders to change: A Guide to Enhancing Engagement in Therapy (pp. 3-13). Chichester, UK: Wiley. https://doi. org/10.1002/9780470713471.ch1. 
Meijer, S. S., Catacutan, D., Ajayi, O. C., Sileshi, G. W., \& Nieuwenhuis, M. (2015). The role of knowledge, attitudes and perceptions in the uptake of agricultura and agroforestry innovations among smallholder farmers in sub-Saharan Africa. International Journal of Agricultural Sustainability, 13(1), 40-54. doi: 10.1080/14735903.2014.912493.

Mertz, O., Mbow, C., Reenberg, A., \& Diouf, A. (2009). Farmers' perceptions of climate change and agricultural adaptation strategies in Rural Sahel. Environmental Management, 43, 804-816.

MFPDE. (2006a). Monographie de la Province Gitega, Gitega.

MFPDE. (2006b). Monographie de la Province Muyinga, Muyinga.

MINAGRIE. (2012). Plan National d'Investissement Agricole (PNIA). Bujumbura, Burundi.

Mupfasoni, B., Nkurunziza, D., Akintore, A., Matovu, F., \& Birungi, P. (2013). Social Protection and the Vulnerable Communities in East Africa: Implications for Household Welfare in Burundi. International Development and Research Centre.

Murphy, J. (2012). The contribution of facilitated group learning to supporting innovation amongst farmers. Studies in Agricultural Economics, 114(2), 93-98. https://doi. org/10.7896/j.1106.

Ndagijimana, M., Asseldonk, M. A. P. M. van., Kessler, C. A., Habonimana, O. \& Houtekamervan Dam, A. (2017). Facing climate change in burundi with an integrated agricultural and health insurance approach. In The state of microinsurance Microinsurance Network, Microinsurance Network's Annual Journal 3 (pp. 32-37).

Ngombe, J., Kalinda, T., Tembo, G., \& Kuntashula, E. (2014). Econometric analysis of te factor that affect adoption of coservation farming practices by smallholder farmers in Zambia. Journal of Sustainable Development,7(4), 124-138. https:// doi.org/10.5539/jsd.v7n4p124.

Niragira, S. (2016). Understanding smallholder farming systems for food security in Burundi. Doctoral dissertation, Ghent University, Belgium.

Niragira, S., D’Haese, M., D’Haese, L., Ndimubandi, J., Desiere, S., \& Buysse, J. (2015). Food for Survival: Diagnosing crop patterns to secure lower threshold food security levels in farm household of Burundi. Food and Nutrition Bulletin, 36(2) 196-210. doi: 10.1177/03795721 15587491.

Ntukamazina, N., Onwonga, N. R., Somer, R., Rubyogo, J. C., Mukankusi, M. C., Mburu, J. \& Kariuki, R. (2019).Index-based agricultural insurance products: challengies, opportunities, and prospects for uptake in sub-SaharaAfrica. Journal of Agricultural and Rural Development in Tropics and Subtropics 118 (2): 171-185.

Nyanga, A., Kessler, A., \& Tenge, A. (2016). Key socio-economic factors influencing sustainable land management investments in the West Usambara Highlands, Tanzania. Land Use Policy, 51, 260-266. https://doi.org/10.1016/j.landusepol.2015.11.020.
Paridaens, A.-M., Belotti, L., Régi, S., Mahwane, J., \& Zoem, J.-P. (2012). Analyse des données secondaire de la sécurité animentaire, vulnérabilité et nutrition au Burundi. Burundi. Retrieved from https://documents.wfp.org/stellent/groups/public/ documents/wfp253438.pdf.

Prokopy, L. S., Floress, K., Arbuckle, J. G., Church, S. P., Eanes, F. R., Gao, Y., Singh, A. S. (2019) Adoption of agricultural conservation practices in the United States: Evidence from 35 years of quantitative literature. Journal of Soil and Water Conservation 74(5), 520-534. https://doi.org/10.2489/jswc.74.5.520.

Rogers, E. M. (1962). Diffusion of innovations (1st ed.). New York: Free Press of Glencoe.

Roth, J. \& McCord, M. J. (2008). Microinsurance-Global Practices and Prospects (R. Berold, ed.). The Microlnsurance Center, LIC; 1045N. Lynndale Drive, Ste; Appleton, W 54914 USA.

Sabatini, F. (2017). Renewing local planning to face climate change in the tropics. Green Energy and Technology, 21-40. https://doi.org/10.1007/978-3-319-59096-7.

Saguye, T. S. (2017). Analysis of farmers' perception on the impact of land degradation hazard on agricultural land productivity in Jeldu district in West Shewa Zone, Oromia, Ethiopia. Journal of Agricultural Extension and Rural Development, 9(6), pp. 111-123,. doi: 10.5897/JAERD2017.0854.

Schroeder, L. A., Isselstein, J., Chaplin, S. \& Pell, S. (2013). Agri-environment schemes: Smallholders' acceptance and perception of potential 'Payment by Results' in grassland A case study in England. Land Use Policy, 32, 134-144. doi: 10.1016/j. landusepol.2012.10.009.

Shahidur, K. R., Samad, H. A., \& Koolwal, A. (2010). Handbook on impact evaluation: Quantitatives methods and prctices. In Learning (Vol. 1). Retrieved from http:// documents.worldbank.org/curated/en.pdf.

Sibiko, K. W., Veettil, P. C., \& Qaim, M. (2018). Small farmers' preferences for weather index insurance: Insights from Kenya. Agriculture and Food Security, 7 (1), 1-14. https:// doi.org/10.1186/s40066-018-0200-6.

Slovic, P., Fischhoff, B., \& Lichtenstein, S. (1982). Why Study Risk Perception? Risk Analysis 2 (2): 83-93. doi: https://doi.org/10.1111/j.1539-6924.1982.tb01369.x.

Smith, V. H., \& Goodwin, B. K. (2006). Crop insurance, moral hazard, and agricultural chemical use. American Journal of Agricultural Economics, 78(2), 428. https:// doi.org/10.2307/1243714.

Sinha, S., \& Tripathi, N. K. (2016). Assessing the challenges in successful implementation and adoption of crop insurance in Thailand. Sustainability (Switzerland), 8(12). https://doi.org/10.3390/su8121306.

Sulewski, P., \& Kloczko-Gajewska, A. (2014). Farmers' risk perception, risk aversion and strategies to cope with production risk: an empirical study from Poland. Studies in Agicultural Economics, 116 (2014) 140-147. 
Tadesse, M. A., Shiferaw, B. A., \& Erenstein, O. (2015). Weather index insurance for managing drought risk in smallholder agriculture: lessons and policy implications for subSaharan Africa. Agricultural and Food Economics, 3(1). https://doi.org/10.1186/ s40100-015-0044-3.

Takahashi, K., Ikegami, M., Sheahan, M., \& Barrett, C. B. (2016). Experimental evidence on the drivers of index-Based livestock insurance demand in Southern Ethiopia. World Development, 78, 324-340. https://doi.org/10.1016/j.worlddev.2015.10.039.

Tanui, J., Groeneveld, R., Klomp, J., Mowo, J., \& lerland Van, C. E. (2013). Explaining investents in sustainable land management: The role of various income source in the smallholder farming systems of western Kenya. Paper presented at the 2013 AAAE Fourth International Conference, September 22-25, 2013, Hammamet, Tunisia 161275, African Association of Agricultural Economists (AAAE), Hammamet, Tunisia. https://ideas.repec.org/p/ags/aaae13/161275.html.

Teshome, A., de Graaff, J., \& Kassie, M. (2016). Household-level determinants of soil and water conservation adoption phases: Evidence from North-Western Ethiopian Highlands. Environmental Management, 57(3), 620-636. https://doi.org/10.1007/ s00267-015-0635-5.

Teshome, A., Graaff, J. d., \& Ritsema, C. J. (2014). Influence of land related factors on sustainable land management in the Ethiopian Highlands. Paper presented at the EGU General Assembly 2014, held 27 April - 2 May, 2014, Vienna, Austria.

Tiwari, K. R., Sitaula, B. K., Nyborg, I. L., \& Paudel, G. (2008). Determinants of farmers' adoption of improved soil conservation technology in a middle mountain watershed of Central Nepal. Environmental Management, 42(2), 210-222. https://doi.org/10.1007/s00267-008-9137-z.

Traerup, S. L. M., \& Mertz, O. (2011). Rainfall variability and household coping strateties in northern Tanzania: A motivation for district level strategies. Reg. Environ. Chang. 11,471-481.

Turvey, C. G. \& Kong, R. (2010). Weather risk and the viability of the weather insurance in China's Gansu, Shaanxi, and Henan provinces. China Agricultural Economic review 2 (1) : 5-24.

Ullah, S., Israr, M., Ahmad, S., Ahmad, N., \& Yaseen, A. (2019). Farming household socioeconomic influences on land degradation in district Mardan of Pakistan. Sarhad Journal of Agriculture, 35(2), 449-458. doi:http://dx.doi.org/10.17582/journal. sja/2019/35.2.449.458.

Ullah, R., Shivakoti, G. P., \& Zulfiqar, F., lqbal, N. M., Shah,A. A. (2017). Disaster ris management in agriculture: tragedies of the smallholders. Nat Hazards 87, pp 1361-1375. doi: https://doi.org/10.1007/s11069-017-2821-7.

Wairiu, M. (2017). Land degradation and sustainable land management practices in Pacific Island Countries. Regional Environmental Change, 17(4), 1053-1064.
Wauters, E., Van Winsen, F., De Mey, Y., \& Lauwers, L. (2014). Risk perception, Attitudes towards risk and risk management: Evidence and implications. Agricultural Economics (Czech Republic), 60(9), 389-405.

World Bank. (2015). Achievements in ACP countries by Global Index Insurance Facility Phase 1 (2010-2015). Available at: http://docum ents.world bank.org/curat ed/en/48276 1490702615 329/Achievements-in-ACP-Count ries-by-Global-Index-Insur anceFacil ity-GIIF-Progr am-Phase-1-2010-2015.

www.weatherbase.com. (2015). Monthly-Weather Averages Summury. Retrieved August 30, 2016, from http://www.weatherbase.com./weather/name=Burundi.

Xu, Y., Gao, C., Li, X., Yang, T., Sun, X., Wang, C. \& Li, D. (2018). The design of a drought weather index insurance system for summer maize in Anhui Province, China. Journal of Risk Analysis and Crisis Response, 8 (1): 14-23.

Young-Peyton (2009). Innovation diffusion in heterogeneous populations: Contagion, socia influence, and social learning. American Economic Review, 99 (5): 1899-1924.

Zimmerman, J. F. \& Carter, R. M. (2003). Asset smoothing, consumption smoothing and the reproduction of inequality under risk and subsistence constraints. Journal of Development Economics 71 (2003) 233- 260. doi: 10.1016/S03043878(03)00028-2. 


\section{English summary}

A large part of the Burundian population lives in rural areas with nearly $90 \%$ of the population depending on agriculture for food and income. Land productivity has been declining over time due to the depletion of soil fertility and increasing soil erosion. Climatic hazards, mainly excessive rainfall, droughts, pests and diseases cause large losses in agricultural production that affect the living conditions of both producers and consumers. The main challenge is how to manage land more sustainably and enable farmers to cope with these risks that undermine their agricultural production, as such finding strategies that stimulate agricultural investments.

Facing this challenge, the objective of this thesis is to shed light on factors influencing investments in sustainable land management (SLM) and to what extent an index-based crop insurance (IBI) helps farmers to overcome risks associated to farming. To reach this objective, four research questions were formulated and the results are presented in six chapters.

The introductory chapter 1 sets the scene and delineates the problem statement. It briefly explains the land degradation problem in Burundi, potential SLM investments (i.e., practices) farmers can undertake, the risks related to farming, and conceptual aspects of crop insurance and an IBI in particular.

Chapter 2 examines the factors influencing the SLM investments using a multinomial logistic regression (MLR) model. The results indicate that farmers from the study area experience severe land degradation which is manifested by soil erosion and soil fertility depletion. The results of the MLR model show that the occurrence of soil erosion on the farm, access to credit, time spent by the household head in farming, and age of the household head, all increase investments of households in SLM. Hence, in order to enhance farmers' investments in SLM practices and more effectively cope with land degradation, this chapter suggests that decision makers should particularly focus on improving farmers' access to credit markets and on strengthening their management skills. This would not only enable farmers to buy necessary fertilizers, but credit is used also for hiring manpower to construct soil conservation practices such as trenches on the contour-lines and diversion ditches.

Chapter 3 analyses the risks associated with farming and households' coping strategies, using a path analysis model. On average, the most important risks experienced by farmers in the study area are drought and excessive rainfall, pests and diseases affecting crops, hail and input price fluctuations. The results of the risk perception index (RPI) indicate that droughts (0.59), flooding ( $\mathrm{RPI}=0.49)$, and pests and diseases affecting both crops ( $\mathrm{RPI}=0.50)$ and stored products $(\mathrm{RPI}=0.34)$ are perceived as most severe in the study area. In terms of households' 
coping strategies. The ex-post coping strategies are the dominant mechanisms in the study area. However, most of these coping strategies are survival mechanisms with limited mid and long-term effects, such as sale of assets (e.g., radio, television, phones, jewellery). Furthermore, about $5-15 \%$ of the households do nothing when facing risks associated with farming, while unfortunately the risks causing substantial losses are those that farmers are not able to deal with ex-ante. This chapter suggests that in order to support farmers to adapt to long-term climate variability it is crucial to provide them with information and train farmers on better risk management strategies.

Chapter 4 assesses the effect of the village savings and loan associations (VSLAs) on IB adoption under limited liabilities. It highlights the determinants of $\mid \mathrm{BI}$ adoption using difference-in-difference and multinomial logistic regression models. These determinants comprise variables related to VSLAs, variables related to both index insurance design and limited liabilities, as well as control variables. The results show that VSLAs are the key entrance financial structures in fostering IBI adoption and as a result members of VSLAs who save money collectively for premium payments and who regularly attend VSLA meetings were more likely to adopt crop insurance. In addition, VSLA members trained on both land and crop management and those running their farm with the integrated farm planning (PIP) approach are more open to IBI adoption. Trainings are considered as a crucial motivator in helping smallholders to improve their knowledge in terms of risk management including the use of crop insurance, and we find that farmers with higher education levels are more eager to adopt the IBI. However, the limited liability associated with the IBI as designed in this study slows down the level of adoption. This chapter suggests that given the unprecedented role of VSLAs in fostering IBI adoption, their mode of operation should be enhanced with a particular emphasis on collective savings for insurance payments.

Chapter 5 analyses the links between IBI adoption and agricultural investments, using a multivariate regression model. The analysis compares IBI adopters and non-adopters. The results indicate that adopters invest much more in chemical fertilizers and land and crop management practices than non-adopters. In addition, the average treatment effect for adopting an IBI amounts to US\$10.19 per season and per farmer for chemical fertilizers, and to US\$3.99 for land management. However, the results did not show differences between IB adopters and non-adopters concerning crop diversification and the use of organic fertilizers. These practices require either more substantial investments (for crop diversification) or require more labour (as is the case of organic fertilizers). This chapter suggests that - next to promoting IBI adoption - additional activities (such as enhancing farm inputs availability and improving access to credit for low-income farmers) are needed to further and more quickly transform Burundian agricultural towards sustainability.
Chapter 6 provides the synthesis of the thesis. This chapter discusses and summarizes the main findings and it highlights the limitations and research contribution to both science and society. It concludes that Burundian agricultural faces enormous risks related to climate change and that farmers have been resorting to survival mechanisms for a long time due to the lack of adequate strategies. The newly introduced IBI approach has enabled farmers to cope with risks that were previously out of farmers' control, although the adoption rat is relatively low, especially for those farmers with low incomes. The VSLAs were found to be essential community-based financial structures in stimulating the $|\mathrm{B}|$ adoption. Furthermore, VSLAs' members running their farm based on PIP are more likely to adopt a crop insurance. Through the facilitated group and peer learning methods, farmers in the study area were able to manage the IBI program themselves. Furthermore, expenditures incurred in the implementation and maintenance of certain SLM practices in dealing with land degradation remain major challenges faced by farmers in the study area. To support farmers' investments in more resilient and productive agriculture, this thesis suggests that VSLAs should be strengthened and supported, particularly with regard to saving collectively for premium payments, and by means of subsidized risk premiums for low-income farmers. Finally, access to credit markets by farmers in rural areas should be improved to motivate them to increase investments in SLM practices on their farm. 


\section{Acknowledgements}

This research was made possible thanks to the joint support of many people. Without their commitment, I would not have been able to achieve this remarkable work. It is therefore an opportunity to express my heartfelt gratitude to those who have stayed around me during this academic course. I would like to first thank my promotor Prof. Coen Ritsema for accepting me as a PhD student within the Soil Physics and Land Management (SLM) Group. I have no words to express my appreciation for his valuable support, suggestions, and his insightful comments that have shaped the thesis. This thesis would not have been possible without genuine support, patience and encouragement from my co-promoters Dr. Aad Kessler and Dr. Marcel van Asseldonk, from the very beginning to the completions of this thesis. Aad, I much appreciate your remarkable supervision and strategic guidance in the course of this research. Your excellent advice and friendly approach have been invaluable on both an academic and a personal level, for which I am extremely grateful, thank you so much! Marcel, I am really lucky to work with you in this research. I learnt from you a lot of tips in data analysis, and without them this work would not have had the quality that it has. I am also grateful to Dr. Jean Ndimubandi, my local supervisor, for his wise advice and the good scientific discussions which allowed me to successfully carry out this research.

I am thankful to NUFFIC for funding this research, and I would like to thank the entire staff and fellow students of the SLM Group of Wageneningen University for their assistance and discussions. Special thanks to Marnella van der Tol, Rianne Maasen, Anita Kok an Kees van der Klift for handling smoothly administrative and financial issues throughout my study.

My deepest gratitude goes to the farmers from Gitega and Muyinga particular those from the Communes of Bukirasazi, Makebuko, Butihinda, and Giteranyi for their genuine cooperation and precious time for replying to questionnaires and discussions. Meeting those farmers would have been difficult without the support from Oswald Habonimana, CEO of the Income Security Company (ISECOM) and Cleophace Musavyiwayezu, coordinator of the Micro-Finance and Insurance Cooperative (MAFICO).

I would like to express my profound gratitude to my wife Jeanine Ngendakumana and my daughters and son Ange Gabriella, Anaelle Kevine, and Eliel David Ndagijimana for their endurance during my stay away from home for a noble cause. My sincere thanks go to my mother Marie Banyanka, my brothers Stany Nirera, Dr. Marc Nzambimana, Ing. Etienne Bigirima, Ing. Albin Ndorimana, and my sisters Joconde Nikundana, Adelphine Mbonimpa for their prayers, love, encouragment and assistance throughout my life. To all of you, thank you for your priceless contributions. 


\section{About the author}

Marcien Ndagijimana was born in Kivumu-Mugamba, the province of Bururi in Burundi, on July $8^{\text {th }}, 1980$. He graduated at the University of Burundi with a bachelor degree in agricultural engineering in 2010 and served as research assistant at the Department of Rura Economics of the Faculty of Agronomy. In 2011, he started an inter-University program at the University of Liège and Catholic University of Louvain in Belgium under the grant of European Commission where he obtained an Advanced Master degree in Agricultural Economics with a specialisation in Rural Economics and Sociology on August $6^{\text {th }}, 2012$. From March 2013 to 2017, he was recruited by different universities to work as part-time lecturer. Parts of BSC courses taught include Rural Economics and Food Security and Sustainable Development, and supervised thesis for BSc students. A part of academic background, Marcien served as consultant for some United Nations Agencies (WFP and UNICEF).

In September 2014, he was awarded a PhD scholarship by NUFFIC and admitted at Wageningen University and Research within the Soil Physics and Land Management Group. From 2017 up to 2018, he implemented a pilot project on the potential of crop insurance in Burund under IFDC and WUR financing. His future research focus on climate change adaptation, food security, and rural entrepreneurship. He can be reached at ndagijimana1980@gmail. com or Mobile: +25779494487

\section{Scientific Publications}

Ndagijimana, M., Asseldonk van, M., Kessler, A., Ndimubandi, J. 2020. Effect of Villages Savings and Loan Associations on adoption of index-based crop insurance under limited liabilities. Journal of Agriculture and Rural Development in the Tropics and Subtropics. http://doi.org/10.17170/kobra-202002281031.

van Asseldonk, M. A. P. M., Ndagijimana, M., Kessler, C. A., Deering, K., Girvetz, E., Hella, J., Ruben, R. 2019. Community-based finance and Climate-Smart Agriculture. In The 5th Global Science Conference on Climate-Smart Agriculture 2019, 8-10 October 2019, Bali, Indonesia: Abstract Book (pp. 64-65). Australian Centre for International Agricultural Research (ACIAR).

Ndagijimana, M., Kessler, A., Asseldonk van, M. 2018. Understanding factors influencing farmers' investments in sustainable land management. A case study of Gitega and Muyinga. Land Degradation \& Development Journal, https://doi.org/10.1002/ Idr.3231.

Ndagijimana, M., Asseldonk van., M., Kessler, A., Habonimana, O., Houtekame-van Dam, A. 2017. Facing climate change in Burundi with an integrated agriculture and health insurance approach in Micro-insurance solutions to address climate change, www.microinsurancenetwork.org, ISBN: 978-2-9199453-1-3 [Page 32-37]. 
Ndagijimana, M., Kessler, A., Asseldonk van, M. 2020. Analysing risk experience, risk perception and coping strategies in Burundian agriculture. Natural Resource Forum, a United Nations Sustainable Development Journal (submitted)

Ndagijimana, M., Kessler, A., Asseldonk van, M., Ndimubandi, J. 2020. Analysing the links between index-based insurance adoption and agricultural investments in Burundi. International Journal of Agricultural Management (accepted)

Ndagijimana, M. 2015. Enjeux de la Privatisation de la filière café au Burundi, Editions Universitaires Européennes : ISBN-13: 978-3-8416-7482-1. 


\section{SENSE}

Netherlands Research School for the

Sciences of the Environment

\section{I P L O}

for specialised PhD training

The Netherlands research school for the Socio-Economic and Natural Sciences of the Environment (SENSE) declares that

\section{Marcien Ndagijimana}

born on 8 July 1980 in Kivumu- Mugamba, Burundi

has successfully fulfilled all requirements of the educational PhD programme of SENSE.

Wageningen, 1 February 2021

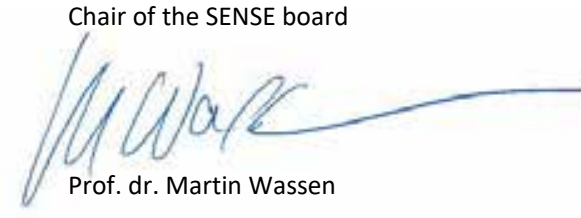

The SENSE Director

dr. Martin Wassen

Prof. Philipp Pattberg

The SENSE Research School has been accredited by the Royal Netherlands Academy of Arts and Sciences (KNAW)

KO N I N KL I I K E N E DERLA N D S H

A K A D E M I E V A N W E TEN S C H A P P E N

\section{SENSE}

The SENSE Research School declares that Marcien Ndagijimana has successfully fulfilled al requirements of the educational PhD programme of SENSE with a work load of $36.3 \mathrm{EC}$, including the following activities:
.

SENSE PhD Courses

Grasping sustainability (2014)

ext (2015)

Research in context activity: 'Designed, implemented and evaluated a pilot project entitled "Feasibility study and potential for upscaling of an agri-insurance in Burund (Gitega and Muyinga)" (2016-2017)'

Other PhD and Advanced MSc Course

"Information literacy including EndNote introduction" and "Data Management Planning", Wageningen Graduate Schools (2014)

Communicate with the media and the general public, Wageningen Graduate Schools (2014)

"Interpersonal comminication for PhD students" (2014) and PhD competence assessment" (2015), Wageningen Graduate Schoo

Analyse du cadre de suivi-évaluation de la stratégie nationale de la protection sociale au Burundi, Basteel/Canada (2017-2018)

te for Training and Research: (Shangements climatiques", "Specialized module change" (2017) Overlapping Deprivation Analysis (MODA) with STATA software, Institute of Statistics and Economic Studies of Burundi (ISTEEBU) (2019)

Management and Didactic Skills Trainin

Co-organizing a workshop with the International Fertilizer and Development Centre, in Bujumbura, Burundi

BSc student supervision on 'Analyse comparative de la rentabilité de la contonculture et de l'apiculture dans la région de P'MBO. Cas de la commune Rugombo' (2016-2017)

Panel member in 4 BSC theses assessment committees (2016-2017)

Teaching in the BSc courses 'Agriculture, Food Secunty and Sustainable Development',

\section{Oral Presentations}

Feasibility study and potential for upscaling of an agri-insurance in Burundi. Workshop on 'on Supporting agricultural productivity in Burundi', 30 October 2017, Bujumbura,
Burundi

SENSE coordinator PhD education

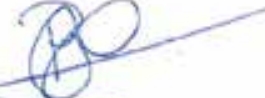

Dr. ir. Peter vermeulen 


\section{Funding statement}

This research described in this thesis was financially supported by The Netherlands Universities Foundation for International Cooperation (NUFFIC)

Cover design by Dorien Roggekamp

Printed by ProefschriftMaken 